coofoois -1

ine? $0016-01$
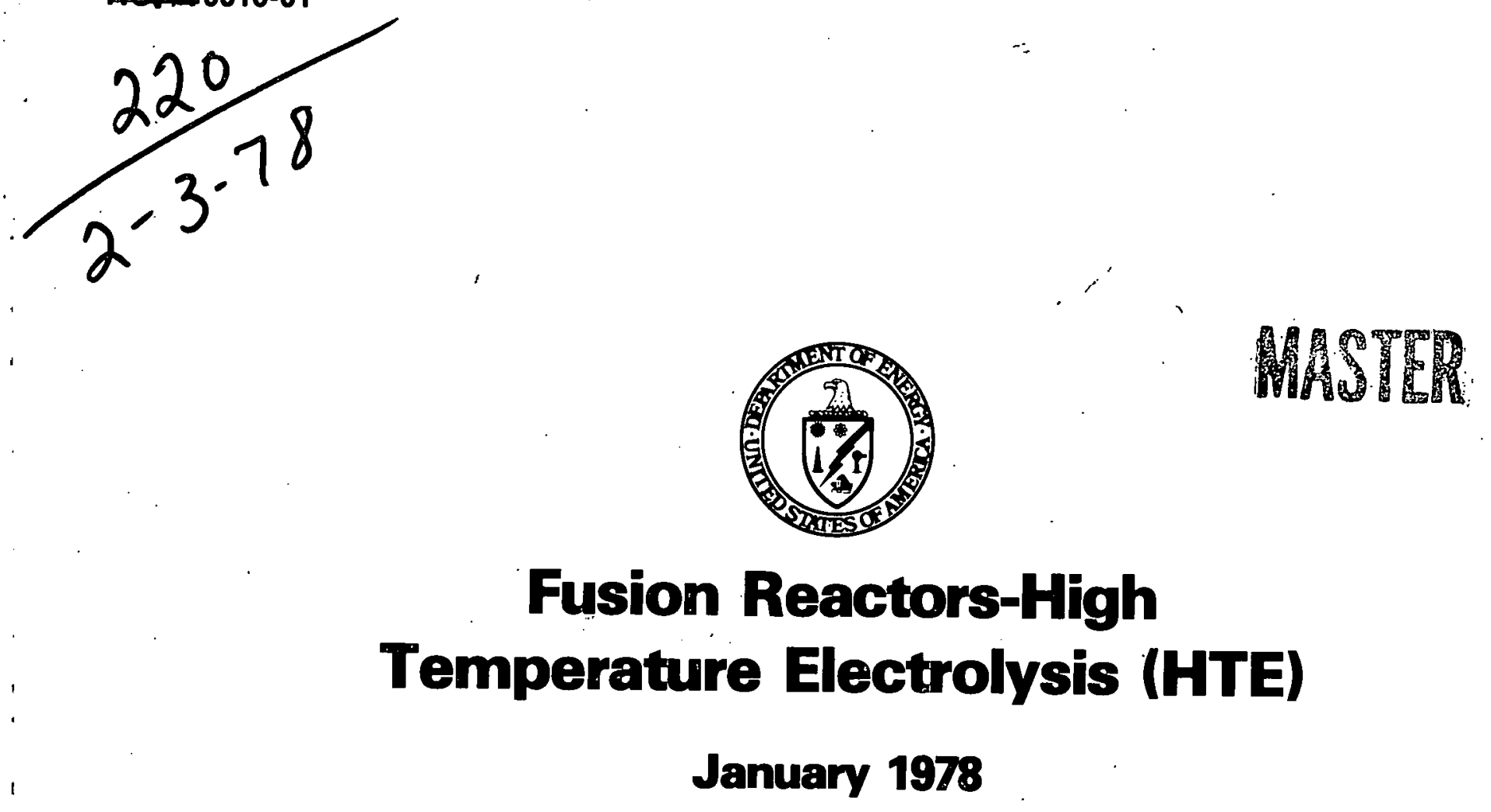

Prepared For

U.S. Department of Energy

Assistant Secretary for Energy Technology

Division of Magnetic Fussion Energy

Under Contract No. EY-76-C-02-0016 


\section{DISCLAIMER}

This report was prepared as an account of work sponsored by an agency of the United States Government. Neither the United States Government nor any agency Thereof, nor any of their employees, makes any warranty, express or implied, or assumes any legal liability or responsibility for the accuracy, completeness, or usefulness of any information, apparatus, product, or process disclosed, or represents that its use would not infringe privately owned rights. Reference herein to any specific commercial product, process, or service by trade name, trademark, manufacturer, or otherwise does not necessarily constitute or imply its endorsement, recommendation, or favoring by the United States Government or any agency thereof. The views and opinions of authors expressed herein do not necessarily state or reflect those of the United States Government or any agency thereof. 


\section{DISCLAIMER}

Portions of this document may be illegible in electronic image products. Images are produced from the best available original document. 


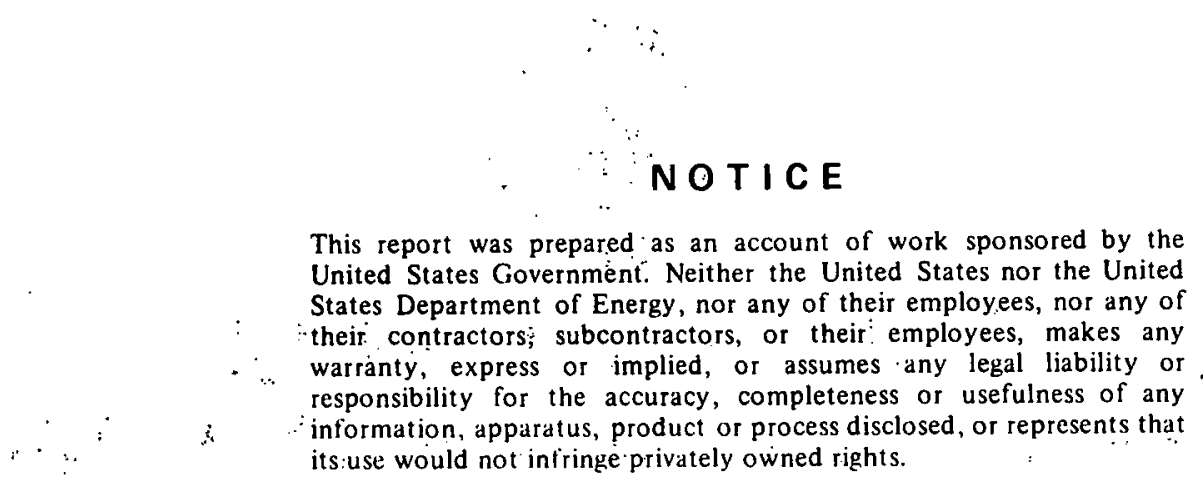

This report was prepared as an account of work sponsored by the Thited States Government. Neither the United States nor the United makes any warranty, express or implied, or assumes any legal liability or wor the accuracy, completeness or usefulness of any its:use would not in tringe privately owned rights.

Ava1lable from:

National Techinical Information Service (NTIS)

U.S. Department of Comnerce

5285 Port Royal Road

Springfield, Virginia 22161

Price:

Printed Copy:

$\$ 7.25$

Mtcrofiche:

$\$ 3.00$ 


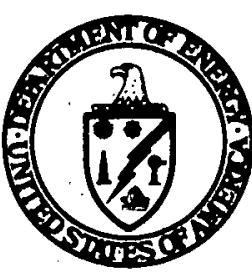

\title{
Fusion Reactors-High Temperature Electrolysis (HTE)
}

\section{January 1978}

\author{
Editor: \\ J. A. Fillo \\ Prepared By \\ Brookhaven National Laboratory \\ Upton, New York
}

For The

\author{
U.S. Department of Energy \\ Assistant Secretary for Energy Technology \\ Division of Magnetic Fusion Energy \\ Washington, D.C. 20545 \\ Under Contract No. EY-76-C-02-0016
}




\section{ACKNOWLEDGEMENT:}

The following contributors are recognized for their participation in this publication:

R. Benenati (Consultant, Polytechnic Institute of New York)

V. D. Dang

J. Fillo

S. Fogelson (Consultañt, Burns \& Röe)

H. Isaacs

H. Kouts

M. Kushner (Consultant, Burns \& Roe)

O. Lazareth

S. Majeski

H. Makowitz

J. Powell

F. Salzano

T. V. Sheehan (Consultant; BNL).

M. Steinberg 
EXECUTIVE SUMMARY

1.0 INTRODUCTION-FUSION AS A SYNTHETIC FUEL. PRODUCER ......... 1

1.1. Need for Synthetic Fuels Using Some Type of Inexhaustible Resource $\ldots \ldots \ldots \ldots \ldots \ldots \ldots \ldots \ldots, 1$

1.2 Basic Options of Hydrogen Production from

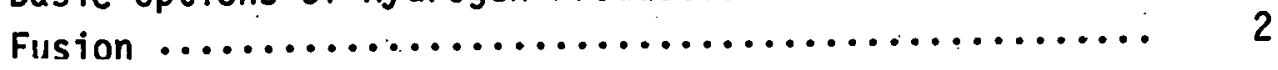

1.3 Synthetic Fuels Using Fusion $. . \ldots \ldots \ldots \ldots \ldots \ldots \ldots . .3$

2.0 HIGH TEMPERATURE ELECTROLYSIS (HTE) - METHOD

OF HYDROGEN PRODUCTION $\ldots \ldots \ldots \ldots \ldots \ldots \ldots \ldots \ldots \ldots \ldots \ldots, 7$

3.0 OVERALL DESCRIPTION OF. REFERENCE DESIGN -

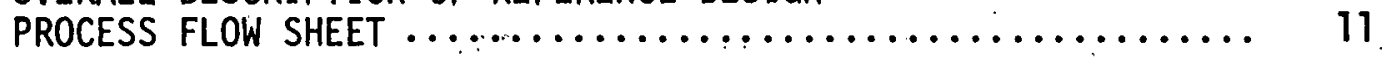

3.1 FAST (Fusion Augmented Steam Turbine)

Power Cycle ............................... 15

3.1.1 Description of FAST Cycle $\ldots \ldots \ldots \ldots \ldots \ldots \ldots \ldots . \quad 15$

3.1.2 Implications of the FAST Cycle for Fusion ........ 22

4.0 FUSION BLANKETŚ FOR HIGH TEMPERATURE

ELECTROLYSIS PROCESSES $\ldots \ldots \ldots \ldots \ldots \ldots \ldots \ldots \ldots \ldots \ldots \ldots, 27$

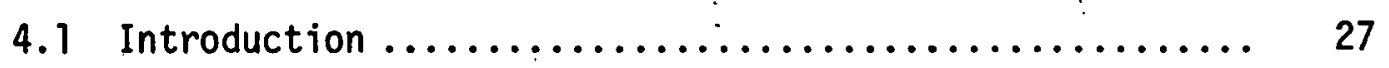

4.2 Blanket Neutronics ........................ 33

4.3 Thermal Hydraulic Aspects of Blanket Design ......... 38

4.4 Mechanical Design $\ldots \ldots \ldots \ldots \ldots \ldots \ldots \ldots \ldots \ldots \ldots \ldots, 41$

4.5 Conclusions $\ldots \ldots \ldots \ldots \ldots \ldots \ldots \ldots \ldots \ldots \ldots \ldots \ldots \ldots \ldots, 43$ 
Page

5.0 THE HIGH TEMPERATURE ELECTROLYZER (HTE) $\ldots \ldots \ldots \ldots \ldots \ldots ., 46$

5.1 Previous Work $\ldots \ldots \ldots \ldots \ldots \ldots \ldots \ldots \ldots \ldots \ldots \ldots, 46$

5.2 Electrochemistry of Solid 0xides ............... 50

5.3 Solid Oxide Electrolytes ..................... 53

5.4 Electrodes ............................... 56

5.5 Interconnections Between Electrodes ............ 57

5.6 Design of the High Temperature Electrolyzers ........ 57

5.7 Factors Influencing the Design of Electrolytes ...... 63

6.0 PLANT PROCESS AND POWER CONVERSION DESIGN $\ldots \ldots \ldots \ldots \ldots \ldots 67$

6.1 Description of Plant Process and Power
Conversions Design. - Factors Affecting Design ....... 67

6.2 Heat, Mass and Power Balance $. . \ldots \ldots \ldots \ldots \ldots \ldots \ldots, 71$

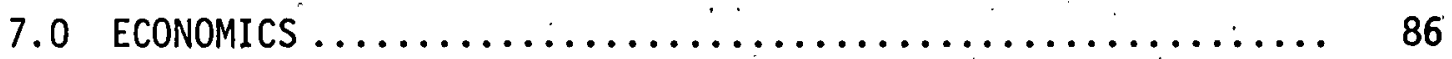

8.0 RESEARCH AND DEVELOPMENT REQUIREMENTS $\ldots \ldots \ldots \ldots \ldots \ldots \ldots, 91$

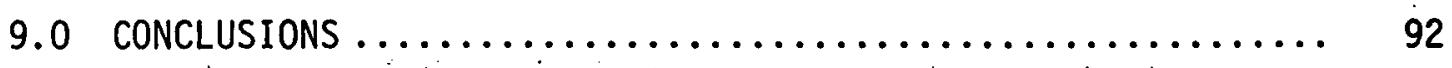

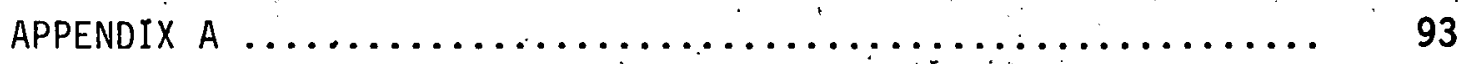

APPENDIX B.................................... 104

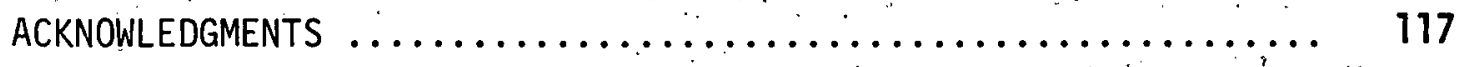

REFERENCES

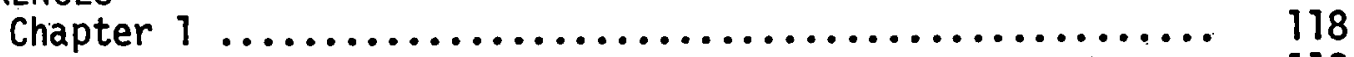

Chapter 3 ...................................... 118

Chapter 4 ........................................ 118

Chapter 5 ........................................ 119

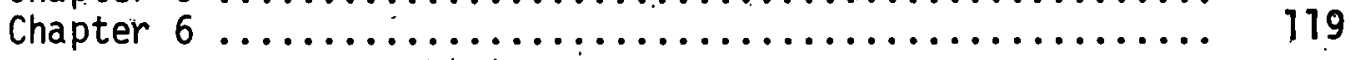

LIST OF TABLES ............................... 120

LIST OF FIGURES $\ldots \ldots \ldots \ldots \ldots \ldots \ldots \ldots \ldots \ldots \ldots \ldots \ldots \ldots, 121$ 


\section{EXECUTIVE SUMMARY}

This report represents the results of a scoping study by Brookhaven National Laboratory to identify and develop a reference design for synfuel production based on fusion reactors. Because of the short timescale of the study, only one option could be investigated. The most promising option identified by an advisory group* to DMFE. for hydrogen production was high temperature electrolysis (HTE). This option was selected for the reference design in this study. Key components of the reference design include: a) fusion blanket designs for high temperature steam as well as electrical power generation and tritium production; neutronics scoping. studies, structural and thermal-hydraulic calculations have been considered; b) process design for hydrogen production which required equipment design, plant design as well as mass and energy balances; c) preliminary economic estimates of hydrogen production including capital investment and fuel production costs; and d) a definition of problem areas and research and development requirements:

The principal findings of this study are as follows:

1. HTE has the highest potential efficiency for production of synfuels from fusion; a fusion to hydrogen energy efficiency of $\sim 70$ percent appears possible with $1800^{\circ} \mathrm{C}$ HTE units and $60^{\circ}$ percent power "cycle efficiency; an efficiency of $\sim 50$ percent appears possible with $1400^{\circ} \mathrm{C}$ HTE units and 40 percent power cycle efficiency. These results are summarized in Fig. A-3.

2. Relative to thermochemical or direct decomposition methods HTE technology is in a more advanced state of development, e.g., single cell units have been built and tested at $1000^{\circ} \mathrm{C}$.

3. Thermochemical or direct decomposition methods must have lower unit process or capital costs if they are to be more attractive than HTE.

4. While design efforts are required, HTE units offer the potential to be quickly run in reverse as fuel cells to produce electricity for restart of Tokamaks and/or provide spinning reserve for a grid system.

*From report to DMFE,. "Fusion Energy Applied to Synthetic Fuel Production" - A report to the ERDA Division of Magnetic Fusion Energy based on a preliminary study by an ad-hoc advisory group; L. A. Booth, Chairman, August, 1977. 


\section{HYDROGEN PRODUCTION FROM FUSION REACTORS \\ HIGH TEMP. ELECTROLYSIS (HTE) WITH}

CONV. (CP) AND ADVANCED POWER (AP) CYCLE

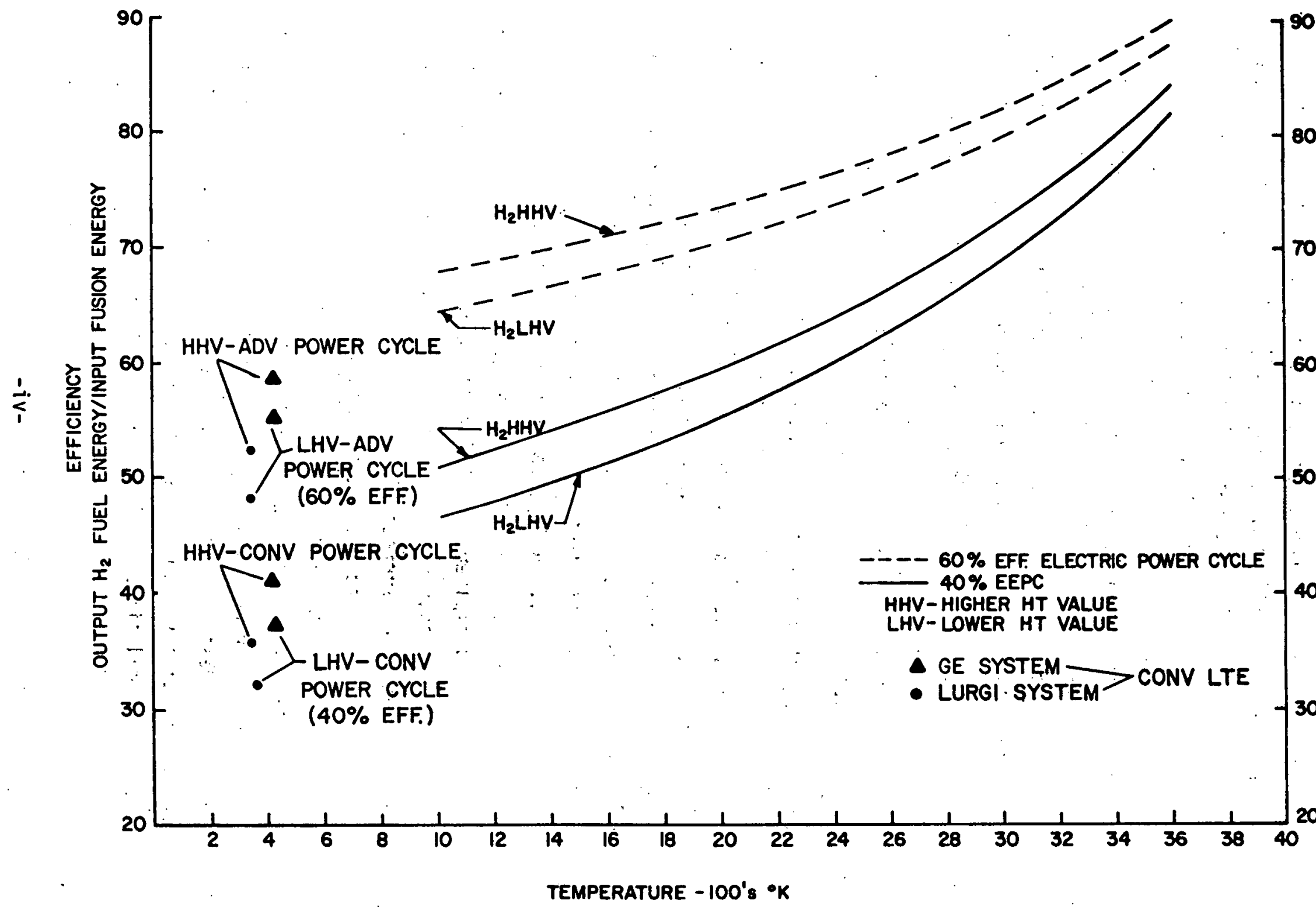


5. Because of the short timescale of the study, no detailed economic evaluation could be carried out. However, a comparison of costs could be made by employing certain assumptions. For example, if the fusion reactorelectrolyzer capital installation is $\$ 400 /(\mathrm{KW}(T)$ [ $\$ 1000 / \mathrm{KW}(E)$ equivalent], the $\mathrm{H}_{2}$ energy production cost for a high efficiency ( $\sim 70$ percent) fusionHTE system is on the same order of magnitude as a coal based SNG plant based on 1976 dollars.

6. The present reference design indicates that a $2000 \mathrm{Mw}(\mathrm{th})$ fusion. reactor could produce as much at $364 \times 10^{6}$ standard $\mathrm{cu}$. ft./day of hydrogen which is equivalent in heating value to 20,000 barrels/day, of $: j$ gasoline. This would fuel $\sim 500,000$ autos based on average driving patterns.

7. A factor of three reduction in coal feed (tons/day) could be achieved for syngas production if hydrogen from a fusion-HTE system were used to gasify coal, as compared to a conventional syngas plant using coal derived hydrogen.

With regard to system components, key results are:

1. Approximately 60 to 70 percent of the $\sim 20 \mathrm{MeV}$ total energy re- : leased in each fusion reaction can be extracted as high temperature heat from the hot interior of the blanket modules. This fraction depends on blanket design and materials, but is reasonably constant for the range of designs and materials considered.

2. The electric generation modules can be designed to have tritium breeding ratios up to $\sim 1.9$ using vanadium as the structure and beryllium as the neutron multiplier. Breeding ratios up to 1.4 can be achieved with $\mathrm{PbO}$ as the neutron multiplier. The HTE modules cannot breed tritium in the interior but can achieve breeding ratios in the range of 0.5 to 0.7 with $\mathrm{LiAlO}_{2}$ on the outer surfaces:

3. The reactor can be self-sufficient in tritium for the full range of design parameters considered.

4. Stainless steel module structures appear viable from the standpoint of tritium breeding. The heating rates are reasonable in terms of thermal hydraulic design of the coolant system, but the thermal stresses appear to be relatively high. Vanadium structures also appear viable and alleviate the thermal stress problem to some degree. 
5. A lead compound can be used as the neutron multiplier with the reactor self-sufficient for tritium production under all assumptions as to fraction of HTE energy as process heat and electroc generation efficiency, if there is partial tritium breeding on the surfaces of the HTE. Lead compounds can be used for neutron multiplication and tritium self-sufficiency maintained with no tritium on HTE module surfaces, if the power cycle efficiency is 40 percent or if the fraction of thermal energy input to the HTE is 30 percent.

6. There does not appear to be any significant neutronics difference between $\mathrm{MgO}$ and $\mathrm{Al}_{2} \mathrm{O}_{3}$ interiors for the HTE process heat modules.

7. Wall loadings of 2 to $3 \mathrm{MW}(\mathrm{th}) / \mathrm{m}^{2}$ appear to be compatible with the coolant circuit designs for the HTE and electric generation modules. The principal problem appears to be high thermal stresses with stainless steel structure.

8. For the water cooled structure of the electric generation and HTE modules, water flow in the tubes along the module length appears satisfactory. The He coolant flow path in the electric generation modules, as well as the steam coolant flow in the HTE modules should be radial to avoid excessive pressure drops.

9. No special operations and/or maintenance problems are foreseen for the HTE and electric generation modules. The steam circuit will probably be strongly activated by $\mathrm{Na}^{24}$ ( 15 hours half life) released from the hot interior of the modules, but this will decay to negligible levels in a few days. Other relatively long-lived activations from blanket impurities and/or crud from low temperature piping systems will be present but should present less problems than now faced on LWR's.

10. The key issues for the blanket appear to be primarily related to materials. The module structure has to mainta in vacuum integrity in the radiation/thermal cycling environment for several years. This problem is common to all fusion reactor blankets and no new class of problems 
appears to be generated by fusion reactors using the HTE process. The materials effort now underway in the fusion program should lead to the development of satisfactory structural materials for these applications. More specialized material questions related to the HTE applications appear, however. These are concerned with the stability of oxides such as MgO and $\mathrm{Al}_{2} \mathrm{O}_{3}$ in the high temperature steam under radiation and thermal cycling conditions. Such materials will be used both in the form of solid rods or balls, as well as a low density solid block or fibrous thermal insulation. The principal requirement is that these materials not crumble or inject excessive amounts of fines to the coolant system, and that thermal insulation capability be maintained during the life of the module. Because of the more specialized aspects of these materials, it may be advisable to ensure that they will also be considered in the fusion materials development program.

The general design concepts involved for such high temperature blankets. appear feasible. Given satisfactory materials, there appears to be no bars to the development of high temperature blankets for fusion reactors. using the HTE process to produce synfuels.

11. An assessment of the available information on fuel cell and electrolyzer designs indicates that it should be possible to construct an HTE without any excessive $R$ \& $D$ commitments.

12. A conceptual design of an. HTE has been presented which may be employed over a wide range of temperatures. The active cell is based on a fuel cell design which incorporates three layers of the electrolyte, anodes, cathodes, and interconnections between cells. The thin layer design reduces the resistance of the cell components making low temperature operation possible. High temperature operation will depend on the compatibility and strength of the cell components and the porous tube on which they are deposited.

13. The design of the electrolyzer tubes minimize thermal stresses since they are sealed at one end. The design requires only a single seal. The tubes are supported at the unsealed ends to reduce stresses on the tube. 
They are free to move in a horizontal direction during thermal cycling, preventing the buildup of stresses.

14. $\cdots$ The efficiency of the electrolyzer, the physical dimensions of the tube, the current densities, and the number of tubes required are all interrelated and dependent on the velocity of the $\mathrm{H}_{2} \mathrm{O} ; \mathrm{H}_{2}$ gas mixture. A11 of these parameters require optimization.

15. A major area which wi 11 require future investigation is related to the high temperature property of materials and their compatibility and the electrochemical parameters including the maximum current density and electron conductivity of the electrolyte. 


\subsection{INTRODUCTION - FUSION AS A SYNTHETIC FUEL PRODUCER}

1.1 Need for Synthetic Fuels Using Some Type of Inexhaustible Resource World reserves of oil and gas are being rapidly depleted and the general consensus is that they will be essentially gone in a short period of time. Many of the industrialized nations, the United States for example, are now importing a large fraction of their petroleum needs, with consequent worries about. sources of supply to maintain continued growth patterns, future prices, and effects on the balance of payments.

It is generally believed that future energy demands which have in the past relied on oil and gas will in the future have to be supplied by alternate sources. This will mean an increased reliance on established energy sources such as coal and nuclear (LWR) to meet the projected energy deficit.

Coal can supply both electricity and synthetic portable fuels, but there appear to be concerns as the degree to which it can meet future demands, in terms of production rates, total available resources, and possible harmful environmental effects. For example, the potential long-range climatological effects of large additions of $\mathrm{CO}_{2}$ to the atmosphere are being studied.

Nuclear (LWR) sources, though, will supply energy primarily to generate electric power. This will help to abate some of the demands, for oil and gas. However, for a number of demand sectors, practical technology has not yet been developed (and may never be) for direct electrical use. Also, nuclear (LWR) may be found wanting as an energy source in a few: decades due to heavy pressure on uranium reserves. The long-range próspects for nuclear energy deployment also depend upon demonstration of terminal waste disposal technology and resolution of broader energy policy questions.

These conditions have led to an increased interest to identify a way to produce substitute fuels from the inexhaustible energy sources, that is, 
solar, geothermal, fission (breeder), and fusion. Thermonuclear fusion : as a future inexhaustible energy source appears to have the advantage of relatively high power density as compared to alternate inexhaustible energy sources such as solar or geothermal, with the potential of favorable economics. Further, it has no apparent geographic or climatological constraints. The supply of deuterium and lithium fuels for fusion reactors appears to offer no significant resource concern. If the synthetic fuel derived from fusion energy is hydrogen, it can serve multiple functions; as a chemical feedstock for much more efficient coal liquification and gasification; ammonia production and metal-ore reduction; as an efficient. source of electricity by using fuel cells; and uitimately, as a primary transportable fuel. The supply of hydrogen would be virtually unlimited since it is obtained from water.

Inexhaustible fission technologies, such as the LMFBR or GCFR can ailso be considered as a source for the production of synthetic fuels based on hydrogen. Here, however, the primary product is expected to be electricity, and production of synthetic fuels will probably have to follow the route of conventional electrolysis, at a relatively low efficiency. compared to the potential for fusion reactors.

In contrast, fusion reactors have the potential to supply unique energy forms (e.g., radiation and very high temperature heat) that may lead to significantly increased efficiency for the production of synthetic fuels. An evaluative study of the application of fusion energy to synthetic fuel production has been recently carried out, (1) which identifies a number. of promising approaches.

\subsection{Basic Options of Hydrogen Production from Fusion}

Three basic candidate methods of hydrogen production from neutron energy have been identified: a) direct decomposition including high temperature electrolysis; b) thermochemical cycles including partial radiolysis; and c) direct radiolysis: While comparision of these methods are difficulti to make, engineering judgment can be exercised so that expected relative 
efficiencies of the processes and relative engineering feasiblility, i.e., complexity, materials compatibility and temperature limitations; mechanical design requirements, etc, , can be made. Based on these subjective comparisons, preferential ranking of the above methods is possible and is discussed in some detail in the panel study (1) on fusion synfuels production. One of the most promising is high temperature electrolysis which is expected to have the highest efficiency [ $250-55 \%$ based on a conventional power cycle (40\% efficient) and as high as $70 \%$ with an advanced power cycle (60\% efficient)l. Its technology is also more near at hand compared, for example, with thermochemical or radiolysis.

While a two-step thermochemical process can potentially have high efficiency (45-50\%), the engineering problems of circulating high temperature corrosive liquids and gases through the blanket may be a limiting factor in the process. Coupling thermal energy and ionizing radiation for a multi-step thermochemical cycle could simplify the thermochemical cycle, but additional blanket problems appear as well as product separation problems. A significant problem in attempting to carry out designs of multi-step thermochemical systems is the lack of experimental verification of specific thermochemical cycles. At present the relatively low efficiency of radiolysis finds it wanting as a synthetic fuels producer. The preliminary evaluations developed in Ref. (1) formed the basis of choosirg high temperature electrolysis. for the fusion synfuels reference design in this study.

\subsection{Synthetic Fuels Using Fusion}

The high energy neutrons from DT fusion reactions can penetrate very deeply into materials before their kinetic energy is transformed to heat. This unique feature of fusion energy, and the fact that $280 \%$ of the energy released. per. DT fusion reaction is carried by $14 . \mathrm{MeV}$ neutrons, can,dramatically increase the efficiency of electric power generation, as well. as produce $\mathrm{H}_{2}$ and $\mathrm{H}_{2}$ based synthetic fuels at high efficiency. 
This deep penetration of the primary neutrons makes two temperature region blankets feasible. In this concept, a relatively low temperature metallic structure is the vacuumicoolant pressure boundary, while the interior of the blanket, which is a simple packed bed of non-structural material, operates at very high temperatures. Separate coolant circuits are required for the two temperature regions, as well as a thermal insulator between them.

Materials for the hot interior are capable of much higher temperatures than HTGR type conditions $\left(800^{\circ} \mathrm{C}\right)$. Further, the coolant for the hot interior need not be lielium, but can be a process fluid like steam or $\mathrm{CO}_{2}$. This direct heating feature eliminates the transfer of high temperature heat across a metallic primary heat exchanger, which could severely limit the maximum temperature and choice of coolant.

Table I shows the melting point of some candidate high temperature refractory materials for the hot interior. All appear compatible with helium or argon coolant. Only the oxide refractories, and perhaps some carbides (e.g., SiC), would be compatible with steam or $\mathrm{CO}_{2}$ coolant. The hot interior probably would be a packed bed of small diameter . $(1-2 \mathrm{~cm})$ rods or balls.- The low peak power densities $\left(i 10 \mathrm{MW} / \mathrm{m}^{3}\right)$. and the large surface area in the blanket should result in relatively low temperature differences (on the order of $100^{\circ} \mathrm{C}$ ) between the coolant and the packed bed.

In high temperature blankets for electric production tritium is bred in a solid lithium compound (e.g., $\left.\mathrm{LiAlO}_{2}\right)$ in the high temperature interior. The characteristic time for release into the inertigas coolant is. only a few minutes, from which it is recovered. With steam coolant, however, this mode of tritium breeding is not. feasible, since the tritium cannot be readily extracted from the steam circuit. Instead, a solid lithium compound can be placed on the outer surfaces of the module. The bred tritium will then diffuse to the vacuum chamber and be recovered. from the plasma exhaust. Breeding ratios of $\sim 0.4$ to $\sim 0.6$ can be achieved 
with $\mathrm{MgO}$ or $\mathrm{Al}_{2} \mathrm{O}_{3}$ interiors, but breeding ratios of $\sim 1.0$ require "BeO interiors. This implies that two types of blanket modules may be required to satisfy tritium breeding requirements - the steam cooled type just described, as well as blanket modules which have a high tritium breeding ratio. These could be inert gas cooled, high temperature solid, breeding blankets, capable of achieving breeding ratios of 27.3 to 1.8 .

Direct heating of steam by neutron energy to high temperatures in refractory oxide fusion blankets appears practical, and is the mode of generating process heat for the high temperature electrolysis process. Circulating high-temperature steam through the bianket poses some engineering design problems, but these are not deemed insurmountable. A high temperature electrolysis process should generate $\mathrm{H}_{2}$ from water at an overall efficiency of $250-70$ percent depending on design. Since hydrogen production cost by electrolys is is primarily determined by electric power cost, the fact that high temperature process blanket steam is used for directly decomposing water to $\mathrm{H}_{2}$ and that high overall. efficiency ( 50 percent compared with $30-35$ percent by conventional electrolysis) can be achieved, implies significant potential economic ádvantages of a fusion-HTE system.

The previously noted unique ability of fusion neutrons to directly heat the interior of a blanket to very high temperatures, offers great potential for the high efficiency power cycles using fusion heat. The FAST (Fusion Augmented Steam Iurbine) power cycle (discussed in Chapter 3). can admit steam, superheated directly in the blanket, to the turbine inlet at temperatures of $\sim 2000^{\circ} \mathrm{F}$." Power cycle efficiencies of $\sim 60$ percent appear possible under these conditions with a power cycle efficiency of 60 percent and HTE units operating at $1800^{\circ} \mathrm{C}$. The potential efficiency for generation of $\mathrm{H}_{2}$ from fusion energy is very high, on the order of 70 percent. 


\begin{tabular}{|c|c|c|c|c|c|c|}
\hline Carbides & M.P. $\left({ }^{\circ} \mathrm{K}\right)$ & Oxides & M.P. $\left({ }^{\circ} \mathrm{K}\right)$ & Nitric & & M.P. $\left({ }^{\circ} \mathrm{K}\right)$ \\
\hline $\mathrm{HFC}$ & 4161 & $\mathrm{ThO}_{2}$ & 3573 & TaN & & 3361 \\
\hline $\mathrm{TaC}$ & 4148 & $\mathrm{MgO}$ & 3098 & $B N$ & - & 3273 \\
\hline $\mathrm{NBC}$ & 3773 & $\mathrm{HfO}_{2}$ & 3085 & TIN & & 3205 \\
\hline Zrc & 3533 & $\mathrm{ZrO}_{2}$ & 2973 & $\mathrm{Z} N \mathrm{~N}$ & 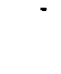 & 3203 \\
\hline Tic & 3523 & $\mathrm{CaO}$ & 2843 & & - & - \\
\hline sic & 3100 & $\mathrm{BeO}$ & 2725 & & & . \\
\hline VC & 3083 & $I_{2} O_{3}$ & 2323 & & & \\
\hline
\end{tabular}


2.0 HIGH TEMPERATURE ELECTROLYSIS (HTE) - METHOD OF HYDROGEN PRODUCTION

This report represents the results of a scoping study by Brookhaven National Laboratory to identify and develop a reference design for synfuel production based on fusion reactors. Because of the short timescale of the study, only one option was investigated. Key components of the reference design include: a) fusion blanket designs for high temperature steam as well as electrical power generation and tritium production in which neutronics scoping studies, structural and thermal hydraulic calculations, have been considered, b) process design for hydrogen production including equipment designil plant design, and mass and energy balances; c) preliminary economic estimates of hydrogen production including capital investment and fuel production costs; and d) a definition of problem areas and research and development requirements.

The reference design couples fusion, the prymoty

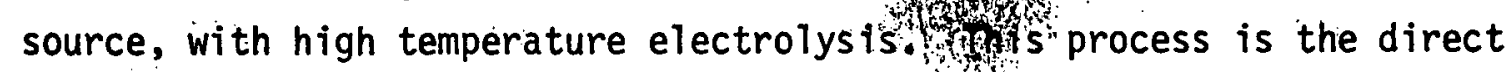
decomposition of water at temperatures whereby' a significant fraction of the decomposition energy is provided by thermal energy. Steam is transported from the blanket system and distributed to the electrolyzers. The balance of energy is made up by electrical work supplied to the electrolytic cells. The source of work is generated by converting a fraction of the fusion energy to thermal enerdy which in turn is converted to electricity in a standard thermalicycle. A simplified process flow sheet which couples the three basic elements of the system with hydrogen and oxygen as products is shown in Fig. 2-1.

A conceptual deisin depicting the system is shown in Fig. 2-2. The electrolyzers which are pressure vessels surround the fusion reactor and are housed outside the reactor assembly in separate compartments. They are fed steam directly from the high temperature biankets. The last compartment contains the heat exchangers for $\mathrm{H}_{2}$ separtion as well as the hydrogen storage vessels. To maintain a high steam $/ \mathrm{H}_{2}$ mixture temperature, 


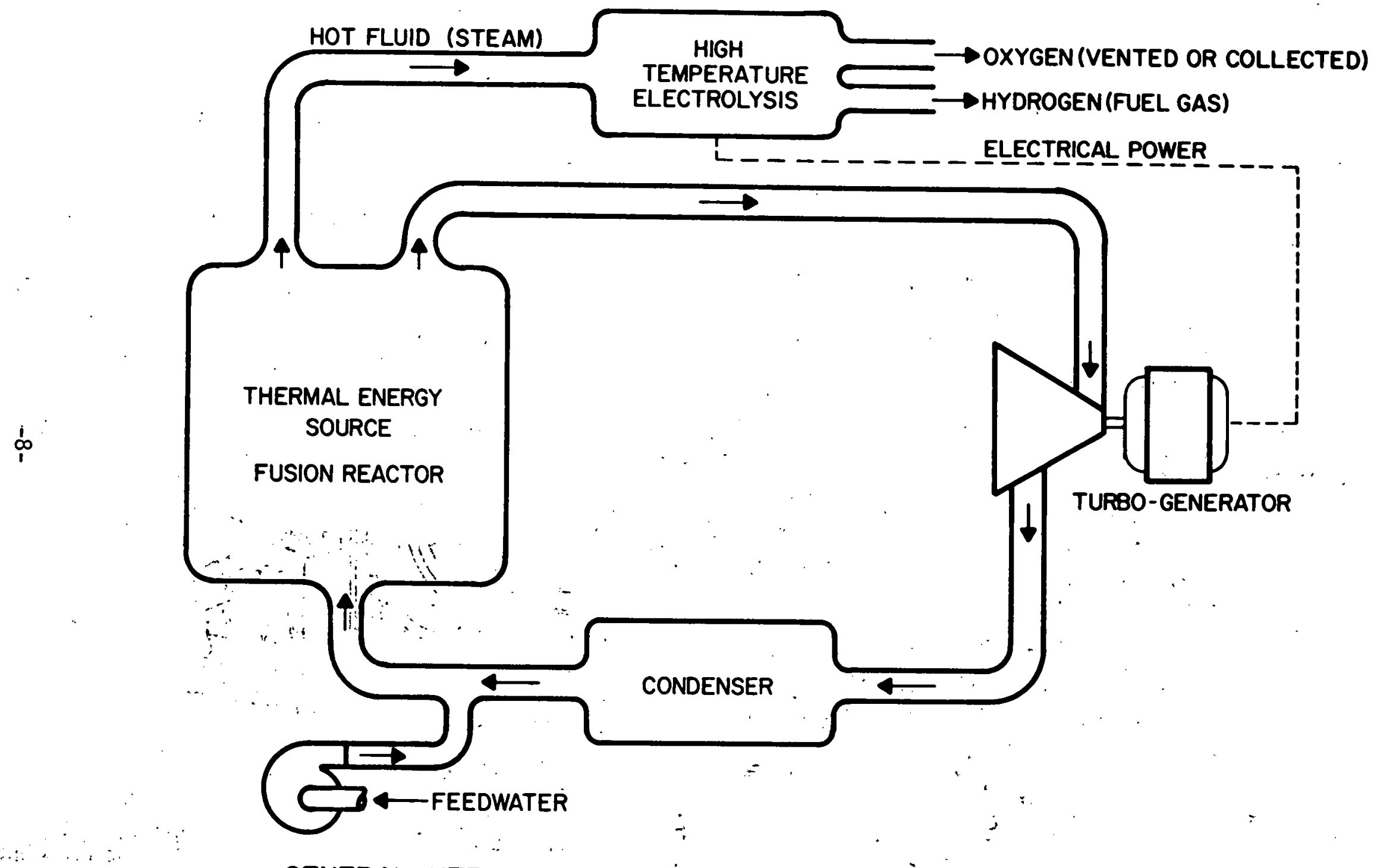

GENERAL HTE PROCESS WITH CONVENTIONAL POWER CYCLE

FIGURE 2-1 


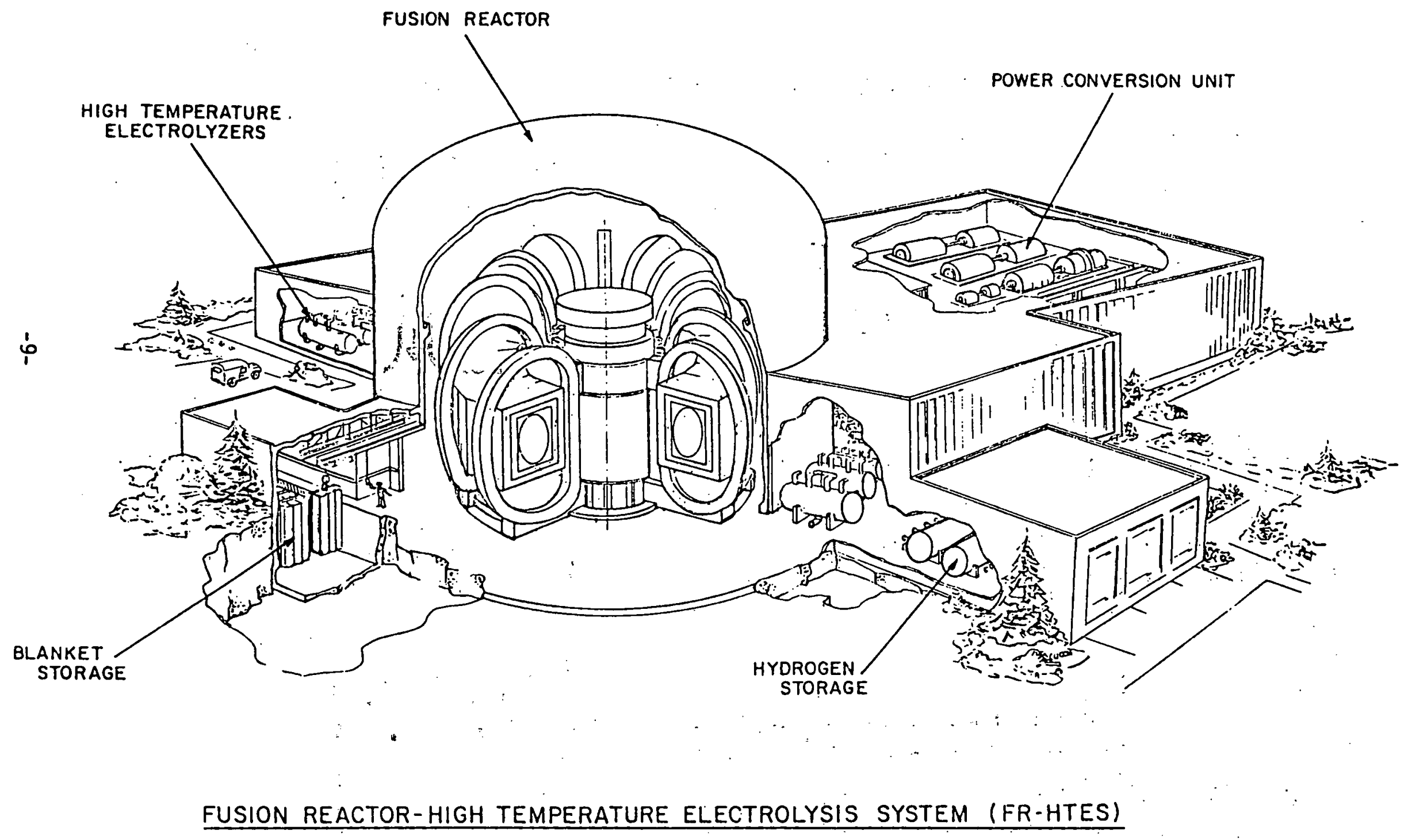

FIGURE 2-2 
the mixture is sent back to the blankets for reheat. The number of electrolyzers is a function of temperature drop across the electrolyzers and hydrogen production requirements. Electrical requirements for the electrolysis process are served by the power conversion unit. The electrical generating plant houses the turbines and steam generators as well as auxiliary systems. Power conversion is based on a helium-steam loop. Not shown are the tritium facilities which must also be accounted for plasma fueling. 


\subsection{OVERALL DESCRIPTION OF REFERENCE DESIGN - PROCESS FLOW SHEET}

The detailed process flow sheet for the conceptual design is shown in Fig. 3-1. The high and low temperature regions refer to the fusion blankets. The high temperature region is further subdivided into two regions.

Basically the blanket is a stainless steel or vanadium shell which contains a high temperature oxide such as $\mathrm{MgO}, \mathrm{ZrO}_{2}, \mathrm{Al}_{2} \mathrm{O}_{3}$, or $\mathrm{ThO}_{2}$. The shell is thermally insulated from the high-temperature refractory material and is independently cooled by a bank of coolant tubes. The insulator is a fibrous material, compatible with the high temperature oxide.

The shell structure, $\sim 0.75 \mathrm{~cm}$ thick, is maintained at $\sim 350$ to $400^{\circ} \mathrm{C}$. Typically, 30 percent of the fusion energy is deposited in this region assuming no thermal leakage from the high temperature zone. The coolant tubes are compatible with the shell structural material, and in the stainless steel design, the tubes are typically $\sim 0.5 \mathrm{~cm}$ ID, $0.2 \mathrm{~cm}$ wall thickness. Low temperature steam and/or water mixture is the coolant. Operating conditions are $\sim 2000$ psi. The high temperature refractory zone is either a packed ball bed or rods through which steam, $\sim 1500$ to $2000^{\circ} \mathrm{C}$, is passed. If tritium breeding is required in the high temperature blanket, $\mathrm{LiAlO}_{2}$ may be placed between the coolant tubes and shell with tritium diffusing into the plasma chamber. Preliminary calculations indicate that breeding ratios of $i 0.5$ to 0.7 may be achieved. The deficit in tritium is provided by high breeding blankets designed for electric power production. Actually, calculations indicate that the high breeding blankets would provide sufficient tritium so that additional make-up would not be required.

Structurally the high breeding blankets are essentially the same as the high temperature blankets, the outside shell being cooled by a bank of coolant tubes which operate at the same process conditions as noted before. A neutron multiplier, Be or $\mathrm{PbO}$, and a solid lithium compound, $\mathrm{LiAl}_{2}$ and neutron moderator replace the high temperature refractory: These materials are thermally insulated from the structural shell by a fibrous graphite cloth. The multiplier-breeder-moderator zone is cooled by helium at 700 to $800^{\circ} \mathrm{C}$ and $30 \mathrm{~atm}$. 


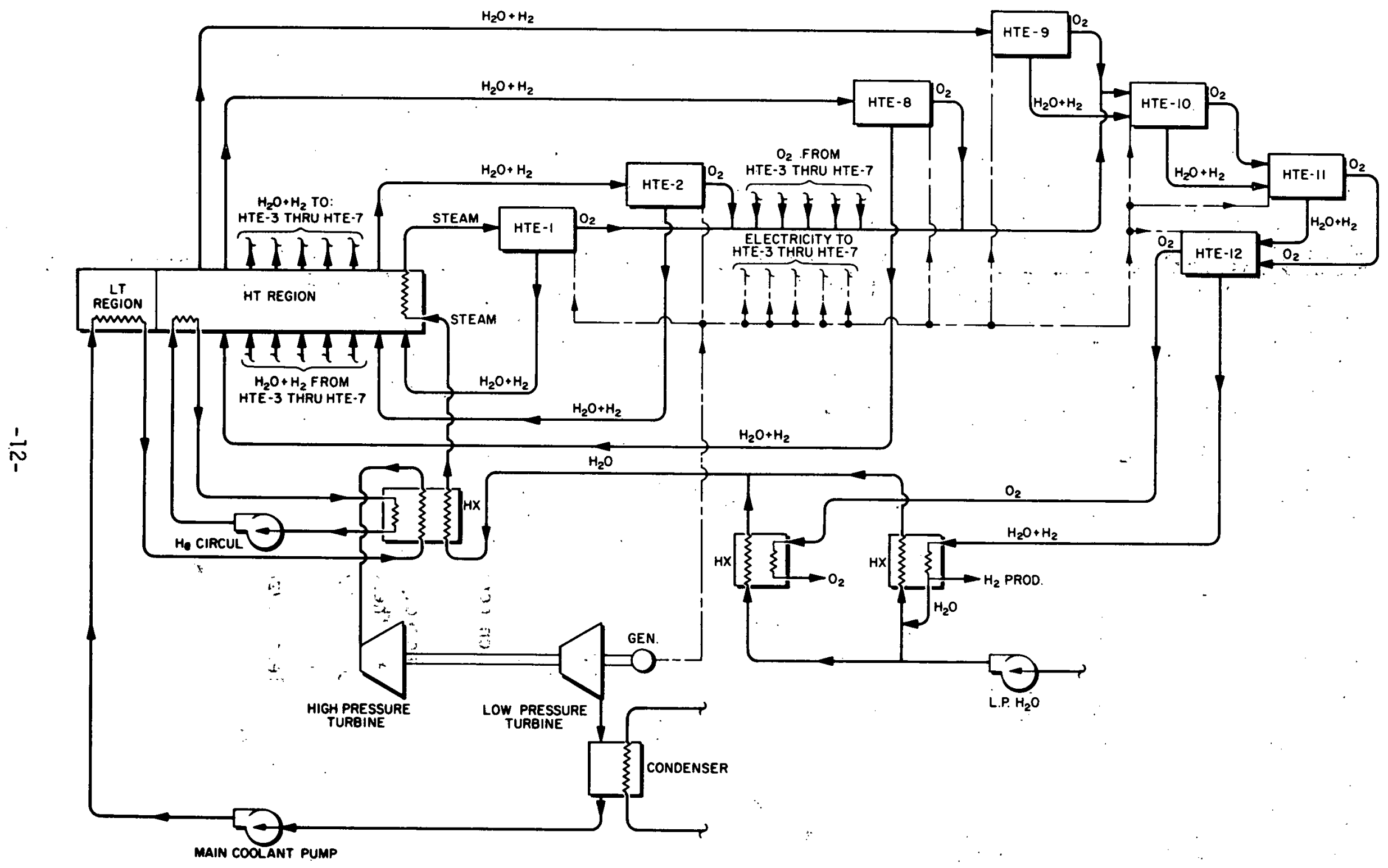

FR,-HTE PROCESS FLOW SHEET

FIGURE 3-1 
High temperature steam leaving the high temperature refractory zone of the blanket is distributed to the electrolyzers in ceramic-lined ducts. The electrolyzers typically $\sim 2.5 \mathrm{~m}$ long and $\sim 1 \mathrm{~cm}$ diameter, are tubular in shape with electrodes and electrolyte-interconnector materials mounted on the tube wall. As a consequence of the high volumetric flow rate, a large number of tubes are required per electrolyzer unit. There are $\sim 100,000$ tubes contained in a pressure vessel structure $\sim 7 \mathrm{~m}$ 1ong, $3.5 \mathrm{~m}$ in diameter, and maintained at $10 \mathrm{~atm}$. The electrolyzers are arranged 1 ike shell and tube heat exchangers with steam and hydrogen flowing in the tube side and oxygen flowing in the shelil side. Because of the endothermic reaction for electrolysis, the steam/hydrogen mixture experiences a temperature drop along the tube from the inlet to the outlet. This temperature drop is arbitrarily fixed at $150^{\circ} \mathrm{C}$.

The basic thermodynamics of the decomposition of water as well as an idealized cycle analysis is given in Appendix $A$. It is shown that the thermal efficiency of hydrogen produced increases as the electrolysis reaction temperature increases. In order to maintain a high reaction temperature, the outlet stream of steam/hydrogen from the HTE is sent back to the blanket to absorb heat for temperature reheat. The mixture is then sent to the next electrolyzer unit, and the reheat process repeated. When the hydrogen concentration has built up to the required level and for a given temperatüre drop along the electrolyzer tube, the gas mixture then passes into lower temperature electrolyzers where the endothermic reaction cools the gases during the last stages of electrolysis to a temperature at which conventional heat exchangers are used for water-hydrogen separation. For a maximum steam temperature of $1377^{\circ} \mathrm{C}$, there are nine electrolyzers--in series-operating at the maximum reaction temperature. These are followed by three electrolyzers operating at lower temperatures, decreasing by $150^{\circ} \mathrm{C}$ per electrolyzer to an outlet temperature of $727^{\circ} \mathrm{C}$. For the maximum steam temperature equal to $1827^{\circ} \mathrm{C}$, the number of electrolyzers are six and six, respectively. The oxygen generated in the high temperature electrolyzers is passed 
directly to the low temperature electrolyzers without reheating. Maximum temperatures will be fixed by material limitations which in turn will set limits on optimum values. Electrical input to the electrolyzers is supplied from the power conversion cycle.

The outlet oxygen and steam/hydrogen mixture from the last set of HTE's is sent to heat exchangers where heat is recovered by the inlet makeup water stream. The make-up water stream from the outlet of . the heat. exchanger will take up heat from the helium loop of the superheater be-i fore returning to the breeding blanket of the fusion reactor. Hydrogen is separated out from steam in the heat exchanger. The separated water will combine with the make-up water for recycle. 0xygen produced can be used as an oxidizing agent.

There are alternative methods to recover heat from the oxygen and steam/ hydrogen streams. For example, one can take $10 \mathrm{~atm}$ saturated steam from the turbine as make-up steam and send it to the $\mathrm{O}_{2}$ heat exchanger and hydrogen/steam heat exchanger to recover the heat. The remaining heat of oxygen and steam/hydrogen streams would be recovered from $25^{\circ} \mathrm{C}$ water in a hydrogen separation unit where hydrogen is separated out from steam by condensation. The coolant water from the hydrogen separation unit would be returned tc the boiler feed water of the power cycle loop.

The electrical power generation plant is similar to a conventional power plant. Low temperature steam from the low temperature blanket region is pumped through a superheater where the temperature of steam is raised by heat absorption from the helium loop. Power is generated through high or intermediate pressure turbines. Steam from the turbine is condensed in a low pressure condenser before returning to the blanket. The cycle efficiency is shown to be $i 38$ percent. The unique ability of fusion neutrons to directly heat the interior of $a, b$ lanket to very high temperatures offers great potential for high efficiency power cycles using fusion heat. Typical values may be 260 percent with a FAST (Fusion Augmented Steam Iurbine) cycle (discussed in the next section). This implies that the overall hydrogen process efficiencies would be high, $\sim 65$ to 70 percent, for, high temperature electrolysis as well as low temperature electrolysis, $\sim 60$. percent. 


\subsection{FAST (Fusion Augmented Steam Iurbine)}

\subsection{1: Description of FAST Cycle}

The unique ability of fusion neutrons to directly heat the interior of a blanket to very high temperatures, while retaining the blanket first wall/ pressure boundary structure at. relatively low temperatures, offers great potential for high efficiency power cycles using fusion heat.

Figure 3-2, from a recent NASA/JPL study on hydrogen energy, (1) shows the inlet temperature trends for steam, and gas turbines from 1900 to the present and projected trends till the year 2000. Steam turbine inlet temperatures have been constrained to $\sim 1100^{\circ} \mathrm{F}$ by heat exchanger material limitations rather than turbine material limitations. The inlet temperatures for gas fired turbines have climbed steadily and approach $2000^{\circ} \mathrm{F}$ at the present time. Gas turbine in let temperatures of $\sim 2400^{\circ} \mathrm{F}$ have been projected for the early $1980{ }^{\prime}{ }^{(2)}$, and it would appear reasonable to expect that this goal will be achieved by mid 1990 when a fusion demo reactor could be projected to operate.

High temperature gas turbines using hydrogen/air and hydrogen/oxygen combusion mixtures have been investigated $(1,3)$ analytically. and experimentally, and it is expected that turbine inlet temperatures for steam and steam-air mixtures can be achieved that are comparable to these for gas fired turbines. Overall ultimate cycle efficiencies approaching 70 percent have been projected for a $\mathrm{H}_{2} / \mathrm{O}_{2}$ combustion turbine ${ }^{(3)}$. The principle area of concern appears to be with the achievement of uniform combustion and the avoidance of fluctuations in turbine inlet temperature caused by variations in the combustion and/or dilution processes (1).

Direct heating of steam to nigh temperatures in refractory oxide fusion blankets appears practical and is the mode of generating process heat for the high temperature electrolysis" process. This direct heating feature eliminates the transfer of high temperature heat across a metallic primary heat exchanger which could severly limit the maximum temperature and choice of coolant. High temperature steam can also be used to great advantage in the electrical power generation cycle. Figure 3-3 compares the temperature entropy diagram for a FAST (Fusion Augmented Steam Iurbine) power cycle, in which the steam is superheated directly in the blanket to a turbine inlet temperature of 


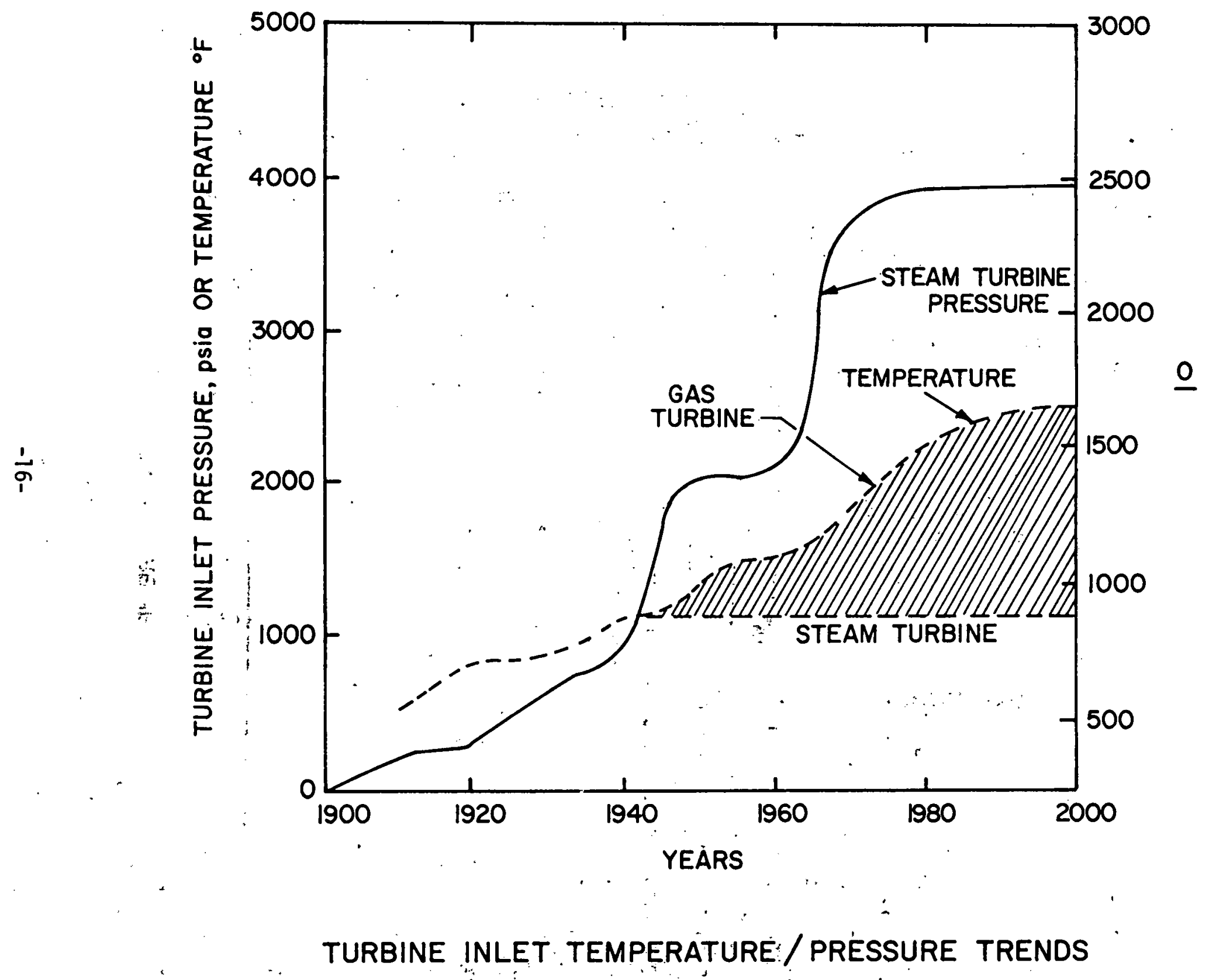

FIGURE 3-2 


\section{TEMPERATURE-ENTROPY DIAGRAM FOR FAST}

\section{CYCLE}

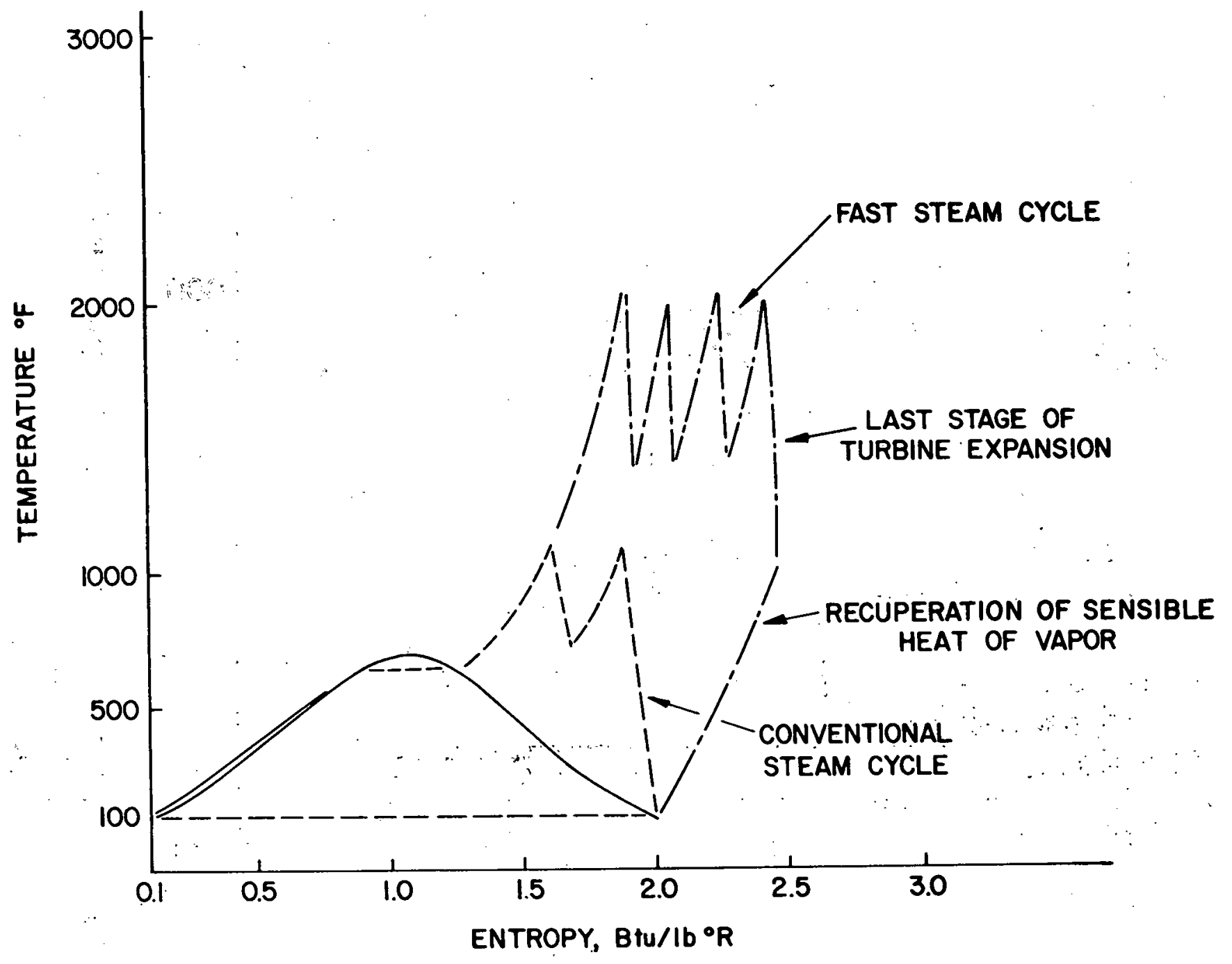

FIGURE 3-3 
$2000^{\circ} \mathrm{F}$ with a conventional steam turbine power cycle operating at a turbine inlet temperature of $1100^{\circ} \mathrm{F}$. The much larger work output (net area on the T-S diagram) per unit amount of steam, which results from operating at a much higher turbine inlet temperature, is readily apparent.

Three reheats are shown for the FAST cycle and one reheat for the conventional cycle. This is a significant feature of the.FAST cycle. Since the steam can be reheated directly in the blanket without a heat exchanger; the optimum number of reheats in the FAST cycle should be considerably more than the conventional power cycle, which typically has one, or at most two, reheats. Figure 3-4 shows the flowsheet for a high temperature fusion blanket coupled to a FAST cycle.

Since the steam exit temperature from the blanket can be much higher than the turbine inlet temperature, it is not necessary to have all of the steam that flows through the turbine circuit go through the blanket. The blanket steam could exit at $\sim 3000^{\circ} \mathrm{F}$, for example, and be mixed with a much: larger volume of steam from the preceeding turbine section. The two steam flows would mix to an intermediate temperature and then go to the next turbine section. With a blanket exit temperature of $3300^{\circ} \mathrm{F}\left(1800^{\circ} \mathrm{C}\right)$, : approximately one-third of the steam flow through the turbine would have to pass through the blanket at each reheat.

Besides increasing overall cycle efficiency, multiple reheats are advantageous for blanket design, since the average pressure for the blanket modules decreases with increasing numbers of reheats. For a given working stress in the blanket module structural wall, the wall thickness must increase with increasing pressure or the characteristic size of the module must decrease: In either case, the fraction of fusion energy deposited in the hot blanket interior will decrease. Energy splits of $\sim 70 / 30$ (hot interior/cool structural wail) appear practical with coolant pressures up to $\sim 500$ psi, but the split will decrease somewhat (e.g., to $\sim 50 / 50)$ for pressures of $\sim 2000 \mathrm{psi}$. With multiple reheats, most of the blanket will be at pressures of 500 psi or less, and the average energy split should approach 70/30. 


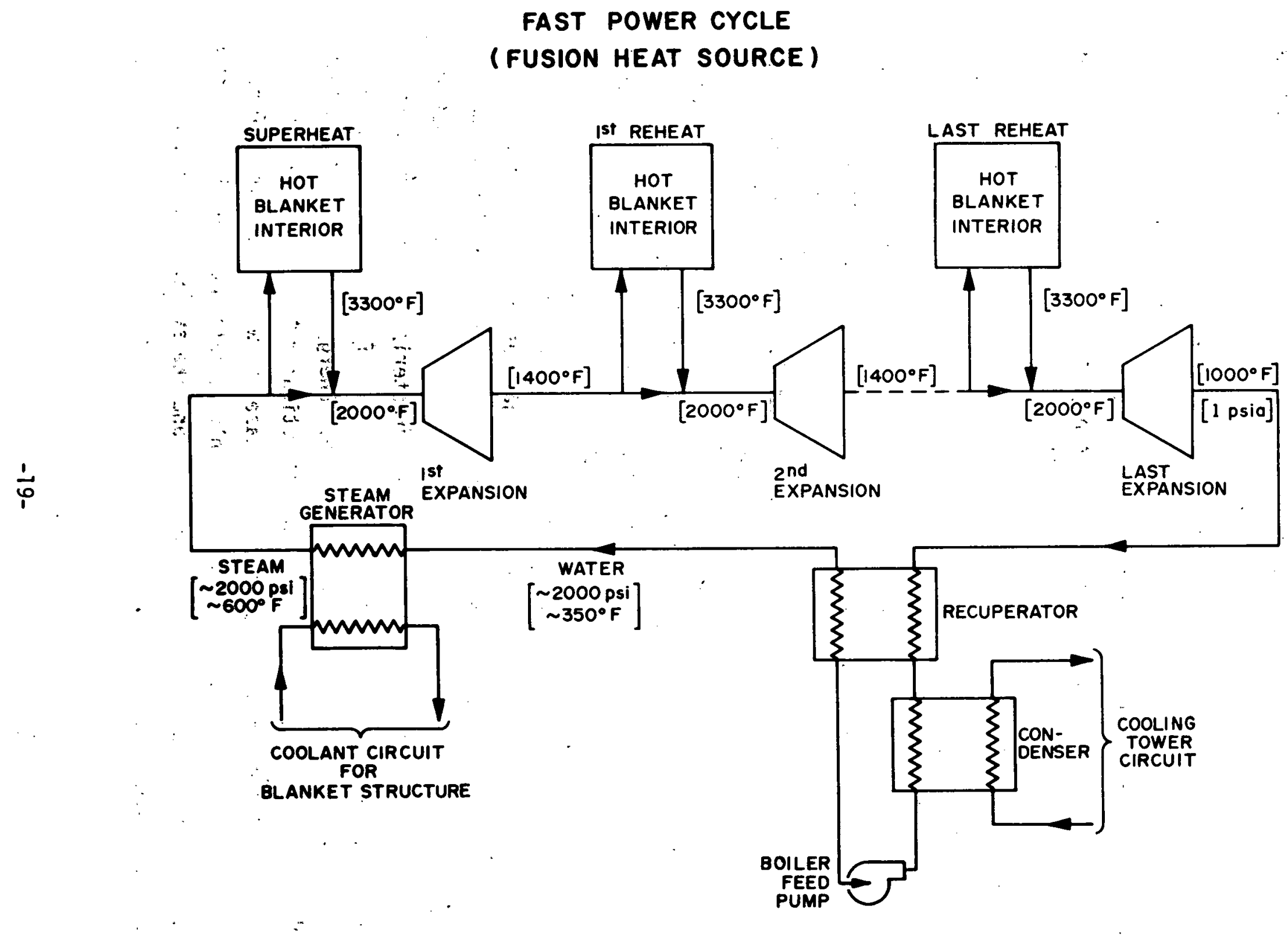

FIGURE 3-4 
The optimum pressure level for the last reheat must be determined by detailed parametric studies. For purposes of illustration in this report, it is taken to be $16 \mathrm{psia}$. The low power density and thinness of the blanket, coupled with the relatively open nature of the coolant passages and large temperature rise in the steam coolant. should result in a low pressure drop even at low absolute blanket pressures.

Figure 3-5 shows the overall efficiency of the FAST power cycle as a function of turbine inlet temperature in the range of 1600 to $2400^{\circ} \mathrm{F}$, for the case of three reheats and the case of continuous reheat. Overall cycle efficiencies of $\sim 60$ percent appear possible even with turbine inlet temperatures of $\sim 2000^{\circ} \mathrm{F}$. While significant performance gains could be achieved with higher turbine inlet temperatures, which should be practical when fusion reactors come on line, the increase in efficiency for a FAST cycle over a conventional cycle ( $\sim 60$ percent vs. $\sim 40$ percent) is large enough to promise a very important improvement for fusion energy sources over other energy sources.

The efficiency calculations in Fig. 3-5 were based on thermodynamic steam tables of Keenan, et. al. (4), assuming a 70 percent recovery of sensible heat from the 1 psia turbine exhaust gas. A comparison with a 90 percent sensible heat recovery is shown for a turbine inlet temperature of $2400^{\circ} \mathrm{F}$. The performance gain, while significant, is relatively small. The steam is highly superheated throughout the turbine and recuperator portions of the circuit, so that no moisture problems should occur in contrast to conventional steam cycles. The exit steam temperature from the turbine exhaust is very high $\left(\sim 1000^{\circ} \mathrm{F}\right.$ for a $2000^{\circ} \mathrm{F}$ turbine inlet temperature), so that the temperature driving force between the exhaust steam and the boiler feed water in the recuperator is very iarge, on the order of $500^{\circ} \mathrm{F}$. Detailed design of the recuperator may indicate that greater sensible heat recovery is possible if pressure drop consjderations are not 1 imiting.

Besides using directly superheated steam, the FAST cycle uniquely applies to fusion in another way. The lower temperature $\left(i 350\right.$ to $\left.400^{\circ} \mathrm{C}\right)$ heat 


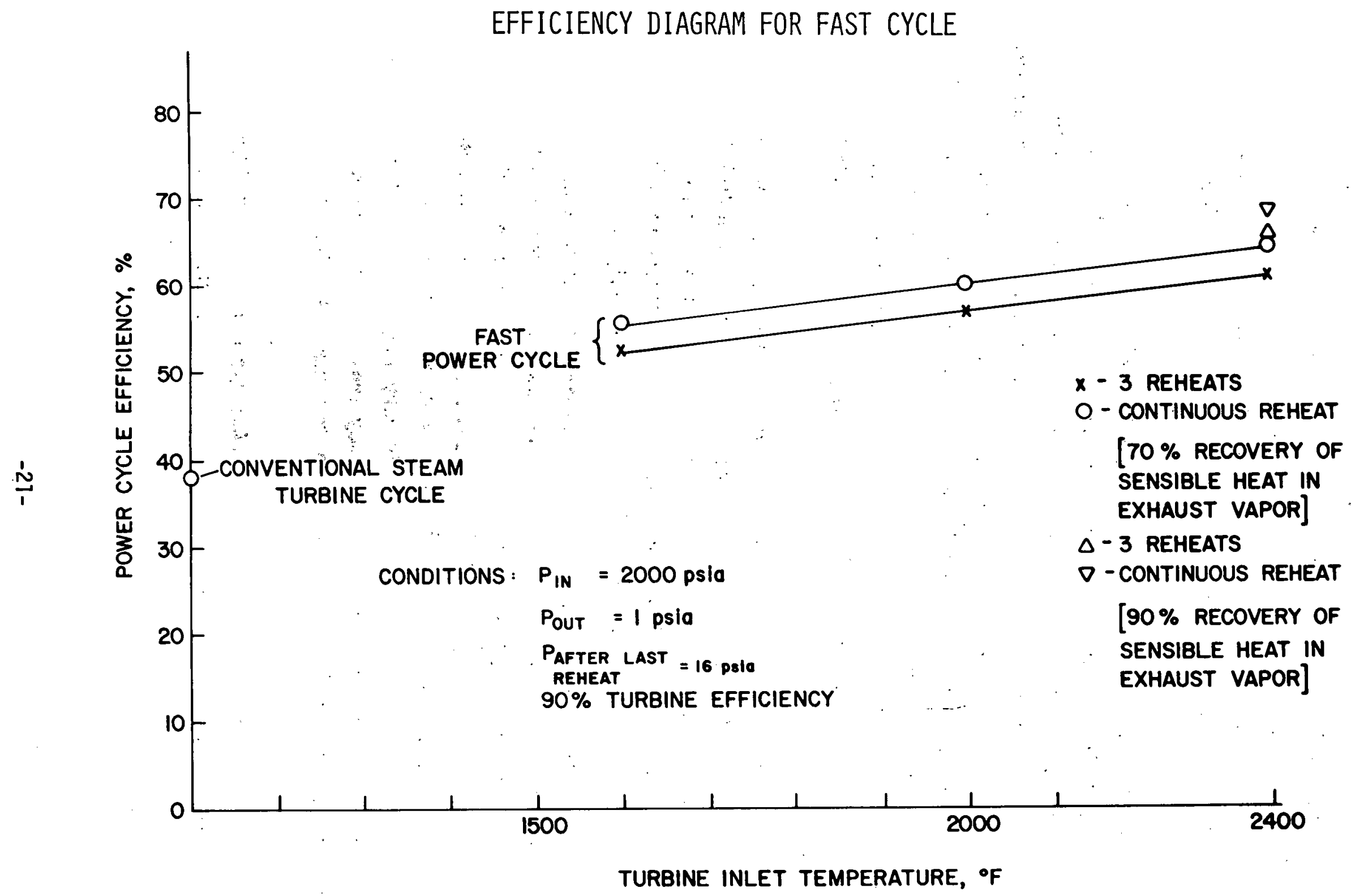

FIGURE 3-5 
available from the blanket structure can be efficiently used to produce saturated high pressure steam, which is then superheated by the heat from the hot blanket interior. Both sources of heat are then used efficiently at their respective temperature levels. With a 70/30 split (hot interior/ cool structure) and source temperatures of $2000^{\circ} \mathrm{F}\left(1094^{\circ} \mathrm{C}\right)$ and $750^{\circ} \mathrm{F}\left(400^{\circ} \mathrm{C}\right)$, the FAST cycle achieves $\sim 80$ percent of Carnot efficiency.

\subsubsection{Implications of the FAST Cycle for Fusion}

The FAST cycle can be used either for electric production to a grid or for electric generation as part of a fusion reactor plant producing synthetic fuels. The higher electrical efficiency generation allows a large reduction in capital cost of the reactor plant. At 60 percent cycle efficiency, the capital cost per $k \dot{W}(e)$ of the reactor plant is reduced by $a$. factor of 1.5 , compared to a reactor using a conventional power cycle with 40 percent efficiency.

This performance gajn appears to be unique to: fusion and achievable with relatively simple, near-term power conversion technology. Table 3-1 shows the achievable power cycle temperatures for the main future energy sources, fission, fusion, and fossil. Only fusion appears to have the capability to directly superheat steam without having to be limited by allowable temperatures in the heat exchangerpofuel cladding.

An important additional benefit of the FAST cycle is the large reduction in thermal pollution and cooling water requirements. A 60 percent efficient FAST cycle rejects much less heat per KWH than either conventional steam coal power plants ( $\sim 38$ percent efficient) or LWR's ( $~ 32$ percent efficient). The reduction in heat rejection per KWH is a factor of 2.5 , as compared to coal/steam plants, and a factor of 3.2 , as compared to LWR's. Besides the obvious environmental benefits, substantial cost benefits can be expected. The unit costs of cooling towers will be greatly reduced and for a given site where thermal pollution or cooling water supply limit plant capacity, the more efficient fusion/FAST plant could be of much higher power rating than a plant with a conventional power cycle. This should result in considerable, cost benefits due to economies of scale. 
TABLE 3-1

FUSION UNIQUE FOR FAST POWER CYCLE

- LWR MATERIAL LIMITS $\approx 600^{\circ} \mathrm{F}$

FBR MATERIAL LIMITS $\sim 1100^{\circ} \mathrm{F}$

- HTGR STEAM CYCLE HEAT EXCHANGER LIMITS $\sim 1100^{\circ} \mathrm{F}$

- coal steam CYCle heAt eXChanger limits $\sim 1100^{\circ} \mathrm{F}$

- OXIDE REFRACTORY FUSION BLANKET LIMITS $\sim 4000^{\circ} \mathrm{F}$ 
Three potential problems might affect the practicality of the FAST power cycle:

1. activation of the turbine circuit: :

2. turbine b7ade erosion from carryover of blanket fines.

3. tritium breeding requirements.

The first problem appears solvable by the use of minimum activity materials in the high temperature interior of the blanket. Oxide refractories like $\mathrm{MgO}, \mathrm{Al}_{2} \mathrm{O}_{3}$, or $\mathrm{BeO}$ will not generate significant amounts of long-lived (i.e., half life greater than one day) activations." Impurities (Fe, Mn $\mathrm{Zn}$, etc) can be kept at a very low level, in the ppm range, and turbine circuit activation from this source will be negligible. $\mathrm{MgO}$ and $\mathrm{Al}_{2} \mathrm{O}_{3}$ generate large amounts of $\mathrm{Na}^{24}$ (haif life of 15 hours); however, the resurting turbine loop contamination will decay to negligible levels in a few days. Carryover of activation products from the staintess'steel (or other activated structure material) module walls should not be of concern since the walls are isolated from the high temperature interior by a relatively thick thermal insulator. Similarly, the high temperature piping system will be lined with a refractory thermal. insulator so that the very high temperature steam can be carried using existing structural materials, e.g., stainless steel, for the piping. The steel piping will be main-... tained at acceptable temperatures by a separate cooling circuit.

There will be some activation of crud from, corrosion of heat exchangers and the low temperature piping system, as: well as erosion products from. the turbine blades. This would not appear to be any more severe than ac- tivation in BWR steam circuits, where steam from the reactor core is passed directly through the turbine. In fact, the FAST cycle with fusion should cause less problems than a BWR, since activation, of corrosion products from fuel cladding will not occur; and there will be no fission products from. leaking fuel pins.

The second potential problem is turbine blade erosion from carryover of blanket fines. Very low particulate loadings, in the order of is $10-50 \mathrm{ppm}$ 
of $\geq 5 . \mu$ diameter particles, ${ }^{(5)}$ are required to prevent excessive turbine blade erosion. This seems achievable. The steam inventory in the circuit wi11. pass on the order of: $10^{9}$ times through the blanket interior during the time a given module is in the reactor. Cleanup of the fines in the condensed steam should result in acceptably low particle loadings in the turbine, even if a significant fraction (e.g., 10 percent) of the blanket interior were to be carried off during the life of the module by the steam coolant. For example, a $10 \mathrm{ppm}$ level of fines in the steam circuit would be maintained if only one part in $\sim 10^{5}$ of. the fines in the condensed steam were removed per pass through the condenser. It appears that it should be quite easy to pass a small portion (e.g., $\left.10^{-3}\right)$ of the condenser flow through a filter to remove fines, and this should prevent any problem with buildup of fines. The steam coolant velocities are low, on the order of 30 $\mathrm{ft} / \mathrm{sec}$, and attrition of the blanket interior should be minimal.

The tritium breeaing requirements for the high temperature electrolysis (HTE) process with a conventional power cycle could be readily met. Here the modules that produced heat for electricity generation also generate surplus tritjum to make up for the tritium deficit of the HTE process heat modules.

With the FAST cycle, the modules cannot breed tritium in the hot bianket interior since the tritium. would enter the stream circuit, and would be very difficult, if not impossible, to extract. With $\mathrm{MgO}$ or $\mathrm{Al}_{2} \mathrm{O}_{3}$ interiors and solid lithium compounds on the outside surfaces of the module, the maximum tritium breeding that could be acheived is on the order of 0.7 . If $\mathrm{BeO}$ is used in the high temperature interior, a tritium breeding ratio of $\sim 1.0$ can be achieved. It thus appears that if all modules are to supply. the FAST cycle and HTE process heat, that BeO must be used. The principal concern here would appear to be Be resource availability. There are a wide range of opinions on the question of how much Be is available and at what cost. Studies would have to examine this question, to see whether Be availability would seriously limit the implementation of the FAST cycle. If $\mathrm{BeO}$ is not used for the blanket, the FAST cycle would require that the tritium deficit be made up from other modules in the reactor that operated at a high breeding ratio, i:e., 27.5 . 
This problem is common to all high temperature fus ion synfuel processes, however, Fusion reactors using thermochemical or direct decomposition. processes will not be able to breed tritium in the high temperature portion of the blanket modules and will have to rely on surplus tritium from other reactors or modules.

In conclusion, the FAST cycle appears to of fer great technical and economic promise for fusion reactors, both for electric generation and synfuel production processes based on electrolysis: it is unique to fusion since the direct heating of steam in high temperature blankets is not constrained by heat exchanger limitations. More work is needed to fully explore this. very new concept to determine what design parameters are best, and to determine what restrictions may exist. 


\subsection{Introduction}

The direct heating of steam in high temperature blanket interiors for HTE process heat applications places design constraints on both the portion of the blanket that generates the high temperature steam, as well as the reactor system as a whole. The constraints may be summarized as follows:

\section{A. Tritium Breeding in HTE Modules}

Tritium cannot be bred inside the high. temperature steam cooled region of the blanket modules. Not only would it be impractical to extract it from the $\mathrm{H}_{2}$ product (which would have objectionably high tritium levels) but the steam would chemically react with whatever lithium material was used for tritium breeding. Solid lithium compounds may be used on the outer surfaces of the module, with the bred tritium escaping directly to the plasma chamber and exhaust. The tritium breeding ratio for this portion of the blanket will be substantially below one.

\section{B. Vacuum/Pressure Boundary for Steam Coolant}

The steam coolant must be prevented from leaking to the plasma chamber by some type of vacuum/coolant structural pressure boundary. Presently, the only practical materials for this purpose appear to be metals such as stainless steel, titanium, aluminum, vanadium, niobium, etc. The top working temperature of these metals is in the range of $\sim 300$ to $500^{\circ} \mathrm{C}$, depending on material, wall thickness, blanket module size, and internal pressure. Because of the temperature limitation, the metal structure must be cooled by a separate coolant circuit (e.g., water) which operates at a considerably lower temperature than the high temperature steam cooled interior.

Blanket designs of this type were first proposed in connection with studies on minimum activity blankets using aluminum structure ${ }^{(1)}$. More recent designs $(2,3,4)$ have developed the low temperature structure/hot interior concept in greater detail. The most promising approach is shown in Fig. 4-1 and Fig. 4-2. Several low temperature shells,.. typically $30 \mathrm{~cm}$ in 


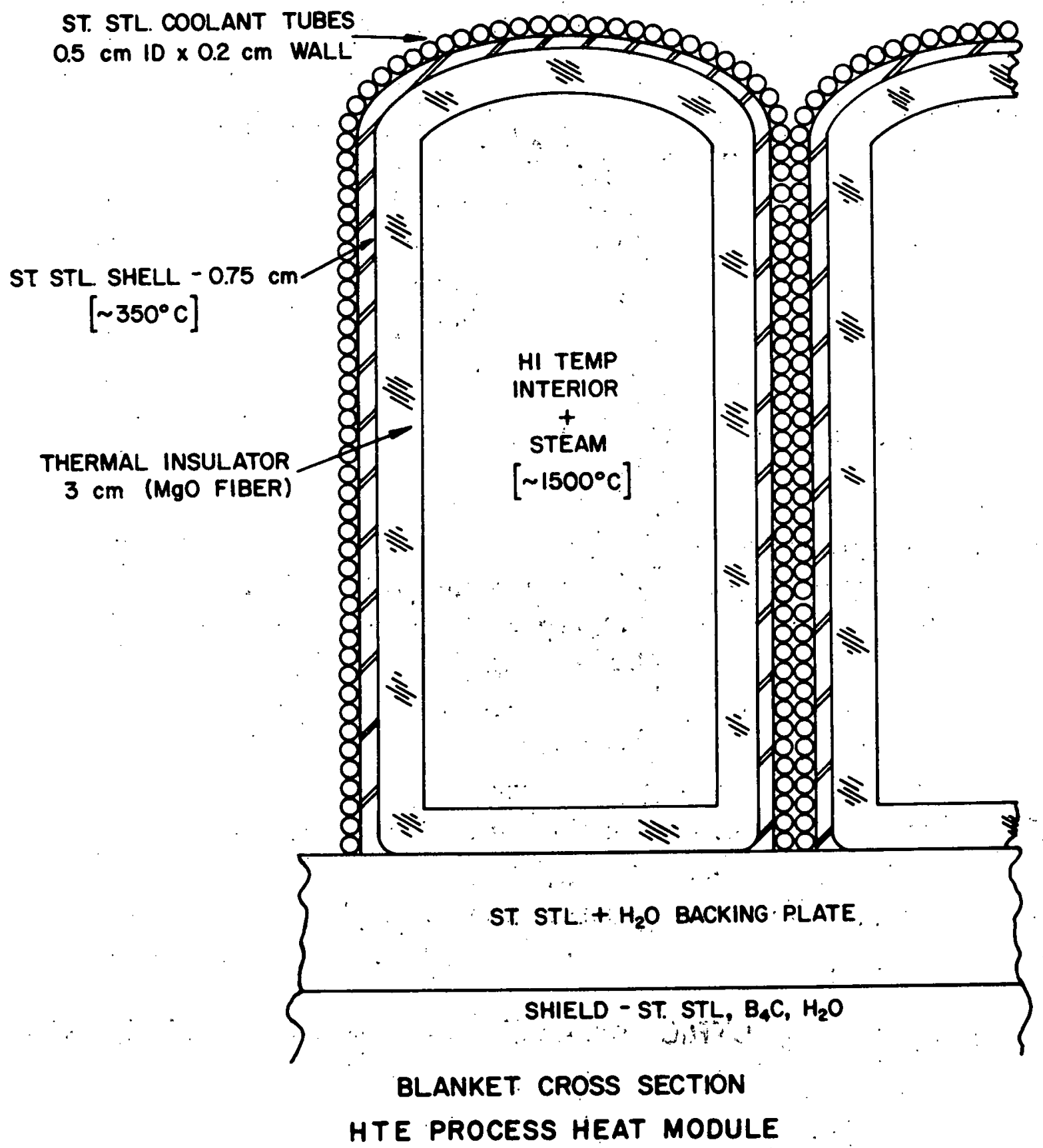

FIGURE 4-1 


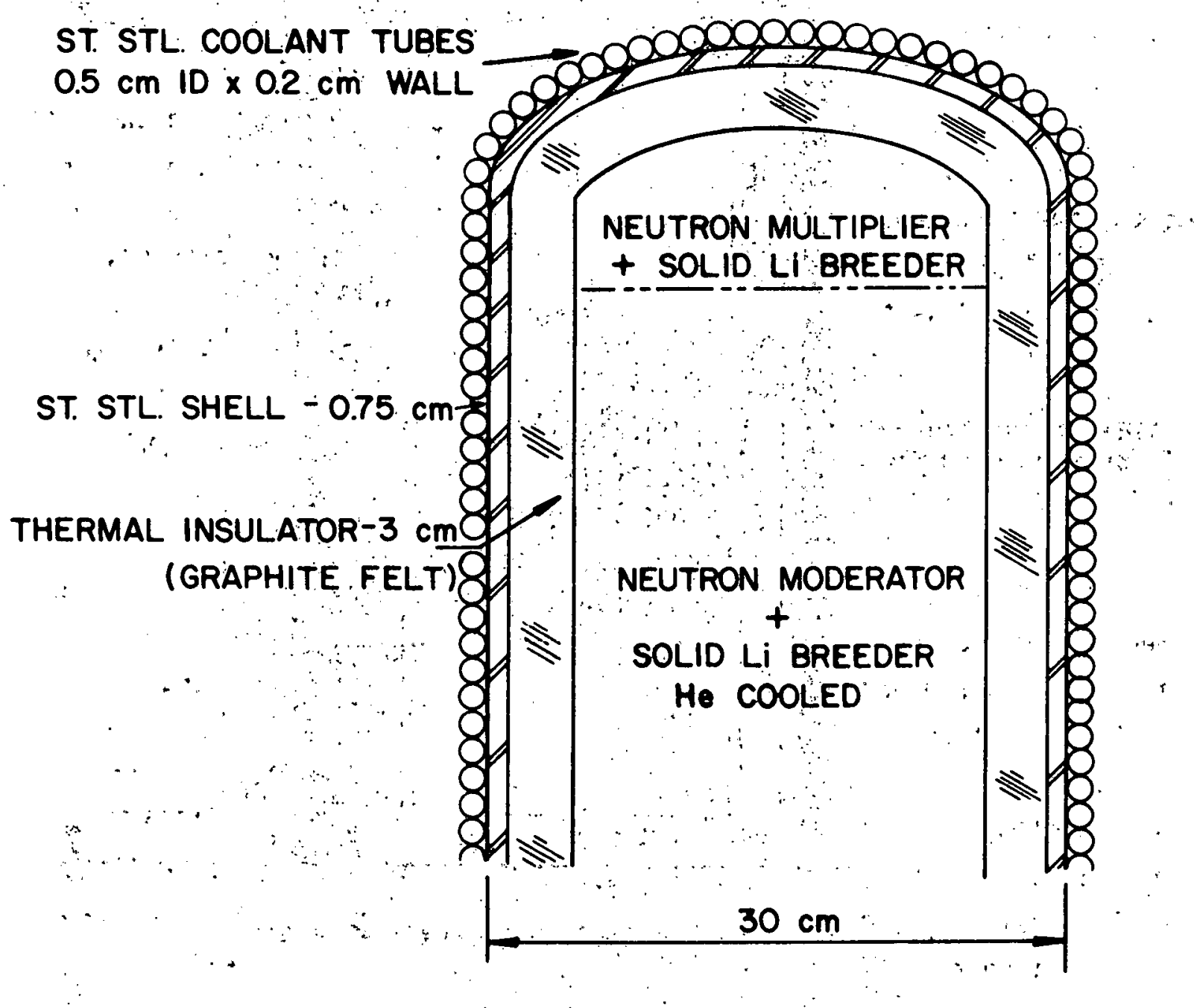

\section{ELECTRIC PRODUCTION MODULE - T. BREEDING}

FIGURE $4-2$ 
width and several 'meters in length, are placed side by side on a strong structural backing plate (Fig. 4-1). Modules are inserted and removed through small access ports in the plasma chamber. Figure 4-3 shows a typical access port arrangement for a Tokamak reactor.

c. Thermal Insulator Between Hot Interior and CoOl Structure A good thermal insulator is required between the hot interior and the cool structure in each blanket module. This material must be compatible with both the steam coolant and the refractory interior. The most promising insulator option is to use the same material as used in the interior, but in a low density form perhaps as a fibrous layer.

D. Compatibility of Blanket Interior with High Temperature Steam The blanket interior will be exposed to high temperature steam. The steam temperatures considered in this study range from 1400 to $1800^{\circ} \mathrm{C}$. Only oxide refractory materials and possibly some carbides (e.g., SiC), appear to be feasible for such operation.

E. Minimum Activation of High Temperature Steam and $\mathrm{H}_{2} / \mathrm{O}_{2}$ Products Neutron activation of the blanket interior will occur and it is very important to prevent this activation from seriously contaminating the high temperature steam circuit and the $\mathrm{H}_{2} / \mathrm{O}_{2}$ product gases from the HTE process. Use of minimum activity materials like $\mathrm{MgO}_{2} \mathrm{Al}_{2} \mathrm{O}_{3}, \mathrm{SiC}$, etc., should eliminate this problem. Considerable $\mathrm{Na}^{24}$ activation (15 hour half $\mathrm{Iife}$ ) will be produced in $\mathrm{MgO}$ and $\mathrm{Al}_{2} \mathrm{O}_{3}$ but will decay to negligible levels in a few days. Activation of impurities should be negligible, since the impurity levels in these blanket materials will be in the ppm range.

F. Tritium Requirements for Overall Fusion Economy Since natural sources of tritium are negligible, new tritium must be bred to make up that burned in the reactor plasma. As discussed previously, the tritium breeding ratio for the modules generating high temperature steam for the HTE process will, at best, be substantially below one (e.g... in the range of 0.5 to 0.7 ). This tritium deficit must be made up from. surplus tritium produced by other modules in the same reactor, or 


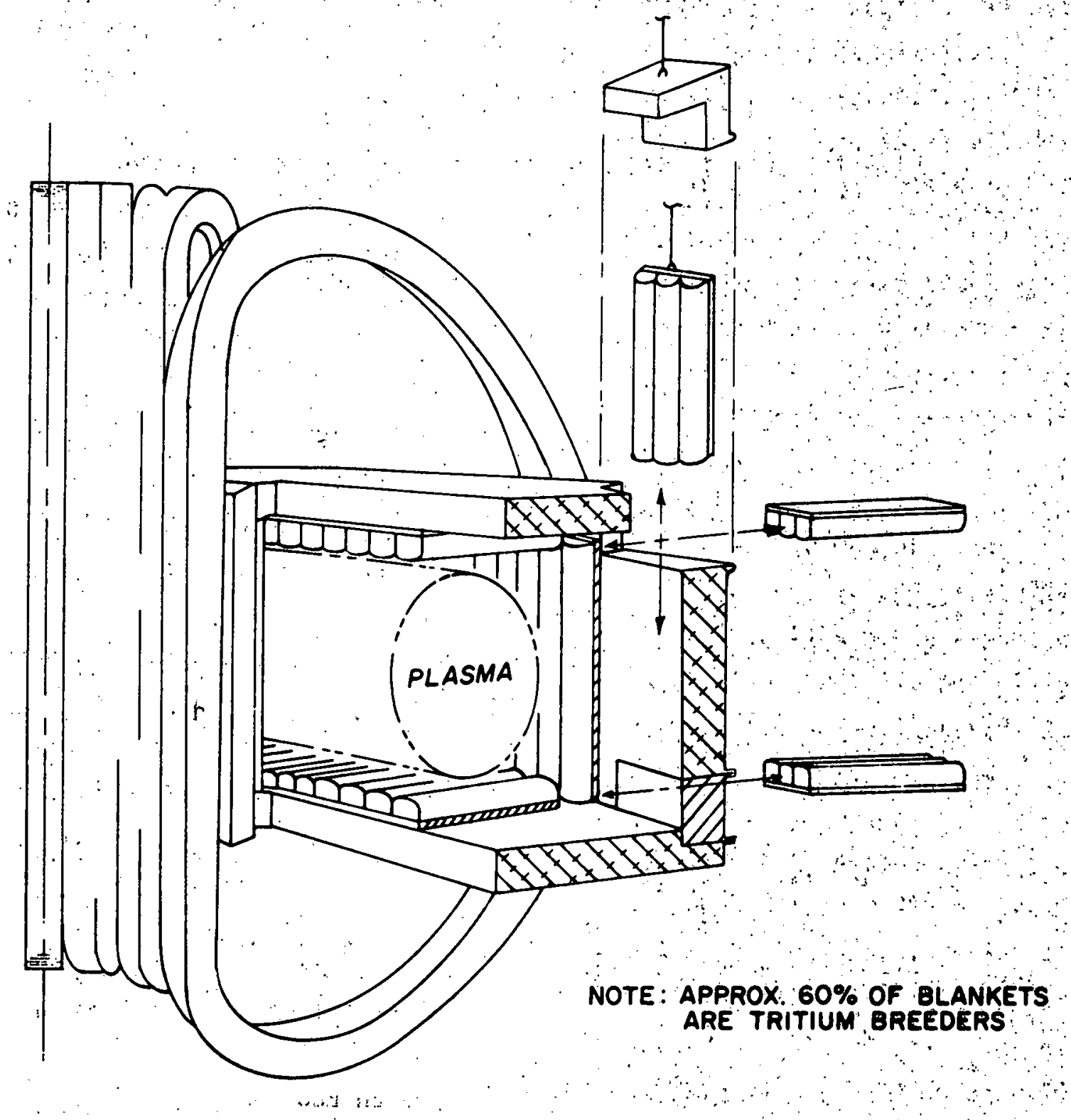

SCHEMATIC SHOWING MODULE REMOVAL

FIGURE 4-3 
by surplus tritium shlpped from other fusion reactors. The HTE fusion synfuel process allows this make-up tritium to be supplied in a very efficient manner.: Part of the blanket in each reactor is used to generate thermal energy for an electric power cycle; 'with the generated electricity consumed by the HTE process units. "Figure 4-2 shows a blanket'module design for electric generation; similar to those developed in earlier studies $(3,4)$. In these designs tritium breeding occurs in the hot interior of the module with the bred tritium rapidly diffusing out of the solid. lithium compound (e.g:, $\left.\mathrm{LiAlO}_{2}\right)$ into the He cololant, from which it is trapped out ${ }^{(5)}$ by absorption in a metal hydride or by conversion to $\mathrm{T}_{2} \mathrm{O}$ and absorption in molecular sieve material. A neutron multiplier (e.g., $\mathrm{PbO}, \mathrm{Be})$ is used in the portion of the module near the first wall in order to maximize tritium breeding ratio: "Previous'blanket design studies indicate that it should be relatively straightforward to make up the tritium deficit from the HTE heat modules in this manner: With other fusion synfuel processes such as thermochemical or direct decomposition, it probably will not be possible to make up the tritium deficit associated with the process heat modules unless a large fraction of the fusion reactor output is devoted to electrical production for the grid.

These design constraints affect both the design of the blanket and indirectiy, the reactor, but also affect the degree to which the overall performance goals can be achieved." These goals can be sumarized as follows:

1. maximum conversion efficiency, fusion heat to $\mathrm{H}_{2}$ chemical energy;

2. maximum amount of fusion energy in the high temperature region of the blanket;

3. blanket/reactor reliability and simplicity;

4. minimum activation of process streams and products; and

5. minimum , blanket/reactor cost:

In the limited timeframe of this HTE study, many blanket design features and issues had to be examined very briefiy. " The principal questions addressed in some detail were as follows: 
1. What fraction of the fusion energy is deposited in the high temperature interior?.

2. What tritium breeding ratios can be achieved in HTE process heat and electric generation modules?

3. Is the reactor self-sufficient with regard to tritium breeding or does make-up tritium have to be supplied from external reactors?

4. Are stainless steel module structures viable from the standpoint of heating and tritium breeding? Are low activity vanadium structures viable?

5. Is beryllium required as a neutron multiplier, or can a lead compound be used?

6. Are there any significant neutronics differences between the $\mathrm{MgO}$. and $\mathrm{Al}_{2} \mathrm{O}_{3}$ options for the high temperature interior?

7. Are wall leadings of $\sim 2$ to $3 \cdot \mathrm{MW}(\mathrm{th}) / \mathrm{m}^{2}$ compatible with the coolant circuits for the HTE and electric generation modules?

8. What coolant flow configurations are desirable for the HTE and electric generation modules? What is the likely range of pressure drop for the coolant? Are coolant velocities high enough to cause serious carryover of fines?

9. Are any special operational and/or maintenance problems foreseen for the HTE and electric generation modules?

10. What are the key issues for the blanket?

\subsection{Blanket Neutronics}

Table 4-1 compares the principal neutronics features for HTE process heat and electric generation modules. The effect of stainless steel (SS) and vanadium (V) structural materials is shown, together with two neutron multiplier options ( $\mathrm{PbO}$ and $\mathrm{Be}$ ). The two materials considered for the hot interior of the HTE process heat modules are $\mathrm{MgO}$ and $\mathrm{Al}_{2} \mathrm{O}_{3}$. Besides a neutron multiplier, the electric generation modules use a graphite $(C)$ moderator and a solid lithium compound $\left(\mathrm{LiAlO}_{2}\right)$ for tritium breeding. 


\section{BLANKET PARAMETERS}

$\left(P_{0} S_{4}\right.$ APPROXIMATION)

PROCESS HEAT REGION . ELECTRIC PRODUCTION REGION

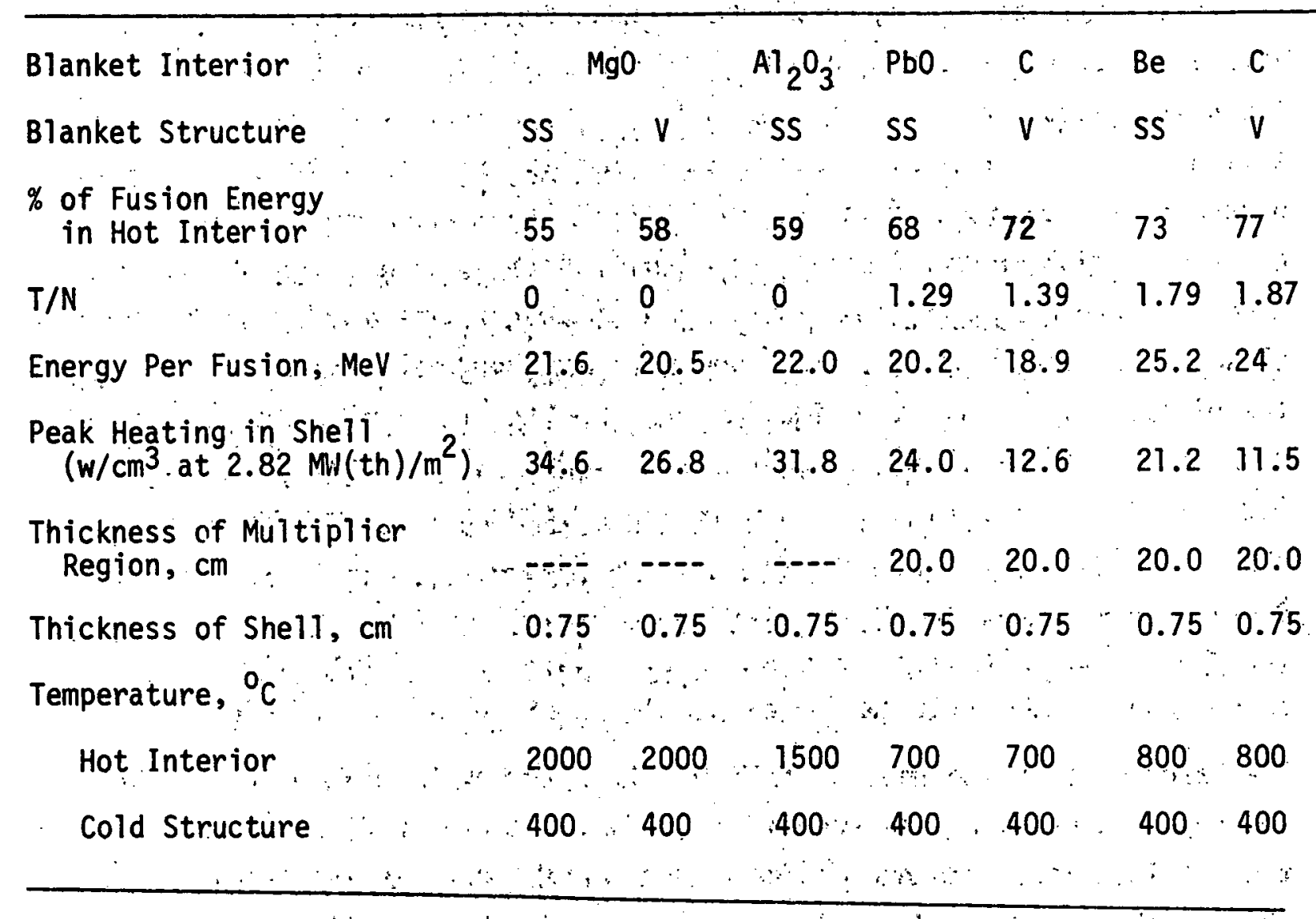

FUSION REACTOR AND PLASMA DIMENSIONS

Major radius $=8.0 \mathrm{~m}$

Minor radịus $=2.7 \mathrm{~m}$ 
A 100 group, 1-D ANISN neutronic model was used to analyze the various blankets. The dimensions of the Tokamak reactor plasma used as the reference for the neutronics calculations are given in Table 4-1. A $\mathrm{P}_{0} \mathrm{~S}_{4}$ approximation was used for most of the neutronics analyses since they were of a scoping nature. Some analyses were carried out comparing results from a more accurate $\mathrm{P}_{3} \mathrm{~S}_{8}$ approximation to those from a $\mathrm{P}_{0} \mathrm{~S}_{4}$ approximation to examine what effect the less accurate $P_{0} S_{4}$ approximation had on the results. In general, the $P_{0} S_{4}$ approximation yielded results accurate enough for the purposes of this study. The breeding ratio was essentially the same for the $P_{0} S_{4}$ and $P_{3} S_{8}$ analyses. With the $P_{0} S_{4}$ approximation heating deposition (both neutron and gamma) rates (Figure 4-4 compares the two approximations for an electric generation module with a $\mathrm{Be}$ neutron multiplier and $V$ structure) tended to be somewhat higher than the more accurate $P_{3} S_{8}$ approximation in the portion of the blanket relatively close to the plasma and somewhat lower in portions relatively far from the plasma. The $\mathrm{P}_{0} \mathrm{~S}_{4}$ approximation also tended to underestimate neutron flux deep into the blanket and shield, particularly for the $14 \mathrm{MeV}$ flux. Figure 4-5 compares the neutron flux distributions predicted by the two approximations, for the same $V$, Be electric generation blanket. The heating rates shown are in $\mathrm{ev} / \mathrm{cm}$, which are proportional to watts $/ \mathrm{cm}^{3}$ for a given wall loading. For a gross wall loading $=2.8 \mathrm{MW}(\mathrm{th}) / \mathrm{m}^{2}$, the corresponding peak volumetric heating rates are shown in Table 4-1.

The large dips in the heating rate in the $C$ regions in Fig. $4-4$ are due to the low density of the thermally insulating. layer on both sides of the hot interior. The neutron/gamma heating in this region is much lower than in the much more dense interior of the blanket.

The abscissa of Fig. 4-4 and Fig. 4-5 is in terms of the interval number in the neutronic analysis, and does not refer to the actual thickness of the different regions, which are given (in $\mathrm{cm}$.) in parentheses under the composition of each region. The ordinate for Fig. $4-4$ is the $\log _{10}$ of the heating rate (in ev/cm). The ordinate for Fig. $4-5$ is the $\log _{10}$ of the neutron flux $\left(\mathrm{n} / \mathrm{cm}^{2} \mathrm{sec}\right)$, with a $2.8 \mathrm{Mw}(\mathrm{th}) / \mathrm{m}^{2}$ wall loading (gross wall loading includes neutron and alpha particle energy). Additional heating rate and neutron flux distributions are shown in Appendix $B$. 
BREEDING BLANKET

HEATING RATES - PO $S_{4}$ COMPARED WITH $P_{3} S_{8}$ NEUTRONICS

CALCULATIONS

STRUCTURAL SHELL-V

NEUTRON MULTIPLIER-Be

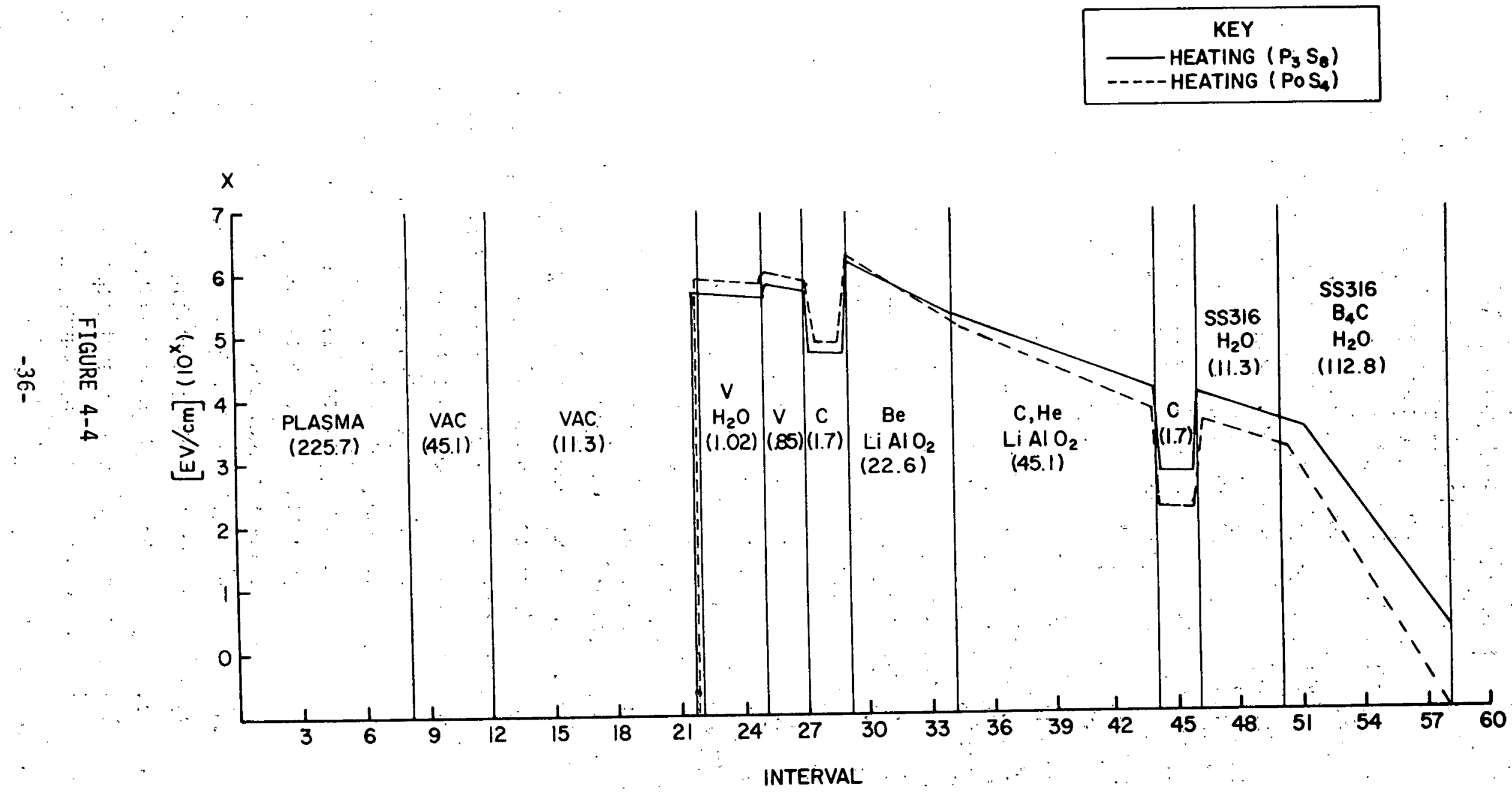




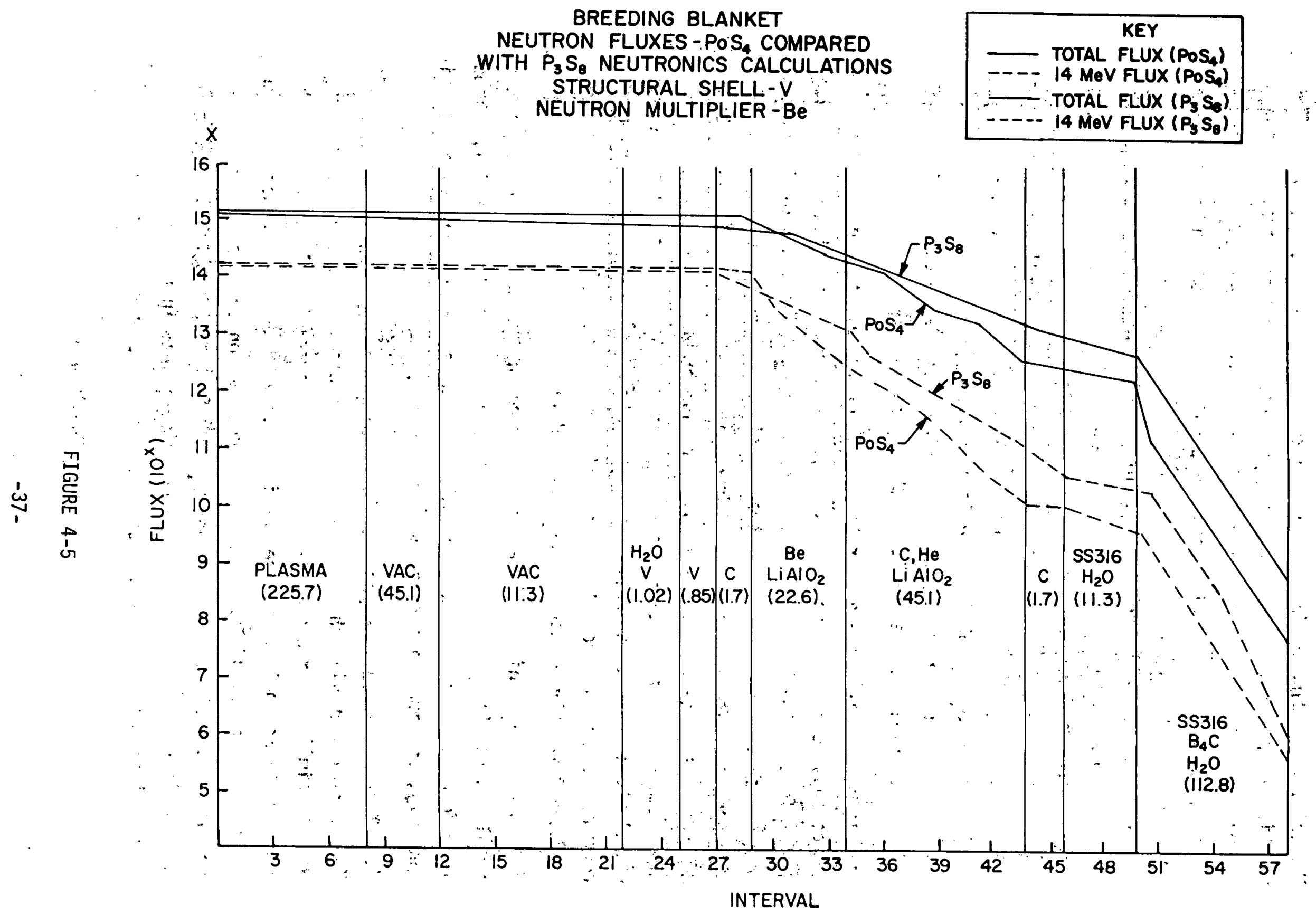


The tritium breeding ratios for the electric generation modules are relatively high for $\mathrm{PbO}$ neutron multipler (1.3 to 1.4) and very high for Be neutron multiplier (1.8 to 1.9). Table 4-2 shows the required tritium breeding ratio in the electric generation modules for the following set of conditions:

1. The reactor is self sufficient in tritium (does not import or export tritium);

2. The tritium breeding ratio in HTE modules is equal to 0.0 (nonbreeding) or 0.7 ( $\mathrm{LiAlO}_{2}$ on outer surfaces of HTE module);

3. The fraction of HTE energy supplied as process heat is equal to 0.30 or 0.50 (balance is electricity):

4. The efficiency of power generation cycle is equal to 0.4 (conventional cycle) or 0.6 (FAST cycle).

The highest required breeding ratio (1.6) for the electric generation modules corresponds to a 50 percent process heat fraction, no tritium breeding on the surface of the HTE modules, and a power cycle efficiency of 60 percent. This can be achieved with Be neutron multipliers in the electric generation modules. The lowest required breeding ratio (1.05) corresponds to a 30 percent process heat fraction, a tritium breeding ration of 0.7 for the HTE modules, and a power cycle efficiency of 40 percent. This can be readily.achieved with a small amount of neutron multiplier. With partial tritium breeding in the HTE modules, $\mathrm{PbO}$. neutron multiplier is more than sufficient for the electric generation modules.

A number of neutronics analyses were carried out of partial breeding HTE modules with $\mathrm{LiAlO}_{2}$ on the outer module surfaces. Tritium breeding ratios were found to be in the range of 0.5 to 0.7 depending on structural material, geometry, and composition of the hot interior.

\subsection{Thermal Hydraulic Aspects of Blanket Design}

The thermal hydraulic characteristics of the electric generation modules will be similar to those developed in previous studies $(3,4)$. The pressure of the He coolant for the hot interior will be on the order of $30 \mathrm{~atm}$, $\Delta T$ on the order of $400^{\circ} \mathrm{C}$, and the pumping power on the order of $1-2$ percent of the blanket thermal power. In effect, the helium coolant circuit conditions will be roughiy comparable to that in the HTGR, with the principal difference being the somewhat lower pressure than the HTGR. 


\section{TABLE 4-2}

\section{TRITIUM BREEDING REQUIREMENTS}

TRITIUM

BREEDING

HTE BLANKET

$(B R=0.7)$

Percentage of HTE Energy as Process Heat

Fraction of Blanket Occupied by HTE Heat Modules

$E_{E] \text { ec }}=0.40$

$E_{E l e c}=0.60$

$0.15 \cdot 0.28$

$0.205 \quad 0.38$

0.15

0.28

30

50
NON-BREEDING HTE BLANKET $(B R=0.0)$

Tritium Breeding Ration in Modules for Electricity Production

EElec $=0.40$

$\begin{array}{llll}1.05 & 1.12 & 1.18 & 1.39\end{array}$

$E_{E l e c}=0.60$

$\begin{array}{llll}1.08 & 1.18 & 1.26 & 1.61\end{array}$


The water coolant conditions for the tubes in the module shell will approxi-.. mate those in PWR's, with a pressure of $\sim 2000 \mathrm{psi}$, a top temperature of $i 300^{\circ} \mathrm{C}$ and peak heating fluxes of $i 100,000 \mathrm{Btu} / \mathrm{hr} \mathrm{ft}^{2}$. The bremsstrahlung surface heating on the sides of the tubes facing the plasma is of the same order as the heating in the module shell. This tends to flatten the azimuthal heat flux distribution around each tube.

The thermal hydraulic conditions in the steam cooled HTE process heat modules tend to be more limiting than those in the $\mathrm{He}$ or $\mathrm{H}_{2} \mathrm{O}$ coolant circuits, for several reasons:

1. The coolant is a gas at a relatively low pressure, e.g., 10:atm (compared to He at $30 \mathrm{~atm}$ )

2. The temperature rise of the coolant in the blanket is low, e.g., $150^{\circ} \mathrm{C}$ (compared to the He circuit where the $\Delta T$ is $\sim 400^{\circ} \mathrm{C}$ ).

3. The coolant makes a large number of passes, on the order of 10; through the blanket since it has to pass in series through a corresponding number of process heat modules.

A thermal-hydraulic analysis of a steam cooled HTE module for process heat has been carried out, assuming a wall load of $2.8 \mathrm{MW}(\mathrm{th}) / \mathrm{m}^{2}$, a steam pressure of $10 \mathrm{~atm}$ and a temperature rise of $150^{\circ} \mathrm{C}$ in the module. The module hot interior is assumed to be composed of a packed bed of $\mathrm{MgO}$ balls, $1 \mathrm{~cm}$ in diameter, with a module length of 4.8 meters, a hot interior module width of $30 \mathrm{~cm}$, and a radial depth of $68 \mathrm{~cm}$. It is evident that pressure drop is excessive if the steam coolant flows along the length of the module. With radial flow, however, the pressure drop is reasonable. This can be accomplished by having the steam flow radially towards the plasma through one half of the packed MgO bed inside the module, then change direction and flow radially away from the plasma:-through the adjoining half of the Mg0 packed bed. The two halves of the module can be separated by a thin ceramic septum plate so as to channel: the steam flow in the desired manner: Inlet and outlet steam headers run the length of the module at its back (i.e., next to the backing plate in Figure 4-1). For the assumed wall load, temperature rise, and steam pressure the pressure drop per pass through the blanket is 4 psia. Eight passes in series 
would result in a total pressure drop of $\sim 2 \mathrm{~atm}$, which is probably somewhat too high. The pressure drop can be reduced to the desired level, e.g., $1 \mathrm{~atm}$, by a small increase in steam pressure and/or temperature rise, which will not significantly affect the performance of the HTE units. Alternatively, one could grade the diameter of the MgO packed bed, using larger balls near the inlet and exit headers, where power density is low, and retain the smaller, e.g., $1 \mathrm{~cm}$ diameter, balls at the front of the module where the power density is high. A final alternative would be to use stacked MgO rods instead of balls, which would reduce pressure drop by a large factor.

The balls will be somewhat hotter than the local steam temperature. The total surface area in the bed is very large, however, so that even with a relatively low film coefficient, the peak temperature difference between balls and steam is estimated to be on $7 y \sim 100^{\circ} \mathrm{C}$.

In summary, both pressure drop and film temperature drop appear reasonable with steam coolant for the HTE blanket modules. Optimum parameters and/ or design may be somewhat different than assumed in this.study, but not significantly so.

\subsection{Mechanical Design}

The primary. stress due to the steam pressure in the HTE module shells will be relatively low ( 3000 psi for a $30 \mathrm{~cm}$ wide module, $0.75 \mathrm{~cm}$ thick shell, and $10 \mathrm{~atm}$ steam pressure). The primary stress in the walls of the tubes carrying water coolant will be comparable to the stress in the module shell.

The thermal stresses in the tube walls and module shells appear to be a more severe design problem than, the primary stresses resulting from the coolant pressure. The maximum temperature differential in the tube wall due to bremstrahlung loading (assuming all of the alpha particle energy is deposited on the first wall) will be $\sim 50^{\circ} \mathrm{C}$ at a wall load of $2.8 \mathrm{MW}(\mathrm{th}) / \mathrm{m}^{2}$. This will produce a maximum thermal stress of $\sim 13,000$ psi in the tube wall, which is relatively high. Comparable temperature differential and thermal stress will be produced in the module shell by neutron and gamma heating. Estimates of what thermal stress and temperature differential 
is allowable will have to be based on much more detailed design and stress analysis, and will have to include the effects of thermal cycling. It is clear that these thermal stresses are high, however. They can be reduced by working at lower wall loads, which is probably undesirable for economic reasons, by using thinner module shells and tube walls, which is probably not practical for mechanical and sputtering reasons, or by using different structural materials. Use of vanadium would reduce the thermal. stress in the module shells by a factor of almost two, due to the lower heating rate, but not the stress due to temperature gradients from bremsstrahlung and ion impacts. If a divertor is used, the bremsstrahlung: and ion impact load could be reduced by a large factor which would reduce the thermal stress in the tube wall by a corresponding factor. Use of aluminum for tube walls and the module shells would reduce thermal-stresses to very low levels, i.e., on the order of 1000 to $2000 \mathrm{psi}$, where they should not be of concern. There are substantial other adyantages in the use of aluminum as the structural material, including the very low level of induced radioactivity and very good resource availability. The radiation damage resistance of aluminum in a fusion neutron spectrum is unknown, however. It exhibits very good resistance to radiation damage in a fission neutron spectrum, but the effects of He gas generation due to $(n, \alpha)$ reactions caused by high energy neturons have not been explored. There is some data on He effects in stainless steel, so it was chosen for this design study. If data on the radiation damage resistance of al uminum proves favorable, then it would probably to the material of choice for the blanket modules.

The primary stresses in the shells of the modules generating heat for the electric power cycle will be greater due to the higher operating pressure of the He coolant. This may make somewhat thicker module shells or smaller width modules more desirable. The thermal stresses will be comparable to those for the HTE modules, assuming the same wall loads and module geometry. 


\subsection{Conclusions}

Conclusions to the principal questions formulated in the introduction are summarized below. These conclusions are preliminary and in some cases, more accurate analyses and more detailed design should be done to confirm them.

A. Approximately 60 to 70 percent of the $\sim 20 \mathrm{MeV}$ total energy released in each fusion reaction can be extracted as high temperature heat from the hot interior of the blanket modules. This fraction depends on blanket design and materials, but is reasonably constant for the range of designs and materials considered.

B. The electric generation modules can be designed to have tritium. breeding ratios up to $i 1.9$, using vanadium as the structure and beryllium as the neutron multiplier. Breeding ratios up to 1.4 .can be achieved with $\mathrm{PbO}$ as the neutron multiplier. The HTE modules cannot breed tritium in the interior but can achieve breeding ratios in the range of 0.5 to 0.7. with $\mathrm{LiAlO}_{2}$ on the outer surfaces.

c. The reactor can be self-sufficient in tritium for the full range of design parameters considered.

D. Stainless steel module structures appear viable from the standpoint of tritium breeding. The heating rates are reasonable in terms of thermal hydraulic design of the coolant system, but the thermal stresses appear to be relatively high. Vanadium structures also appear viable and alleviate the thermal stress problem to some degree.

E. A lead compound can be used as the neutron multiplier, and in all cases the reactor will be self-sufficient for tritium production if there is partial tritium breeding on the surfaces of the HTE modules. Lead compounds can be used for neutron multiplication and tritium selfsufficiency maintained without tritium on HTE module surfaces, if the power cycle efficiency is 40 percent or if the fraction of thermal energy input to the. HTE is 30 percent... .

F. There does not appear to be any significant neutronics difference between $\mathrm{MgO}$ and $\mathrm{Al}_{2} \mathrm{O}_{3}$ interiors for the HTE process heat modules.

G. Wall loadings of 2 to $3 \mathrm{MW}(\mathrm{th}) / \mathrm{m}^{2}$ appear to be compatible with the coolant circuit designs for the HTE and electric generation modules. 
The principal problem appears to be high thermal stresses with stainless steel structures.

H. For the water cooled structure of the electric generation and HTE modules, water flow in the tubes along the module length appears satisfactory. The He coolant flow path in the electric generation modules, as well as the steam coolant flow in the HTE modules, should be radial to avoid excessive pressure drops. The coolant will flow through an inlet header at the back of each module, then flow radially out through half of the hot interior, radially back through the other half, and then out through the outlet header at the back of the same module. For steam coolant at $10 \mathrm{~atm}, 150^{\circ} \mathrm{C}$ temperature rise, $2.8 \mathrm{MW}(\mathrm{th}) / \mathrm{m}^{2}$, and a packed bed of $1 \mathrm{~cm}$ diameter balls in the hot interior, the radial flow pressure drop is $\sim 4$ psi. With helium coolant at $30 \mathrm{~atm}, 400^{\circ} \mathrm{C}$ temperature rise and the same wall load, the pressure drop will be negligible. Some small modification of coolant pressure, $\Delta T$, or bed geometry (i.e., using rods instead of balls) may be desirable for the steam cooled HTE module, but the HTE performance will not be significantly altered. The steam coolant flow velocity through the packed bed in the HTE module is only $\sim 2$ meters/second and carryover of fines should be negligible. The coolant flow velocity in the electric generation modules will be much lower.

I. No special operations and/or maintenance problems are foreseen for the HTE and electric generation modules. The steam circuit will probably be strongly activated by $\mathrm{Na}^{24}$ ( 15 hours half life) released from the hot interior of the modules, but this will decay to negligible levels in a few days. Other relatively long-lived activations from blanket impurities and/or crud from low temperature piping systems will be present but should present less problems than now faced in LWR's.

J. The key issues for the blanket appear to be primarily related to materials. The module structure has to maintain vacuum integrity in the radiation/thermal cycling environment for several years. This problem is common to all fusion reactor blankets and no new class of problems appears to be generated by fusion reactors using the HTE process. The materials effort now underway in the fusion program should lead to the development of satisfactory structural materials for these applications. 
More specialized material problems related to the HTE applications appear, however. These are conceptual with the stability of oxides such as MgO and $\mathrm{Al}_{2} \mathrm{O}_{3}$ in the high temperature steam under radiation and thermal cycling conditions. Such materials will be used both in the form of solid rods or balls, as well as a low density solid block or fibrous thermal insulation. The principal requirement is that these materials not crumble or inject excessive amounts of fines to the coolant system and that thermal insulation capability be maintained during the life of the module. Because of the more specialized aspects of these materials, it may be advisable to ensure that they will also be considered in the fusion materials development program.

The general design concepts involved for such high temperature blankets appear feasible. Given satisfactory materials, there appear to be no bars to the development of high temperature blankets for fusion reactors using the HTE process to produce synfuels. 


\subsection{THE HIGH TEMPERATURE ELECTROLYZER (HTE).}

Electrolysis" of steam offers a method whereby high temperature heat available from a fusion reactor can be efficientiy converted into hydrogen. The decomposition of water requires both thermal and electrical energy and as the temperature is increased; the electrical energy contribution decreases. At present, electricity production is less than $40 \%$ efficient and reducing the electrical energy contribution increases the efficiency of hydrogen production. An additional advantage is often gained with increased temperatures resulting from the greater rates of the electrochemical reaction and decreased voltage losses.

With the decreasing availability of fossil fuels, the need for producing hydrogen from water has been recognized and many processes for the production of hydrogen are being considered. (1) Solid oxides offer a prom-. ising method for high temperature electrolysis $(2-7)$ and have also been the subject of many investigations as an electrolyte in high temperature fuel cells. (7-9) Most of the recent developments have come from the latter programs, where oxide fuel cells could be used for the production of electricity from coal at an efficiency approaching $60 \%$.

\subsection{Previous Work .}

The electrochemical production of hydrogen at high temperatures with solid electrolytes has been considered by a number of organizations. In 1968 General. Electric presented a model and analys is of an electrolyzer for operation at $1000^{\circ} \mathrm{C}$. The approximate size was between 30 and $350 \mathrm{~W}$ electric giving a hydrogen production rate of between 10,000 and $60,000 \mathrm{scf} / \mathrm{day}$.

The size of the designed modules was $15 \times 46 \times 91 \mathrm{~cm}$. Each module contained 248 cylindrical stacks of cells with ten cellis measuring about $30 \mathrm{~cm}$ in length and $1 \mathrm{~cm}$ in diameter. The active surface area was $1.86 \mathrm{~m}^{2}$. The tubular cells were constructed from $\mathrm{ZrO}_{2}-\mathrm{P}_{2} \mathrm{O}_{2}$ with iron oxide added to assist sintering. The anode was either lanthanum or praseodynium cobaltite and the 
cathode was porous nickel with $10 \% \mathrm{ZrO}_{2}$ as sintering inhibitor. The material problems, design and fabricatjon of both single cells and multicell devices were described (4).

An analysis of the thermodynamics and cell design were also given. In one analysis the use of a depolarizing gas consisting of carbon monoxide was added to the $0_{2}$ compartment of the cell to reduce the potential and hence the electrical costs. In the present concept and with future use of high temperature electrolysis, it is unlikely that fuel will be available to operate the cells in this mode. A recent $(10)$ analysis proposed the use of high temperature solid oxide electrolyzers in conjunction with a high efficiency electrochemical plant where the hydrogen produced would be fed to a low temperature fuel cel1: . The dissociation-recombination cycle converts the high temperature energy into electrical energy, and overcomes the need for moving parts wịch limits the present maximum temperature for turbine systems for the production of electricity. This approach was further developed to employ other chemical systems and tests on cell components (6). The electrolyzer design was a hyper-shaped ("like an egg (crate") or flat-disc ceramic electrolyte sandwiched between metal screens. This component was compressed between heavy metal plates which served as current collectors between the cells, as well as heat exchangers, separators, and gaskets.. The size of the proposed stack of cells was $10 \mathrm{~cm}$ in diameter, $0.5 \mathrm{~cm}$ thick, and an electrolyte thickness of $0.25 \mathrm{~mm}$. The power density of the stack was estimated as $360 \mathrm{kw} / \mathrm{m}^{3}$.

During a recent (1975) workshop (i) on water electrolysis. solid oxide cells were discussed. A prototype unit of $10 \mathrm{kw}$ electrical energy was envisioned by 1983 after a demonstration unit of component testing in 1978. This suggests that an acceptable technology exists at present for the solid oxide electrolyzer construction. Work related to the electrolyzers were given in two presentations. Isenberg ${ }^{(2)}$ considered process efficiencies with a Carnot cycle operating at a maximum temperature of $1300^{\circ} \mathrm{K}$ by the year 2000 . The efficiencies were be over $60 \%$. 


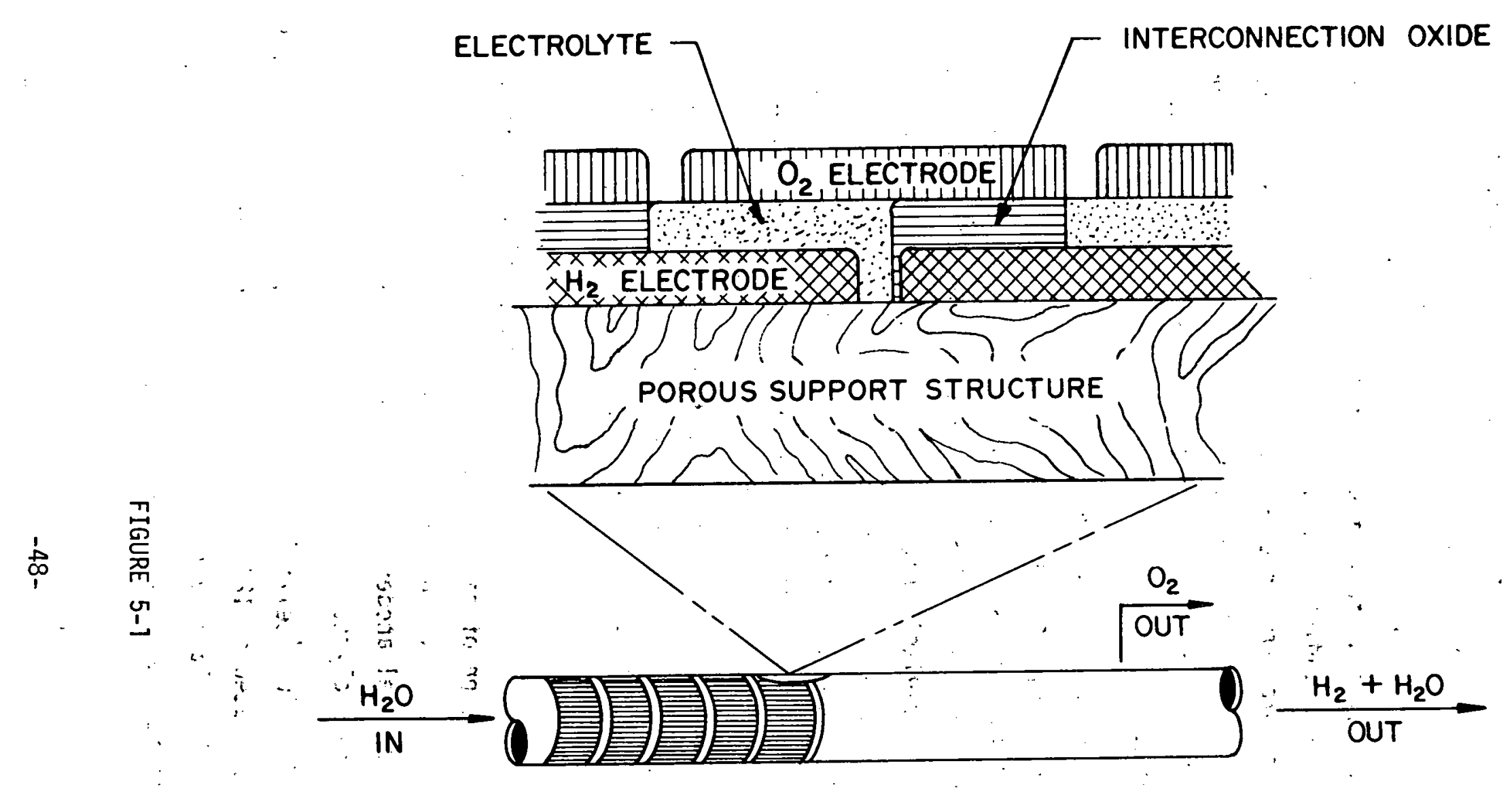

HTE CELL DESIGN (WESTINGHOUSE FUEL CELL) 
Doenitz ${ }^{(3)}$ presented the research program being conducted in Germany. Their program is an analys is of large scale hydrogen production, material problems at high temperatures, and thermodynamics of hybrid proceșes.

The major development of high temperature, solid oxide electrochemical cells has resulted from studies of solid oxide fuel cells. There is an active development program funded by the Division of Conservation, Research, and Technology in the Department of Energy, with Westinghouse as a prime contractor and in which Brookhaven National Laboratory has played an active role.

The Westinghouse design of the fuel cell is based on a supported electrochemical cell in a porous base for operation at $1273^{\circ} \mathrm{K}$. There is a distinct advantage in this approach as the electrolyte thickness can be reduced significantly if it has no load to bear. In the unsupported cell designs, the electrolyte must be considered as a load bearing member. A schematic of their cell design is shown in Fig. 5-1. The cell stack is composed of a porous nickel cermet hydrogen or fuel electrode, a doped indium oxide oxygen electrode, and a $\mathrm{ZrO}_{2}-\mathrm{Y}_{2} \mathrm{O}_{3}$ electrolyte which was ivapor grown to a thickness of somewhat less than 50um: The cell has the additional advantage of being adaptable to mass production where each component of the cell is laid down successively in a manner somewhat similar to the production of integrated semiconductor circuits.

Brown Boveri, in Germany, has tested solid oxide fuel cells for extended periods of time. Operation of single cells have been in progress for over 34,000 hours and lifetimes of more than five years are expected. The cells consist of nickél anodes, lanthanum-nickel oxide cathodes, and a $1.2 \mathrm{~mm}$ thick electrolyte.

The work conducted with fuel cells has shown that high temperature solid oxide cells can be operated at $1273^{\circ} \mathrm{K}$. The major limitation. with these cells had been the difficulties with the connection between cells. However, recent developments have made available mixed oxides, with all the 
required properties for the interconnectors. The use of nickel anodes in fuel cells will probably be the major limitation in reaching higher temperatures. The nickel could be replaced by other conducting oxides which have high conductivities. They should be compatible with the electrolyte and could be the same composition as the interconnector but with a porous structure.

\subsection{Electrochemistry of Solid Oxides}

A simple electrochemical cell is shown in Fig. 5-2. When different compositions of gases are present at the two electrodes, the difference in chemical energy results in a difference in potential. When oxygen is present at one electrode and a mixture of hydrogen and water at the other, a potential equivalent to the difference in oxygen potential develops. The activity of oxygen at the $\mathrm{H}_{2} \mathrm{O}-\mathrm{H}_{2}$ electrode can be calculated from the free energy of formation of $\mathrm{H}_{2} \mathrm{O}$ according to the reaction

$$
\mathrm{H}_{2}+1 / 2 \mathrm{O}_{2}=\mathrm{H}_{2} \mathrm{O}
$$

when the gases are in their standard state, i.e., 1.0 atmosphere pressure. The potential $E^{\circ}$ will be related to the Gibbs free energy $(\Delta G)$ by the equation

$$
E^{0}=\Delta G / 2 F
$$

where $F$ is the Faraday constant. The value of $\Delta G$ is given by

$$
\Delta G=\Delta H-T \Delta S
$$

where $\Delta H$ is the reaction enthalpy and $\Delta S$ the entropy. The variation of $E^{0}$ with temperature is shown in Fig. 5-3 where it can be seen that the potential decreases with increased temperature. When the gases are not in their standard states the potential $E$ is given by the Nernst equation

$$
E=E^{0}-\frac{R T}{n F} \ln \left[\frac{P_{O_{2}}^{\frac{1}{2}}}{P_{H_{2} O / P_{2}}}\right]
$$




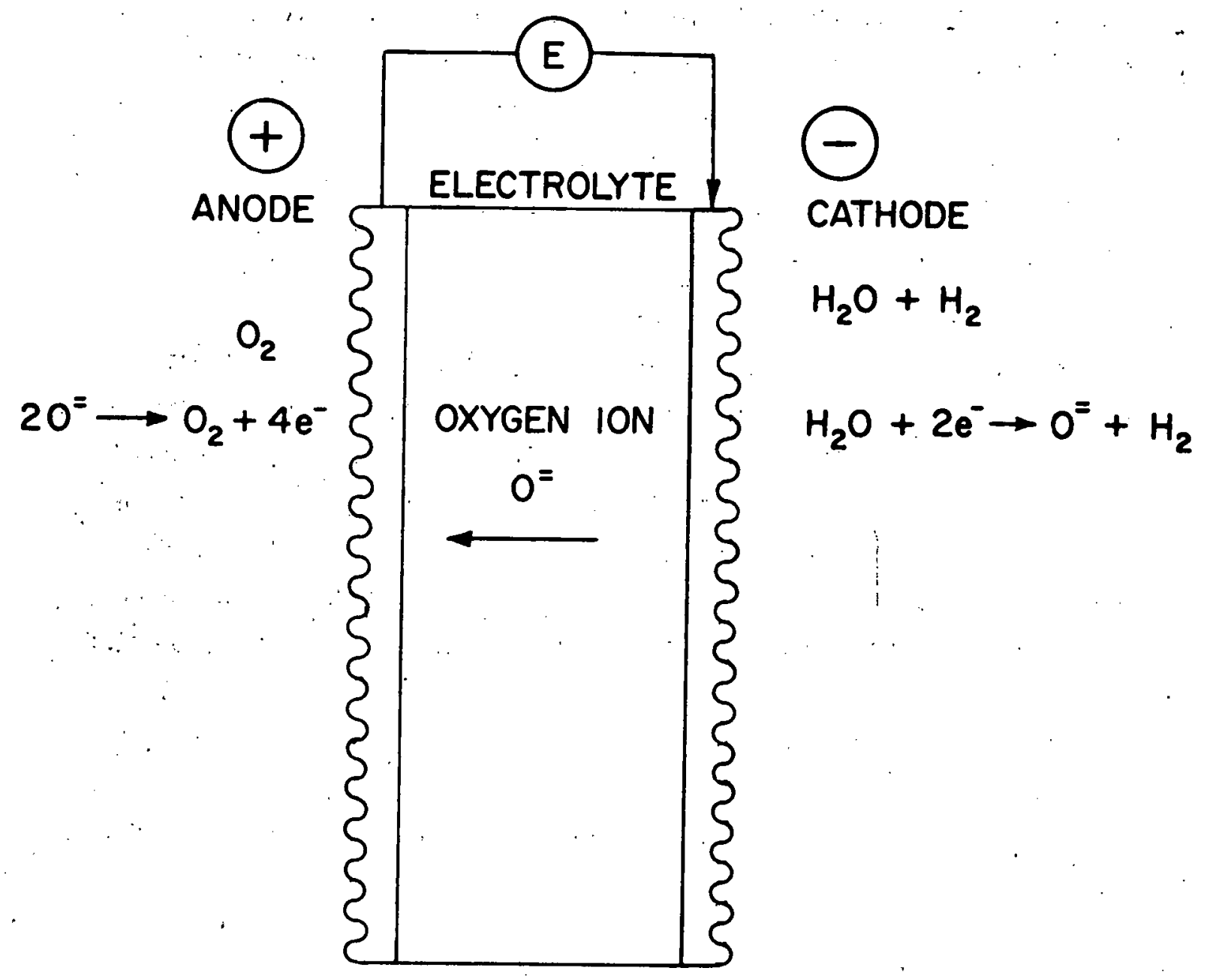

BASIC ELECTROLYTIC CELL

(HTE)

FIGURE $5-2$

$-51-$ 


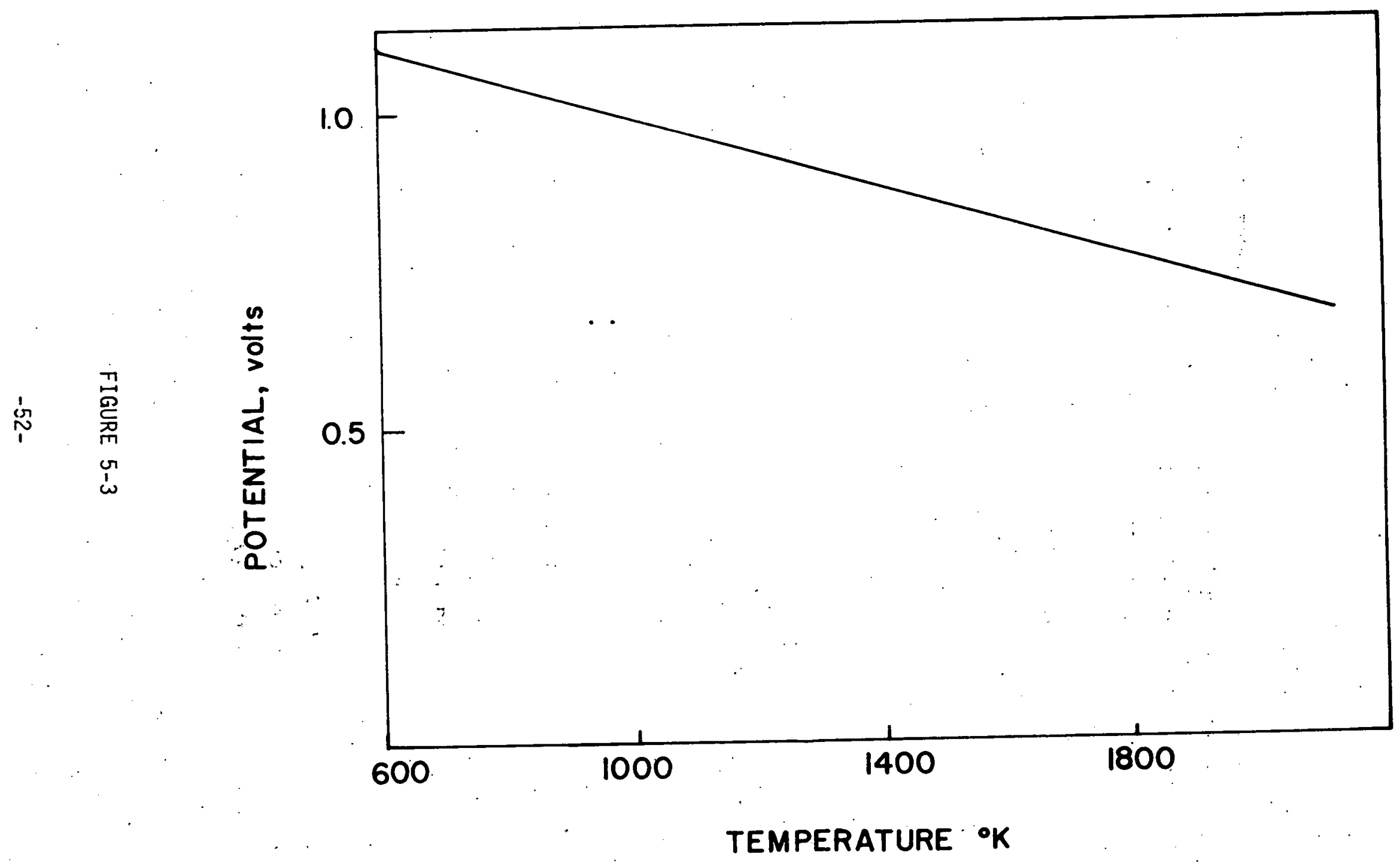

POTENTIAL VARIATION WITH TEMPERATURE 
where $P_{x}$ is the partial pressure of component $x, R$ the gas constant, and $T$ the absolute temperature. As can be seen from the above equation, the potential depends on the oxygen pressure at one electrode and the ratio of water to hydrogen pressures and also on the absolute temperature. When the potential across the cell is changed, current will flow. If $E$ is increased in magnitude current will flow, reducing the water to hydrogen and incorporating the oxygen as an ion in the electrolyte according to the reaction.

$$
\mathrm{H}_{2} \mathrm{O}+\mathrm{V}_{0}^{2+}+2 \mathrm{e}^{-}=\mathrm{O}_{\mathrm{O}}+\mathrm{H}_{2}
$$

where $\mathrm{V}_{0}^{2+}$ is an oxygen vacancy in the electrolyte and $0_{0}$ is an oxygen ion at an oxygen site in the electrolyte. At the oxygen electrode the reaction is

$$
20_{0}=2 \mathrm{~V}_{0}^{2+}+0_{2}+4 \mathrm{e}^{-}
$$

If the potential $E$ is decreased, current will flow in the opposite directions and the reverse of the above reactions will take place. These conditions represent fuel cell behavior. In this context, while design efforts are required, HTE units offer the potential to be quickly run in reverse as fuel cells to produce electricity for restart of Tokamaks and possible spinning reserve for a grid system.

In the electrolyzer the steam or steam/hydrogen mixture entering the electrolyzer enters, at the maximum temperature and minimum $\mathrm{H}_{2}$ concentration: As the fluid flows down the electrolyzer tube, the potential increases as both the hydrogen concentration increases and the temperature decreases. The exiting gas, therefore, represents the highest potential.

\subsection{Solid Oxide Electrolytes}

The flow of oxygen ions in the oxide electrolyte is controlled by the migration of vacancies in the oxygen lattice. The concentration of oxygen vacancies in zirconia depends on the concentration of lower valency metal ions with which the zirconia has been doped. In most electrolyte applications $\mathrm{Y}_{2} \mathrm{O}_{3}$ has been used although in some cases less expensive $\mathrm{CaO}$ and $\mathrm{MgO}$ were substituted. In $\mathrm{ZrO}_{2}$ each tetravalent $\mathrm{Zr}^{4+}$ ion is neutralized by two $0^{2-}$ ions. The trivalent $\mathrm{r}^{3+}$ ion replaces a tetravalent zirconium ion in the metal lattice. To maintain charge 
neutrality with the reduction of positive charges, a vacancy is created in the oxygen lattice to compensate the decrease in the positive charge associated with two yttrium atoms. The oxygen vacancy concentration is directly proportional to the yttrium concentration and also influences the ionic and electronic conductivities of the oxide.

The conductivity of an oxide is the sum of the ionic and electronic conductivities. The fraction of current which is carried by ions is termed the ionic transference number $\left(t_{i o n}\right)$ while the remaining current is carried by electrons or holes. An ideal electrolyte has a $t_{\text {ion }}=1.0$; however, with practical oxide systems there is always some electronic conductivity and a $t_{\text {ion }}$ of .99 is acceptable for an electrolyte. The presence of the electronic conductivity is detrimental to the behavior of the oxide as an electrolyte because it acts to short-out the potential of the cell. This reduces both the available voltage and efficiency.

The electronic conductivity depends on the concentration of oxygen vacancies, the oxygen partial pressure and the temperature. At low. oxygen partial pressure $\mathrm{P}_{2}$ the electronic conductivity increases with decreasing $\mathrm{P}_{2}$. At high values of $\mathrm{P}_{2}$, hole conduction becomes the predominant electronic conduction mode and increases with increasing $\mathrm{P}_{\mathrm{O}_{2}}$. This behavior limits the range of usefulness of the oxide as an electrolyte to a range where both electronic and hole conductivities are low compared to the ionic conductivity, which is essentially independent of $\mathrm{P}_{2}$.

Temperature influences the transference numbers and decreases the range of $\mathrm{PO}_{2}$ where the oxides behave as an electrolyte. This range is shown in Fig. 5-4 which shows the effect of temperature on $t_{i o n}$. At low temperature, below $1000^{\circ} \mathrm{K}, t_{i \text { in }}$ is greater than 0.99 over a range of effective oxygen partial pressure greater than 38 orders of magnitude. When the temperature increases this range inarrows until about $2500^{\circ} \mathrm{K}$ where it disappears. This figure also shows the $\mathrm{PO}_{2}$ values for the ratio of the water to hydrogen pressure, $\mathrm{P}_{\mathrm{H}_{2}} \mathrm{O} / \mathrm{P}_{\mathrm{H}_{2}}$; from $10^{-2}$ to $10^{2}$ (i.e., about $1 \%$ water to $99 \%$ water on the cathode side of the electrolyzer), and $\mathrm{P}_{\mathrm{O}_{2}}=10$ which is the pressure at the anode of the 


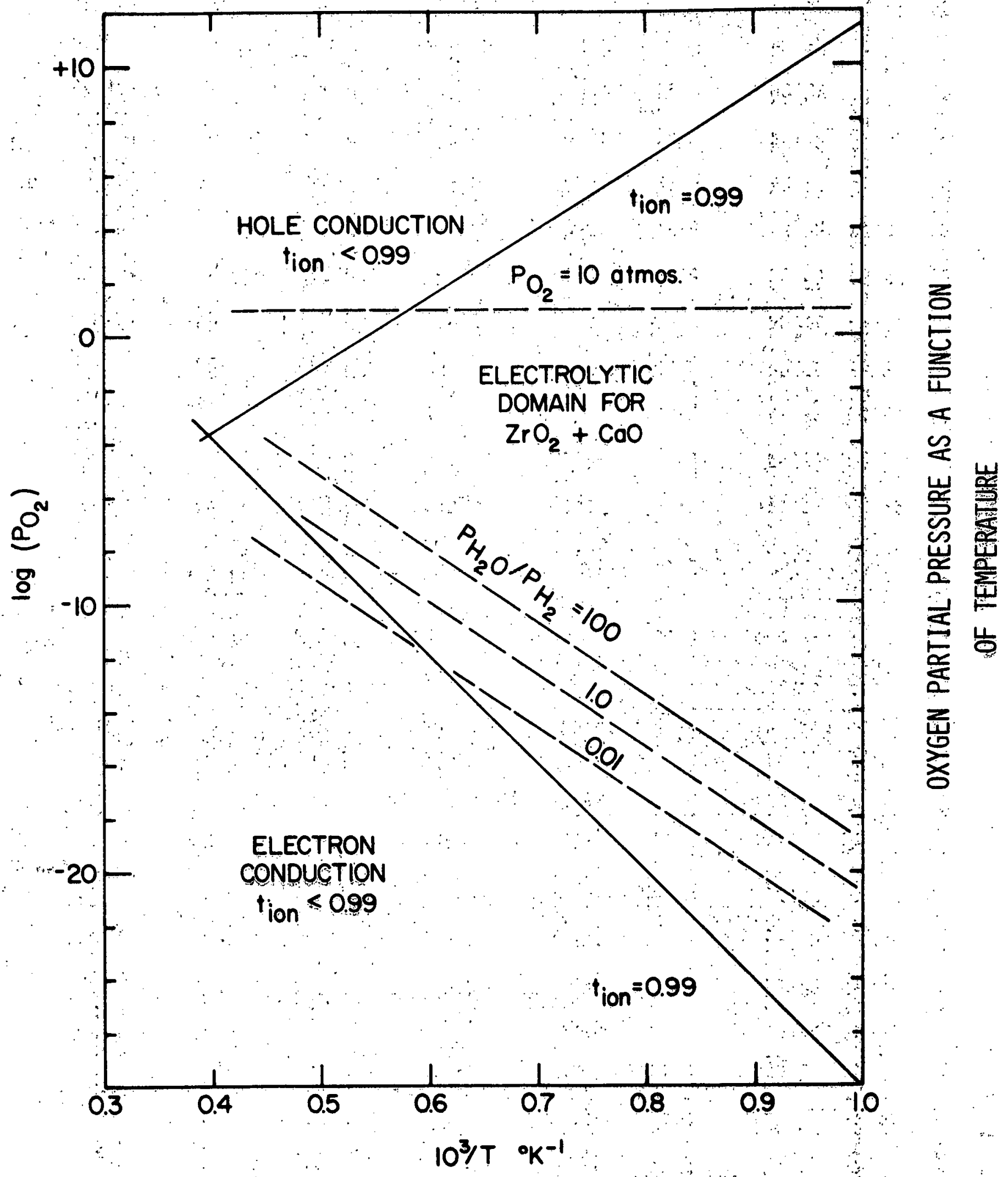

FIGURE $5-4$ 
electrolyzer. As can be seen from Fig.: 5-4 these pressures are within the electrolytic domain $\left(t_{i o n} \geq 0.99\right.$ ) for temperatures up to $17.25^{0} \mathrm{~K}$ for the $\mathrm{CaO}$ doped $\mathrm{ZrO}_{2}$ electrolyte. Above this temperature the hole conduction becomes significant at the oxygen electrode and the current efficiency of the electrolysis would be below $100 \%$. This temperature limit may be lower if there is significant over-voltage at the anode during electrolysis. At high temperatures the over-voltage should be low because of high reaction rates, but this aspect has not been studied experimentally. Indeed, there is only a meager amount of information on which to base designs att high oxygen pressures.' A similar lack of. information is apparent for the assessment of thehydrogen electrode characteristics, and future work should clarify these aspects of electrode performance.

The above analysis applies to $\mathrm{CaO}$ stabilized $\mathrm{ZrO}_{?}$ and is representative of the electrolyte behavior for this material. The behavior will vary depending on the concentration and the specific dopant used. Most electrolytes presently being considered use $\mathrm{Y}_{2} \mathrm{O}_{3}$ as a dopant. Work should be carried out with this material to optimize i.ts composition and characterize its behavior at the relevant temperatures.

\subsection{Elèctrodes}

The electrodes in contact with the electrolyte serve to conduct electrons to or away from the electrolyte interface. They also play a role in determining the kinetics of the reaction. "The reactions at the two elec-" trodes can be represented by

$$
\mathrm{H}_{2} \mathrm{O}+\mathrm{V}_{\mathrm{O}}^{2+}+2 \mathrm{e}^{-} \rightarrow \mathrm{O}_{0}=+\mathrm{H}_{2}
$$

For this reaction to proceed steam reactant is needed; oxygen vacancies are required from the electrolyte, and electrons from the electrode material. The electrode materials must, therefore, be sufficientlyiconducting for electrons, sufficiently porous for the gas diffusion, and must allow sufficient interface between gas, electrode material, and electrolyte where the reaction can occur. 
For temperatures of $\sim 1000^{\circ} \mathrm{C}$, in most applications the hydrogen electrode has been nickel or cobalt metal (or alloys) with the addition of a skeletal structure of zirconia to inhibit sintering. At higher temperatures the sintering of the metal would seal pores in the electrode, so that instead of a metal electrode, conducting oxides that are stable in the reducing environmerit must be used. The anode materials are oxides since most metals. would be oxidized. Silver, gold, platinum, or palladium are too expensive, have too low a melting point, and are too volatile. The oxide materials would be all doped with other metal ions to increase their conductivity, and have been based on $\mathrm{SnO}_{2}$ and $\mathrm{In}_{2} \mathrm{O}_{3}$. Other mixed oxides, e.g., $\mathrm{PrCOO}_{3}, \mathrm{SrRuO}_{3}, \mathrm{LaCO}_{3}$, and $\mathrm{LaCrO}_{3}$, have been considered for fuel cells, and could be used for high temperature electrolyzers, but wili require further development to determine their compatibility. with the electrolyte and vapour losses. In sumary there is a wide range of mixed oxides which have been studied and it appears possible to develop these for both anodes and cathodes at temperatures above $1650^{\circ} \mathrm{K}$.

\subsection{Interconnections Between Electrodes}

One of the major problem areas has been the electronically conducting interconnections between the electrodes. There is a wide range of requirements for this material, including: electronic conductivity; stability in both the oxidizing and reducing gases at both electrodes; and a thermal expansion coefficient close to that of the electrolyte. This interconnection capability now appears feasible as a result of the development of a range of perovskites which exhibit nearly all the desirable properties. The prime candidates are based on $\mathrm{LaCrO}_{3}$.

5.6 Design of the High Temperature Electrolyzers

The high temperature solid oxide electrolyzer consists of a cooled steel symmetrical pressure vessel ; internally insulated, which operates at. 10 atmospheres. Steam or mixture of steam and hydrogen is fed to the electrolyzer where water is reduced to hydrogen on one side of the electrolyte and oxygen is liberated on the other. The existing 


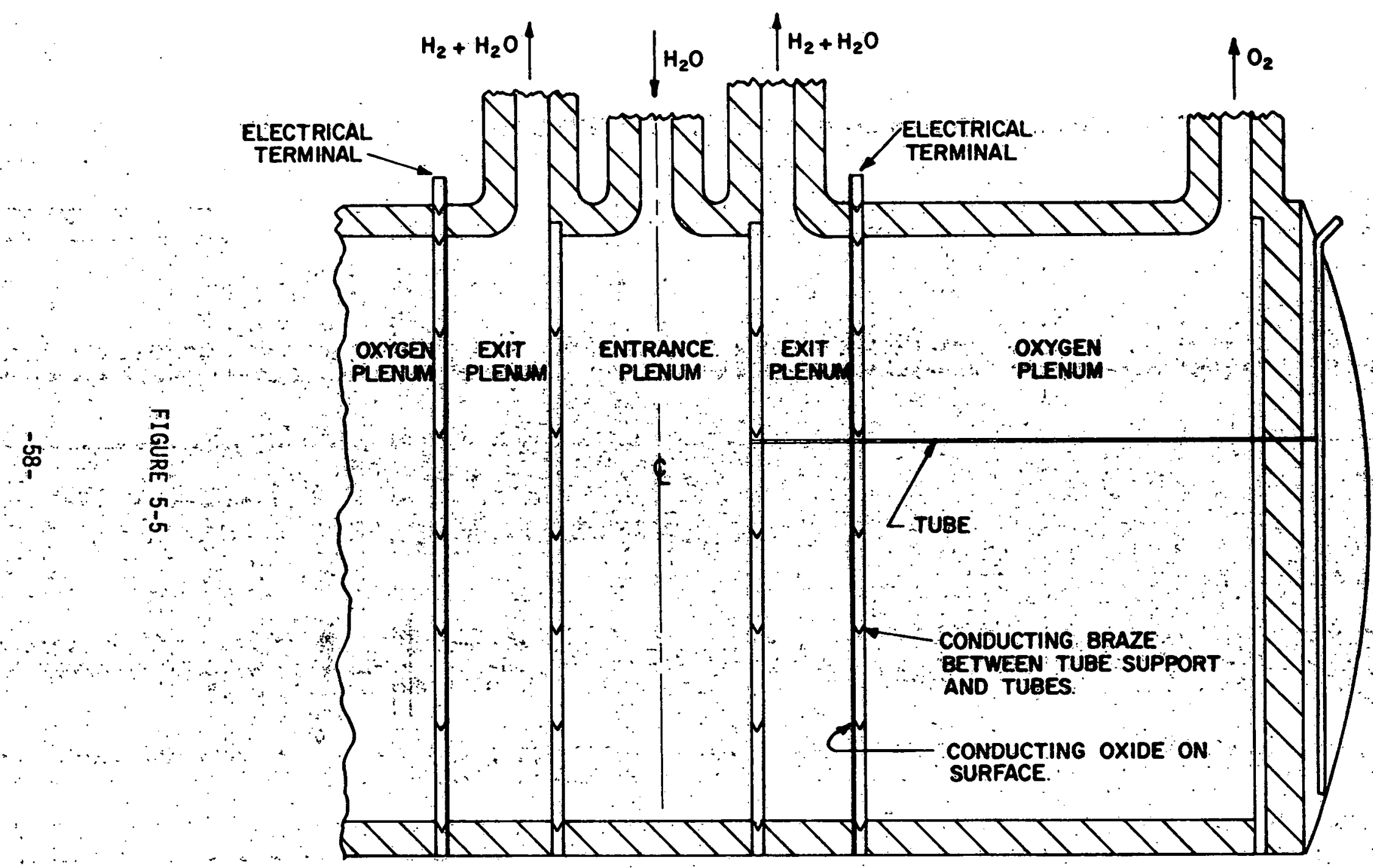

HTE VESSEL 


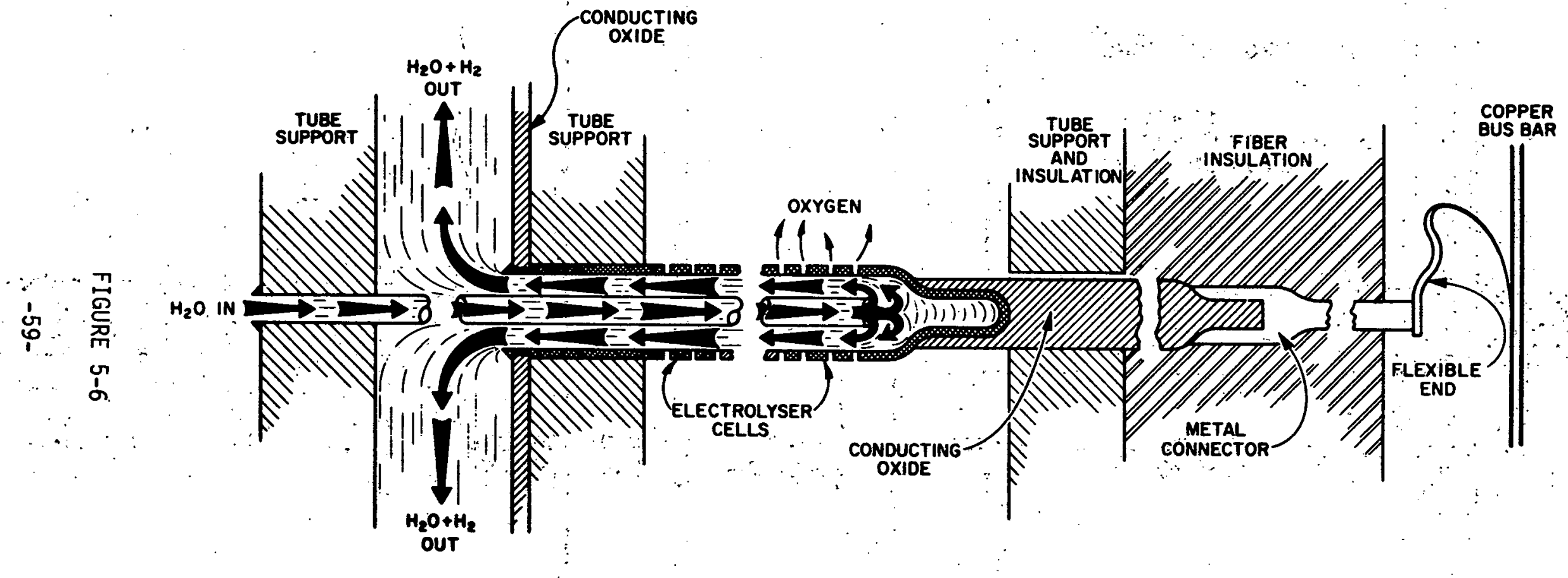

DETAILED CROSS-SECTION OF HTE CELL TUBE 
$\mathrm{H}_{2} / \mathrm{H}_{2} \mathrm{O}$ mixtures are recycled back to the blanket system for reheating so that steam can be electrolyzed at a high temperature. When the hydrogen concentration reaches the design value at the highest temperature, the gas mixture passes into a series of lower temperature electrolyzers. The endothermic electrolysis reaction cools the gases to a temperature where conventional heat exchangers can be used.

The oxygen generated in the first series of high temperature electrolyzers passes directiy to the low temperature electrolyzers without reheating. The low temperature electrolyzers, thus have oxygen inlet and outlet ports, while the high temperature vesseis require only an oxygen exit port for the oxygen produced in the electrolyzer.

A schematic diagram of the HTE is shown in Fig. 5-5. The diameter of the vessel is $3.5 \mathrm{~m}$ and the length is $6.8 \mathrm{~m}$. The central plenum receives the high temperature steam entering the HTE. Two adjacent plenums collect the gas after electrolysis in the tubes. These are next to the large regions in which the oxygen is produced. The two end sections of the HTE unit are at low temperature, and house electrial connections at the end of the electrolyte tubes.

A. major factor in the design of the electrolyzers is the minimization of thermal stresses due to heating and cooling and temperature cycling during operation. The outer cooled region of the containment vessel is held at virtually constant temperature at all times and will not experience any significant problem. Internal components, on the other hand, will experience temperature changes of over $1400^{\circ} \mathrm{C}$ and large dimensional changes when the HTE unit starts up from or shuts down to room temperature. The tubes, for example, are designed so that one end is fixed with the other free to move; to accommodate the dimensional changes.

The gas entering the HTE is $\mathrm{H}_{2} \mathrm{O}$ in the first electrolyzer and a mixture of $\mathrm{H}_{2} \mathrm{O}$ and $\mathrm{H}_{2}$ in subsequent electrolyzers. This gas is distributed from the central plenum through feed tubes. The feed tubes are $2.4 \mathrm{~m}$ 
long and $5 \mathrm{~mm}$ in diameter, and can be joined tubes that are sealed together. The feed tube has spacers to center it in the electrolyte tube and can support the outer tube at high temperatures if required. The feed tubes are centered within the electrolyte support tubes as shown in Fig. 5-6. The gas passes through the feed tube to the base of the electrolyte support tube. It then passes between the tube and feed tubes to the second plenum. During passage the gas diffuses across the porous support tube to the cathode where it is electrolyzed to hydrogen and cooled by the endothermic reaction.

The two tube sheets which hold the feed tubes are the electrolyte support tubes, respectively, are both constructed as interconnecting sections which are sealed together with a ceramic braze. A schematic of the tube sheet section is shown in Fig. 5-7, which consists of $V$ notched edges which fit into adjacent sections. Each section is $0.5 \mathrm{~m}$ square with 46 tube rows of 45 each. The shapes of the sections are designed to conform with the ceramic insulation and support around the walls.

The electrolyte support tubes are constructed as shown by the schematic in Fig. 5-1. The length of each cell depends on the resistivities of the electrodes and interconnection materials but is approximately $1 \mathrm{~cm}$ on the $1 \mathrm{~cm}$ diameter tubes. The tubes are closed at one end. Each end has a conduction oxide layer. At the closed end the conducting surface oxide is in electrical contact with an oxide cap which passes through the insulation. The end of the cap is at a temperature where metai can be used in the oxidizing atmosphere. The metal continues the electrical path to a conducting plate at.each end of the vessel. The plate in turn is connected to an insulated terminal through the pressure vessel. These components are shown schematically in Fig. 5-6. The open end of the electrolyte support tube with its conducting oxide is sealed into the tube sheet section with a conducting seal. The seal in turn makes contact with a conducting oxide facing the tube sheet sections which are also sealed togehter with a conducting ceramic seal. These details of the electrolyte support tube are also shown in Fig. 5-6. 


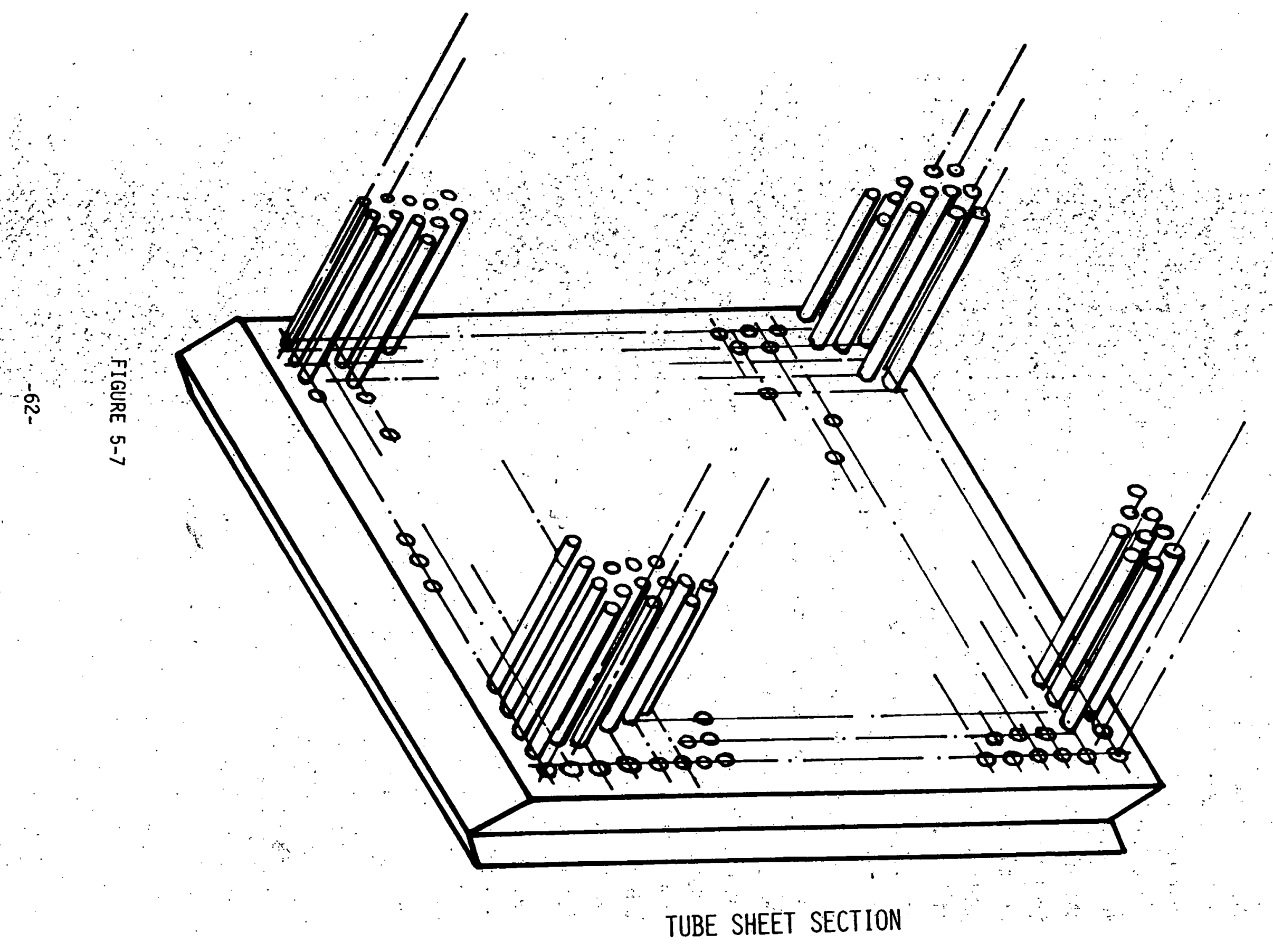


The high temperature solid oxide electrolyzer is supported on a porous zirconia tube as shown in Fig. 5-1. The thickness of the electrolyte can be reduced to about $10 \mu \mathrm{m}$ with the supported el ectrolyte constructed in this manner. The electrolyte must be as thin as practical in order to reduce $I^{2} R$ losses or overvoltages. Fig. $5-8$ shows the oxide thickness which is required to hold the overvoltage due to electrolyte resistance below $50 \mathrm{mV}$ for a current density of $0.5 \mathrm{~A} / \mathrm{cm}^{2}$. At temperatures close to $1650^{\circ} \mathrm{K}$ a thickness of $\sim 1.0 \mathrm{~mm}$ is acceptable whereas at $1000^{\circ} \mathrm{K}$ a $10 \mu$ electrolyte layer would be regutred The material of construction will be the same as those considered in an earlier reaction, e.g., $\mathrm{ZrO}_{2}-\mathrm{Y}_{2} \mathrm{O}_{3}$ electrolyte, doped $\mathrm{In}_{2} \mathrm{O}_{3}$ anode, a perovskite for high temperatures and nickel for low temperature cathodes, doped $\mathrm{LaCrO}_{3}$ for the interconnection materials, and conducting sides.

\subsection{Factors Influencing the Design of Electrolytes}

There are a large number of variables which must be considered in the optimization of solid oxide electrolytes. These include the dfameter and length of the electrolyte support tubes, the current density, and the flow rate of the steam. The rate of heat flow into a given section of tubing is given by the sensible heat of the gases and the flow rate. The heat leaving is the sum of the sensible heat flowing out of the section and the entropy heat absorbed during the endothermic reaction.

The endothermic heat absorbed by the reaction per second $=T \Delta S \alpha$ where $T=$ the average temperature $1 / 2\left(T_{\text {in }}+T_{\text {out }}\right)$.

$$
\begin{aligned}
\Delta S & =\text { the entropy, } \\
\alpha & =\text { the number of moles converted per second, } \\
& =\frac{\pi d x \rho}{2 F} \\
\rho & =\text { current density, } \\
x & =\text { active length of tubing, and } \\
d & =\text { tube diameter }
\end{aligned}
$$




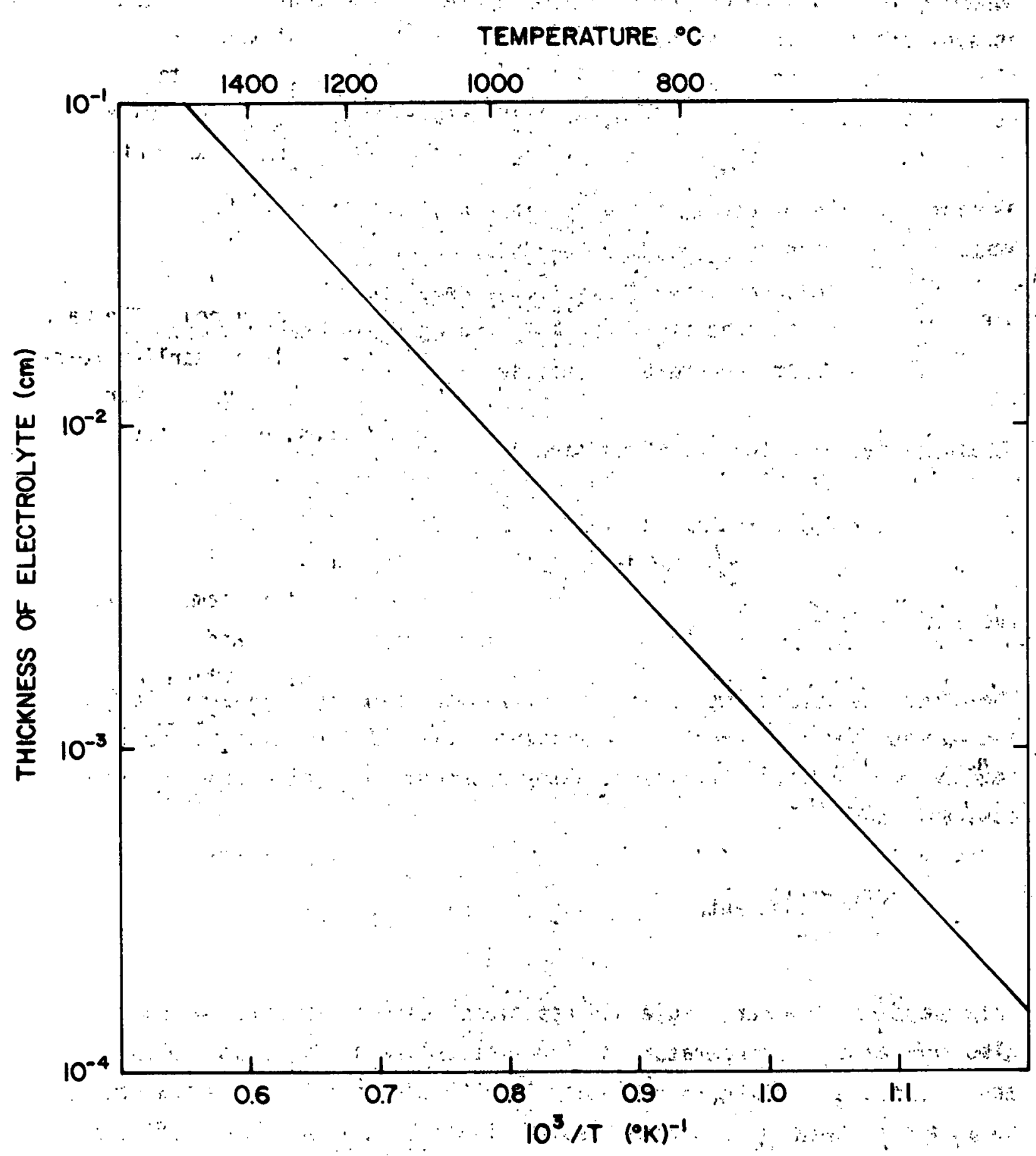

ELECTROLYTE THICKNESS AS A FUNCTION

OF TEMPERATURE

FIGURE $5-8$ 
Assuming the reaction occurs at the mid-point of the tube, the change in sensible heat is given by

$$
\left.\left(f v-\frac{\alpha}{2}\right) \int_{T_{\text {out }}}{ }_{C_{p}}^{\mathrm{H}_{2} \mathrm{O}} \mathrm{dT}+(\mathrm{l}-f) v+\frac{\alpha}{2}\right\} \int_{\text {Tout }}{ }_{\mathrm{P}} \mathrm{Tin}
$$

assuming all the electrolysis takes place at $T$ and

where $f=$ fraction of steam entering tube, $\mathrm{deg}^{-1}$

$\mathrm{C}_{\mathrm{p}}{ }^{\mathrm{H}_{2} \mathrm{O}}=$ heat capacity of steam, call $\mathrm{deg}^{-1}$ mole $\mathrm{e}^{-1}$.

$c_{p}=$ heat capacity of one mole hydrogen plus half mole oxygen

$v=$ molar flow rate, moles $\sec ^{-1}$.

Equating the above two equations gives:

$$
v=\frac{\pi d x_{\rho}}{2 F} \cdot \frac{T \Delta s-1 / 2 \int_{\Delta C p} d T}{f \int_{\Delta C_{p} d T+\iint_{C_{p}} d T}}
$$

where $\Delta C p=C p^{H_{2} O}-C_{p}$

The above equation shows the relation between velocity, diameter, length, and current density for the electrolyzer tube. If the inlet and outlet temperatures and the fraction of water entering an electrolyzer is kept constant then

$$
\frac{d \times p}{v}=\text { constant }
$$

This equation, however, neglects the effects of heat transfer which will also influence the temperature of the electrolyte as discussed below and is a factor related to the velocity. In terms of the incoming steam to an electrolyzer it has been assumed that no external source of heat is transferred across the tube walls and all the thermal energy is to come from the cooling of the steam. This implies that a boundary layer develops on the tube walls, with a subsequent film temperature drop. 
Estimates based on the design parameters show that the film temperature drop required to transfer the sensibile heat from the gas to the electrode. surface is $\sim 50^{\circ} \mathrm{K}$. There are also losses due to excess voltage that may occur during the flow of current. These include electrochemical polarization losses and resistance losses. The resistance losses arise because of the resistivity of the electrodes, electrolyte, and interconnection materiais. These can be reduced by proper cell design" and geometry. "The: polarization losses are related to the electrochemical reaction kinetics. They may be due to the intrinsic activation energy of the reaction which at high temperature may be negligible but which will have to be checked experimentally. The second polarization loss arises due to concentration gradients or slow migration of reactants, to the interface. The latter have been considered and discussed, by Tedmon, et. al. (4) and are not expected to be a problem at the temperatures of interest.

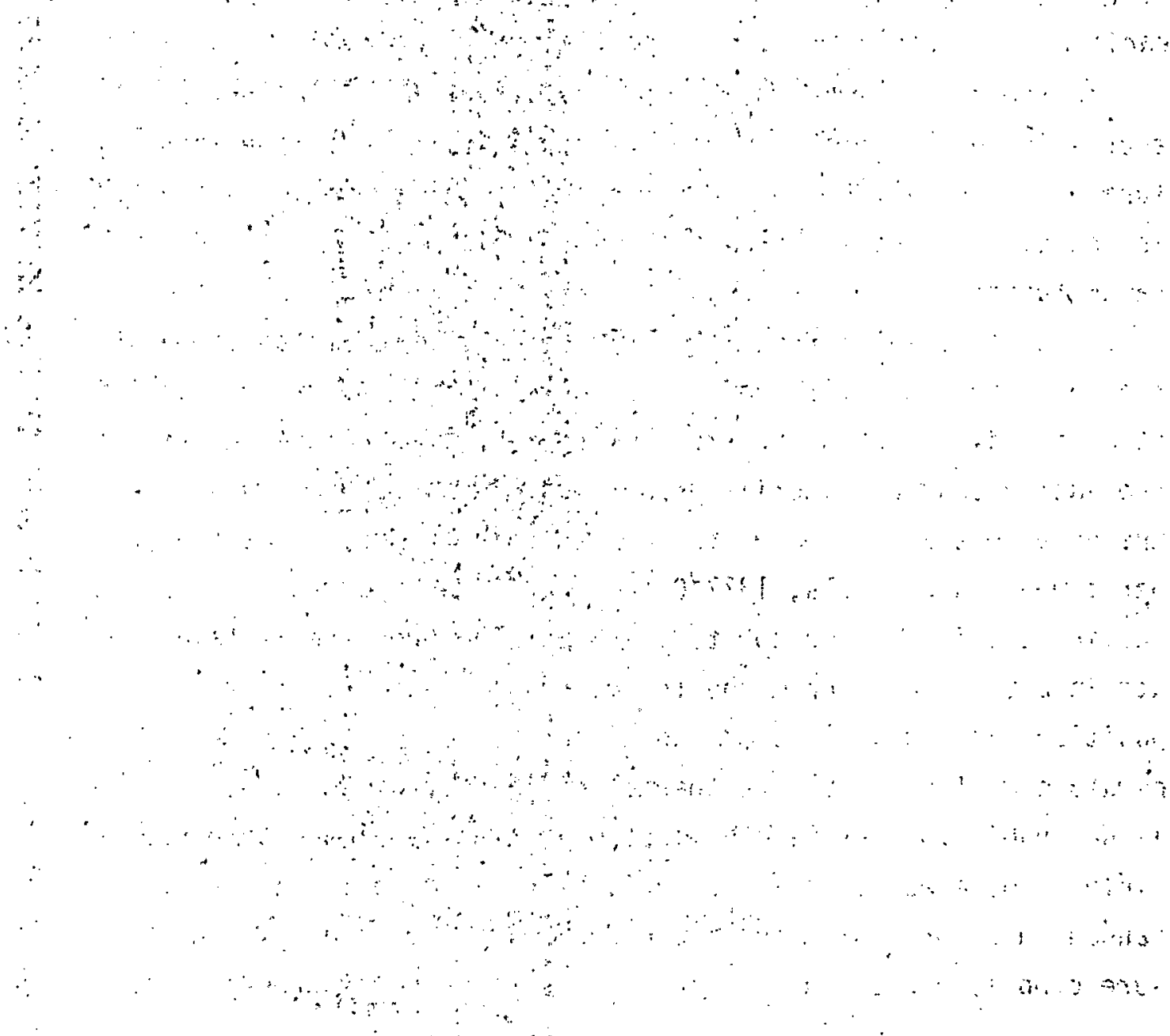




\subsection{Plant Process and Power Conversion Design}

\section{1" Description of Plant Process and Power Conversion}

Desian - Factors Affecting Design

A general description of the process is given in Section 2. In order to have a feasible desiyn, a number of factors affecting the process concept and design have to be considered.

For a self-sustaining fusion reactor system, it is necessary to design the blanket region to breed tritium. The blanket must also be designed so as to produce enough high temperature steam for electrolysis. The remaining water which absorbs the balance of the heat from the fusion reactor will be used for electricity generation and need not be raised to as high a temperature as the steam for electrolysis. The high temperature is achieved by the principle of internal heating described earlier. In general, about 30 percent of the plasma energy is in the low temperature region and the remaining 70 percent of the plasma energy is deposited in the hith temperature region. The capacity of the fusion reactor will be an important factor for economic considerations but is not significant for process desian and evaluation. A $2000 \mathrm{MW}(t)$ tokamak fusion reactor was chosen as the base design. The temperatures and pressures of steam for electrolys is were selected to be compatible with the operating conditions of the electrolyzers. Although high temperature steam is advantaneous for electrolysis in terms of thermal. efficiency of the energy source, material properties such as creep and strength limit the upper operating temperature of the electrolyzer. . At present two upper temperature levels, $1377^{\circ} \mathrm{C}$ and $1827^{\circ} \mathrm{C}$, are considered for the steam leaving the fusion reactor to the HTE. The pressure is taken to be 10 atm in both cases. From the thermodynamic analysis of steam decomposition (Appendix $\dot{A}$ ) it is found that a decrease in the reaction temperature will decrease the thermal efficiency of the process. Hence it is desirable to operate the electrolyzer at as high a temperature as possible. The electrolyzer design is assumed to be in tubular form and arranged in a configuration like a shell and tube heat exchanger. The pressure drop is one of the design factors to be considered in the design of 
the electrolyzers. There are several ways of supplying thermal eneray to the electrolyzers, namely: 1) by sensible heat of the steam; 2) by heat transfer across the electrolyzer wall and 3) by placing the electrolyzer directly in the blanket region of the fusion reactor. The latter two possibilities were eliminated in this study based on materials limitations as well as difficulty of design. Supply of thermal energy for the heat of reaction from the process streams cause a temperature drop in the steam. The fraction of the incoming steam decomposed to hydrogen in the electrolyzer due to a known temperature drop in the steam is then determined. In order to maintain the electrolyzer: at a high reaction temperature, the steam and hydrogen is reheated between each stage of the HTE's and the high temperature region of the fusion blanket. The connecting ceramic-lined tube between the HTE and the blanket module is also an important desian factor. Another design factor is the separation of hydrogen from the unreacted steam which can be accomplished by condensation of steam. This requires that the steam temperature has to be lower than its critical temperature so that heat exchangers are needed. By placing the electrolyzers in series at successively decreasing reaction temperature, one can lower the steam temperature while continuing to carry out the HTE reaction. The exit temperature is fixed at $727^{\circ} \mathrm{C}$. This lower temperature is chosen to be compatible with the materials used for metal tube heat exchanger walls. Adding more HTE stages with a steadily decreasing outlet steam temperature does not lend itself to a more efficient system. 'This lowers the average temperature for the entire high temperature electrolytic decomposition of steam. A high temperature diffusion barrier to separate $\mathrm{H}_{2}$ from $\mathrm{H}_{2} \mathrm{O}$ would maintain a high efficiency in the HTE' cycle and may be considered for further design.

Since electrical energy for electrolys is comes from the power generation. loop, a key design factor is the division of the $2000 \mathrm{MW}(t)$ thermal energy between the electrical energy and the direct high temperature thermal energy needed for the total electrolytic decomposition of steam. Since no excess or deficiency of electrical power is allowed for electrolysis of steam, balancing of the steam is an important factor for 
design.. The temperature. and pressure of the coolant stream from the high temperature: and low temperature region of the fusion reactor must conform to the design constraint of a balanced system.

Changes in gas composition will influence the HTE cell potential and the electrical energy requirements. The calculations assume electrolysis to take place at the exit temperature of the electrolyzer and with the gasses in their standard states. In order to determine whether the energy requirements were conservative, the potential profile across the electrolyzer was computed as a function of the temperature and gas pressures down the electrolyzer tube.' The anode oxygen pressure was taken to be 10 atmospheres and a temperature drop adjacent to the cell was assumed to be $10^{\circ} \mathrm{K}$. Table $6-1$ shows the gas compositions leaving the electrolyzer, and amounts converted to hydrogen, the temperature, the average potentials of the sum of the potentials across the electrolyzer, and the potential assuming the gases are in their standard state at 1.0 atmosphere. The percent differences in the potentials and the weighted changes (which depend on the fraction of gas converted in each electrolyzer) are given. It is of interest to note that only $i$ percent of additional electrical energy would be required above that when standard states are assumed.

Further work will be required to obtain a more accurate assessment of the efficiency of the electrolyzers. These calculations would incorporate losses which are associated with the electrolyzer. and are highly dependent on temperature. The losses arise from overvoltages at the electrodes due to limitations in the reaction kinetics, resistances of the electrodes, the electrolytes, and: the connections between cells and the electrolyzer tubes. The results in Fig. 5-8 indicate one limitation in reducing the temperature. This figure shows the required thickness of the electrolyte at $1000^{\circ} \mathrm{C}$ to be $\sim 10 \mu \mathrm{m}$. This thickness is the present technological limit for the electrolyte and will prevent the use of the electro: lyzer at lower temperatures without significant energy losses in the electrolyte. Higher losses at these temperatures would be expected because of the electrode overvoltages which decrease more rapidly with increasing temperature. For example at $1000^{\circ} \mathrm{C}$ losses would be $\sim 20$ percent whereas at $1400^{\circ} \mathrm{C}$ they would be $\sim 5$ percent. 


\section{TABLE 6-1}

DIFFERENCES IN ELECTRICAL ENERGY REQUIREMENTS BETWEEN STANDARD

STATES AND THE NERNST EQUATION

Temp $1650^{\circ} \mathrm{K}$

Avg. Reaction Temp $1525^{\circ} \mathrm{K}$

$\% \mathrm{H}_{2} \mathrm{O} \% \mathrm{H}_{2}$ \%Convert. iemp in Potent

out out \% Convert. iemp in Potential $E^{0}$ \%Diff. ${ }^{\star}$ \%Change ${ }^{\star \star}$

$\begin{array}{llllllllllll}\text { 1. } & 92.22 & 7.78 & 7.78 & \cdots & 1650 & 0.687 & 0.865 & 25.97 & -2.020\end{array}$

2. $84.63 \cdot 15.37 \cdot 7.58 \quad 1650 \quad 0.784 \quad 0.865 \quad 7.83 \quad-0.957$

$\begin{array}{lllllllll}3 . & 77.23 & 22.77 & 7.40 & 1050 & 0.824 & 0.865 & 4.98 & -0.369\end{array}$

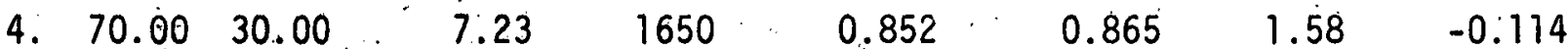

$\begin{array}{lllllllll}5 . & 62.94 & 37.06 & 7.06 & 1650 & 0.874 & 0.865 & -1.03 & +0.073\end{array}$

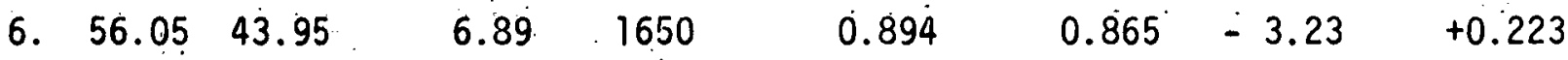

$\begin{array}{llllllllllllll}7 . & 49.33 & 50.67 & 6.72 & 1650 & 0.912 & 0.865 & -5.16 & +0.347\end{array}$

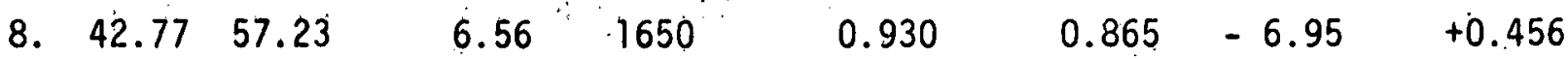

$\begin{array}{lllllllll}\text { 9. } & 36.36 & 63.64 & 6.41 & 1650 & 0.947 & 0.865 & -8.66 & +0.555\end{array}$

10. $27.4072 .60 \quad 8.96 \therefore 1500:-0.996 \quad 0.908-8.83 \quad+0.566$

11. $\quad \begin{array}{lllllllll}17.36 & 82.64 & 10.04 & 1350 & 1.028 & 0.949 & -7.71 & +0.774\end{array}$

$\begin{array}{llllllll}\text { 12. } & 5.65 & 94.33 & 11.64 & 1200 & 1.121 & 0.990 & -11.66\end{array}$

$\therefore \therefore$ Total +0.8920

Percent Change Based on 100\% Hydrogen Product 0.9456

* Perçent difference in energy requirement for the specific electrolyzer

** Percent change in energy requirements to overall system

$E^{0}$ is calculated taking unit conditions and assuming a homogenous reaction and-a temperature drop at electroyte of $50^{\circ}$.

$E$ is calculated taking linear temperature and composition change down the electrolyzer tube, : and calculating the reaction to take place at the midpoint. A temperature drop at the electrolyte of $50^{\circ}$, is taken. 


\subsection{Heat, Mass, and Power Balance}

Calculations have been performed based on two maximum steam temperatures$1377^{\circ} \mathrm{C}$ and $1827^{\circ} \mathrm{C}$. The heat and mass balance for each set of electrolyzers is based on the following macroscopic balance. A schematic diagram for the nth electrolyzer is shown in Fig. 6-1. For simplicity, a basis of $1 \mathrm{~g}$-mole/hr of steam entering the first electrolyzer is assumed.

The inlet streams for the nth electrolyzer are $\mathrm{m} g$-mole/hour with enthalpy $\mathrm{H}_{\mathrm{H}_{2} \mathrm{O}} \mathrm{cal} / \mathrm{g}$-mole at temperature $\mathrm{T}_{1}$, $(\mathrm{l}-\mathrm{m}) \mathrm{g}$-mole/hr of $\mathrm{H}_{2}$ with enthalpy $H_{H_{2}}$ cal/g-mole at temperature $T_{1}, \frac{1}{2}(1-\mathrm{m}) \mathrm{g}$-moles/hr of $\mathrm{O}_{2}$ with enthalpy $\mathrm{H}_{\mathrm{O}_{2}}$ cal/g-mole at temperature, $\mathrm{T}_{3}$. The outlet streams are $(m-\varepsilon) g$-moles/hr of $\mathrm{H}_{2} \mathrm{O},(1-\mathrm{m}+\varepsilon) \mathrm{g}$-moles/hr of $\mathrm{H}_{2}$ at temperature $T_{2}$. It is assumed that $\varepsilon \mathrm{g}$-moles/hr of $\mathrm{H}_{2} \mathrm{O}$ is decomposed in the electrolyzer and the electrical energy input to the electrolyzer is $\varepsilon E$. From the first law of thermodynamics, one can obtain the energy balance for the electrolyzer as

$$
\begin{aligned}
& (m-\varepsilon) H_{H_{2} \mathrm{O}}+1 / 2(1-m+\varepsilon) \mathrm{H}_{\mathrm{O}_{2}}+(1-m+\varepsilon) \cdot \mathrm{H}_{\dot{H}_{2}}=\mathrm{mH}_{\mathrm{H}_{2} \mathrm{O}}+(1-m) \mathrm{H}_{\mathrm{H}_{2}}+ \\
& 1 / 2(i-m) \mathrm{H}_{0_{2}}+\varepsilon E
\end{aligned}
$$

Expressing the enthalpies of the compounds in their proper form, one can rewrite Eq. $(6-1)$ as

$$
\begin{aligned}
& \because(m-\varepsilon)\left[\Delta H_{f}^{0}+\lambda_{T}+\int_{T_{0}}^{T}{ }^{T} C_{p H_{2} 0} d T\right]+1 / 2(1-m+\varepsilon) \int_{T}^{T_{3}} C_{p 0_{2}} d T+
\end{aligned}
$$

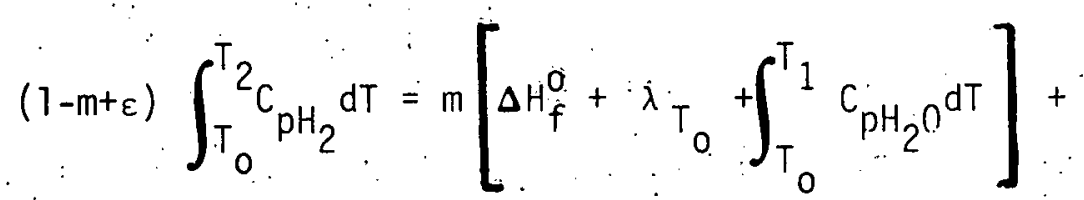

$$
\begin{aligned}
& (1-m) \int_{T_{0}}^{T_{1}} C_{p H_{2}} d T+1 / 2(1-m) \int_{T_{0}}^{T_{3}} C_{p 0_{2}} d T+\varepsilon E
\end{aligned}
$$




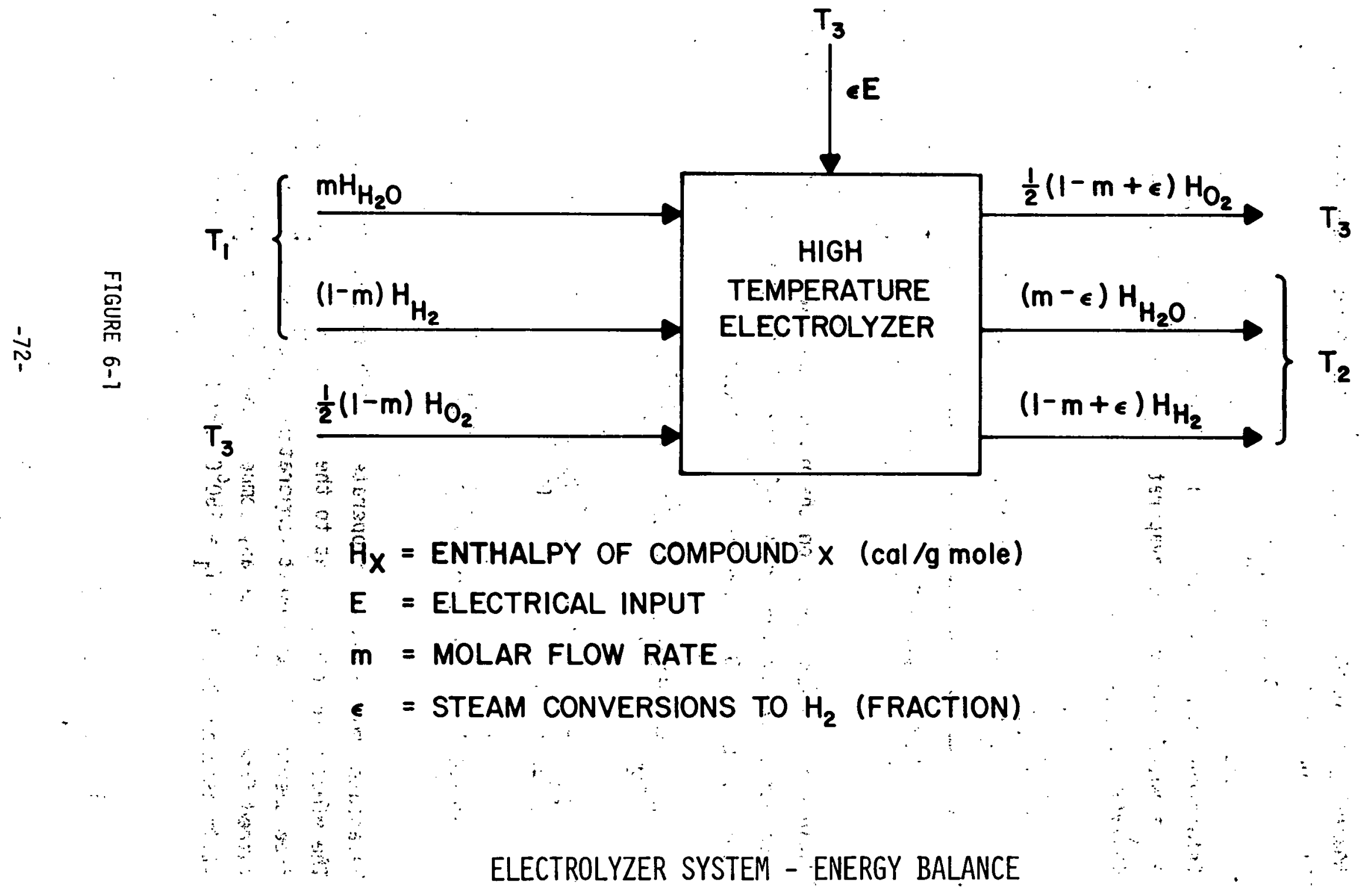


Rearranging Eq. (6-2) and recognizing the thermodynamic relationship

$$
\left.E=\Delta G=\Delta H-T_{3} \Delta S=-\left(\Delta H_{f}{ }^{\circ}+\lambda_{T}\right)-T_{3} \Delta S\right)
$$

[standard state of formation - $1 \mathrm{~atm}$, room temperature, $25^{\circ} \mathrm{C}$ and where $\lambda_{T_{0}}=$ the latent heat of evaporation ] one can then obtain the $\mathrm{H}_{2} \mathrm{O}$ conversion $\varepsilon$ as

$$
\begin{aligned}
& \int_{T_{2}}^{T_{1}} 1\left(m C_{p H_{2} O}+(1-m) C_{p H_{2}}\right) d T
\end{aligned}
$$

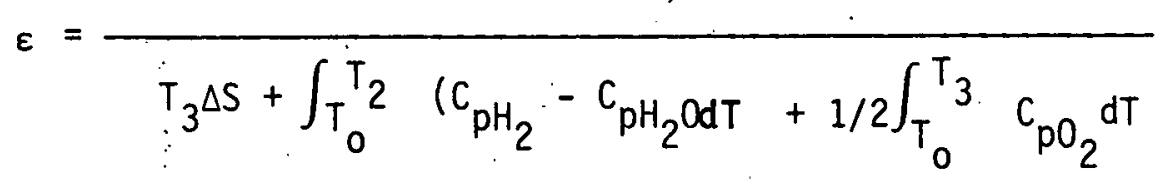

Evaluating the quantities on the right hand side of Eq. (6-4), one can then obtain the conversion of $\mathrm{H}_{2} \mathrm{O}$ to $\mathrm{H}_{2}$ in the electrolyzer. The heat capacity for $\mathrm{H}_{2}, \mathrm{O}_{2}$ and $\mathrm{H}_{2} \mathrm{O}$ are ${ }^{4(1)}$ respectively.

$$
\begin{gathered}
\mathrm{C}_{\mathrm{pH}_{2}}=6.52+0.78 \times 10^{-3} \mathrm{~T}+\frac{12000}{\mathrm{~T}^{2}} \\
\mathrm{C}_{\mathrm{pO}_{2}}=7.16+10^{-3} \mathrm{~T}-\frac{40000}{\mathrm{~T}^{2}} \\
\mathrm{C}_{\mathrm{pH}_{2} \mathrm{O}}=7.17+2.56 \times 10^{-3} \mathrm{~T}+\frac{8000}{\mathrm{~T}^{2}}
\end{gathered}
$$

We assume the electrolyzer operates at 100 percent electrical efficiency. The electrical energy input to the electrolyzer is $\varepsilon \Delta G$ where $\Delta G$ is the free energy of reaction at temperature $T_{3}{ }^{\circ} \mathrm{C}$. Both $T \Delta S$ and $\Delta G$ can be obtained from Fig. A-l at any temperature $\mathrm{T}_{3}{ }^{0} \mathrm{C}$. In the present calculation, it is assumed that $T_{2}-T_{1}=150^{\circ} \mathrm{C}$ and $T_{2}-T_{3}=50^{\circ} \mathrm{C}$ based on prel iminary 
calculations. Since the $0_{2}$ stream is not sent back to the blanket for: reheat, the $\mathrm{O}_{2}$ temperature is less than the $\mathrm{H}_{2}$ /steam mixture temperature. Insofar as the HTE cell is assumed to operate isothermally, that is, the reaction takes place at a constant temperature along the tube, likewise, the oxygen given off at the anode is assumed to be at the reaction temperature. Applying Eq. (6-4) in successive fashion to the HTE's one can determine the number of electrolyzers needed and the overall conversion of steam to hydrogen in the HTE's. The temperature of the hydrogen/ steam from the last HTE is fixed at $727^{\circ} \mathrm{C}$.

The next step is to determine the overall mass flow rate of steam in the system. This is obtained from the energy balance for the total system. The thermal energy supplied in the blanket to heat up the make-up steam stream from $727^{\circ} \mathrm{C}$ to $1827^{\circ} \mathrm{C}$ or $1377^{\circ} \mathrm{C}$ is $\mathrm{M}\left(\mathrm{H}_{2}-\mathrm{H}_{1}\right)$ where $M$ is the molar flow rate of steam in $\mathrm{g}$-mole/hr and $\mathrm{H}_{2}$ and $\mathrm{H}_{1}$ are the enthalpies of steam (cal/g-mole) at $1377^{\circ} \mathrm{C}$ or $1827^{\circ} \mathrm{C}, 10 \mathrm{~atm}$ and $727^{\circ} \mathrm{C}$, $10 \mathrm{~atm}$ respectively. Since there are $n$ electrolyzer units with the steam $\mathrm{H}_{2}$ mixture subject to reheat, the total sensible heat supplied by the high temperature region of the blanket for reheat from $\mathrm{T}_{2}{ }^{\mathrm{O}} \mathrm{C}$ to $\mathrm{T}_{1}{ }^{\mathrm{O}} \mathrm{C}$ is

$$
M \sum_{i=1}^{n} \int_{T_{2}}^{T_{1}}\left[\left(m_{i}-\varepsilon_{i}\right) C_{p H_{2} 0}+\left(1-m_{i}+\varepsilon_{i}\right) \dot{C}_{p H_{2}}\right] d T
$$

If the overall rate of conversion of steam to hydrogen in the outlet stream of the last HTE is $\varepsilon_{0}$, the total recoverable heat from $\mathrm{O}_{2}, \mathrm{H}_{2}$, and $\mathrm{H}_{2} \mathrm{O}$ in the heat exchangers is

$$
\left.M \mid \int_{323}^{1000} \frac{\varepsilon_{0}}{2} C_{p_{2}} d T+\int_{323}^{1050}\left[\varepsilon_{0} C_{p_{2}}+\left(i-\varepsilon_{0}\right) C_{p_{2} O}\right] \cdot d T\right\}
$$


However, this heat rate is not sufficient to heat up the make-up water stream from $30^{\circ} \mathrm{C}$. to $727^{\circ} \mathrm{C}$ and the remaining heat has to be supplied from the helium loop in the superheater. This heat rate is then

$$
\begin{aligned}
& M\left[\int_{303}^{1000} C_{\mathrm{pH}_{2} \mathrm{O}} \mathrm{dT}+\lambda-\int_{323}^{1000} \frac{\varepsilon_{0}}{2} \cdot C_{\mathrm{pO}_{2}} d \mathrm{dT}+\int_{323}^{1050}\left[\varepsilon_{0} C_{\mathrm{pH}_{2}}+\right.\right. \\
& \left.\left.\left(1-\varepsilon_{0}\right) \mathrm{CPH}_{2} \mathrm{O}\right] \mathrm{dT}\right]
\end{aligned}
$$

where $\lambda$ is the latent heat of vaporization of water at $10 \mathrm{~atm}$. Assuming that the power cycle efficiency is $n_{1}$ and that a fraction, $n_{2}$ of the electrical requirements are for operating the fusion reactor, the total thermal energy equivalent of the electrical energy needed for electrolysis is $\frac{M}{n_{1} n_{2}^{*}} \sum_{i=1}^{k} \varepsilon_{i} \Delta G_{i}$ where $k$ is the total number of HTE stages and $n_{2}^{*}=1-n_{2}$. The total system energy balance is

$$
\begin{aligned}
& M\left\{H_{2}-H_{1}+\sum_{i=1}^{n} \int_{T_{2}}^{T}\left[\left(m_{i}-\varepsilon_{i}\right) C_{p H_{2} 0}+\left(1-m_{i}+\varepsilon_{i}\right) c_{p H_{2}}\right] d T+\right.
\end{aligned}
$$

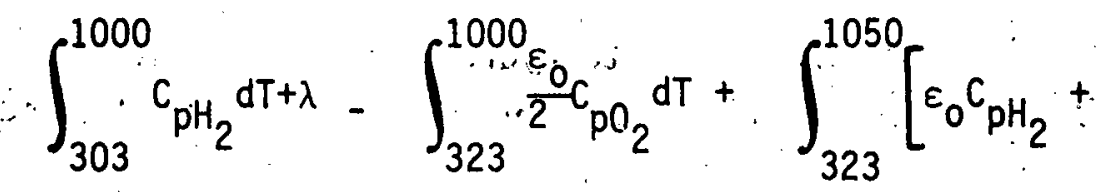

$$
\begin{aligned}
& \left.\left.\left(1-\varepsilon_{0}\right) C_{p_{2} 0}\right] d T+\frac{1}{n_{1} H_{2}} * \sum_{i=1}^{k} \varepsilon_{i} \Delta G_{i}\right\}=\frac{2000 \times 10^{3}}{0.0011626}
\end{aligned}
$$


where $0.0011626 \mathrm{kwh} / \mathrm{kcal}$ is a conversion factor from kilocalorie to kilowatt hour. By evaluating the quantities on the left hand side, one can then determine the total steam flow rate $M$.

The thermal efficiency of the process is defined as the ratio of the heating value of hydrogen produced to the fusion energy input to the system. Therefore, the efficiency is

$n=\frac{\text { heating value of hydrogen produced (HHV - higher heating value) }}{\text { thermal capacity of fusion reactor }}$

In the present calculations, $n_{1}$ the power cycle efficiency is determined to be 38 percent (the net efficiency accounts for pumps, ect.) while $\eta_{2}$ is 2 percent and takes into account beams, magnets, etc. It is assumed that the reactor operates in an ignited state, with long plasma burn and minimal extra recirculating power for special portions of the fusion reactor, i.e., beams, magnets, tritium recycle, etc. that would not be included in the recirculating power requirements associated with the power conversion. The power cycle evaluation is based on procedures outlined by spencer ${ }^{(2)}$. The turbine throttle valves are assumed to be open for the present power cycle balance. The steam turbine selected for the cycle is a GeneralElectric-Tandem-Compound four flow unit operating at $3600 \mathrm{rpm}$ and utiliz-. ing $30^{\prime \prime}$ last stage blade lengths. This cycle is typical of a standard conventional power plant cycle.

Results of the mass and energy balance for the twelve electrolyzers and for two sets of inlet temperatures, $1827^{\circ} \mathrm{C}$ and $1377^{\circ} \mathrm{C}$ to the HTE units are tabulated in Tables $6-2$ and 6-3. The thermal efficiencies of the process are 51.2 percent and 49.3 percent for maximum steam temperatures equal to $1827^{\circ} \mathrm{C}$ and $1377^{\circ} \mathrm{C}$, respectively. Overall conversion from steam to hydrogen is 94.3 percent and 89.4 percent for $1827^{\circ} \mathrm{C}$ and $1377^{\circ} \mathrm{C}$. respectively. It is noted that these conversion levels are based on the present temperature of steam entering the first HTE and leaving the last HTE. The basis for selection of these temperatures are the ability of materials to withstand the steam conditions. 
MASS AND ENERGY BALANCE OF.ELECTROLYZER UNITS - MAXIMUM HTE TEMPERATURE $=1377^{\circ} \mathrm{C}$

Outlet stream from electrolyzer

Steam

$\mathrm{H}_{2}$

$\mathrm{O}_{2}$

No. of

Electrolyzer

Unit

$\frac{\text { metric tons }}{\mathrm{hr}}$

mole $\%$ Enthalpy

$\frac{\text { metrlc tons }}{\mathrm{hr}}$

Enthalpy

metric tons Enthalpy

Reaction

\begin{tabular}{|c|c|c|c|c|c|c|c|c|c|}
\hline 1 & 206.96 & 92.22 & 1406.19 & $\therefore 1.94$ & 7.78 & $\quad 3746.81$ & 15.52 & 914.8 .53 & 1450 \\
\hline 2 & $189: 93$ & 8463 & 11406.19 & 3.83 & 15.37 & $\therefore \quad 8746.81$ & 30.66 & 9148.53 & 1450 \\
\hline 3 & $173: 32$. & $77.23^{\circ}$ & 11406.19 & 5.68 & 22.77 & 8746.81 . & 45.42 & 9148.53 & 1450 \\
\hline 4 & 150.36 & 67.00 & 11406.19 & 7.48 & 30.00 & 8746.81 & 66.58 & 9148.53 & 1450 \\
\hline 5 & 141.25 & 62.94 & 11406.19 & 9.24 & 37.06 & 8746.81 & 73.93 & 9148.53 & 1450 \\
\hline 6 & 125.78 & 56.05 & 11406.19 & 10.96 & 43.95 & 8746.81 & 87.68 & 9148.53 & 1450 \\
\hline 7 & 110.70 & $49.33^{\circ}$ & 11406.19 & - 12.63 & 50.67 & 8746.81 & 101.09 & 9148.53 & 1450 \\
\hline 8 & 95.98 & 42.77 & 11406.19 & 14.27 & 57.23 & 8746.81 & 114.17 & 9148.53 & 1450 \\
\hline 9 & 81.60 & 36.36 & 11406.19 & 15.87 & 63.64 & 8746.81 & 126.95 & 9148.53 & 1450 \\
\hline 10 & $61.49^{\circ}$ & 27.40. & 9782.89 & 18.10 & 72.60 & 7601.2 & 144.83 & 7871.46 & 1300 \\
\hline 1$]$ & 38.96 & 17.36 & 8217.05 & 20.61 & 82.64 & 647.2 .91 & 164.85 & 6618.88 & 1150 \\
\hline 12 & 12.73 & 5.67. & 6708.6 & 23.52 & 94.33 & 5361.86 & 188.17 & 2693.85 & 1000 \\
\hline
\end{tabular}

Total steam entering HTE -224.42 metric tons/hr Make up water flow rate -211.69 metric tons $/ \mathrm{hr}$ 


\section{MASS AND ENERGY BALANCE OF ELECTROLYZER UNITS - MAXIMUM HTE TEMPERATURE $=1827^{\circ} \mathrm{C}$}

Outlet stream from electrolyzer

Steam $\quad \because \because \mathrm{H}_{\mathbf{2}} \quad \because \quad \therefore \quad \mathbf{O}_{\mathbf{2}}$

No. of

Electrolyzer metric tons

Unit

mole $\%$ callo-mole $\frac{\text { metrictons }}{h x}$

Enthalpy $\therefore$ metrfic tons Enthalpy

Reaction

hr

hr

cal/g-mole Temp $\mathrm{K}$

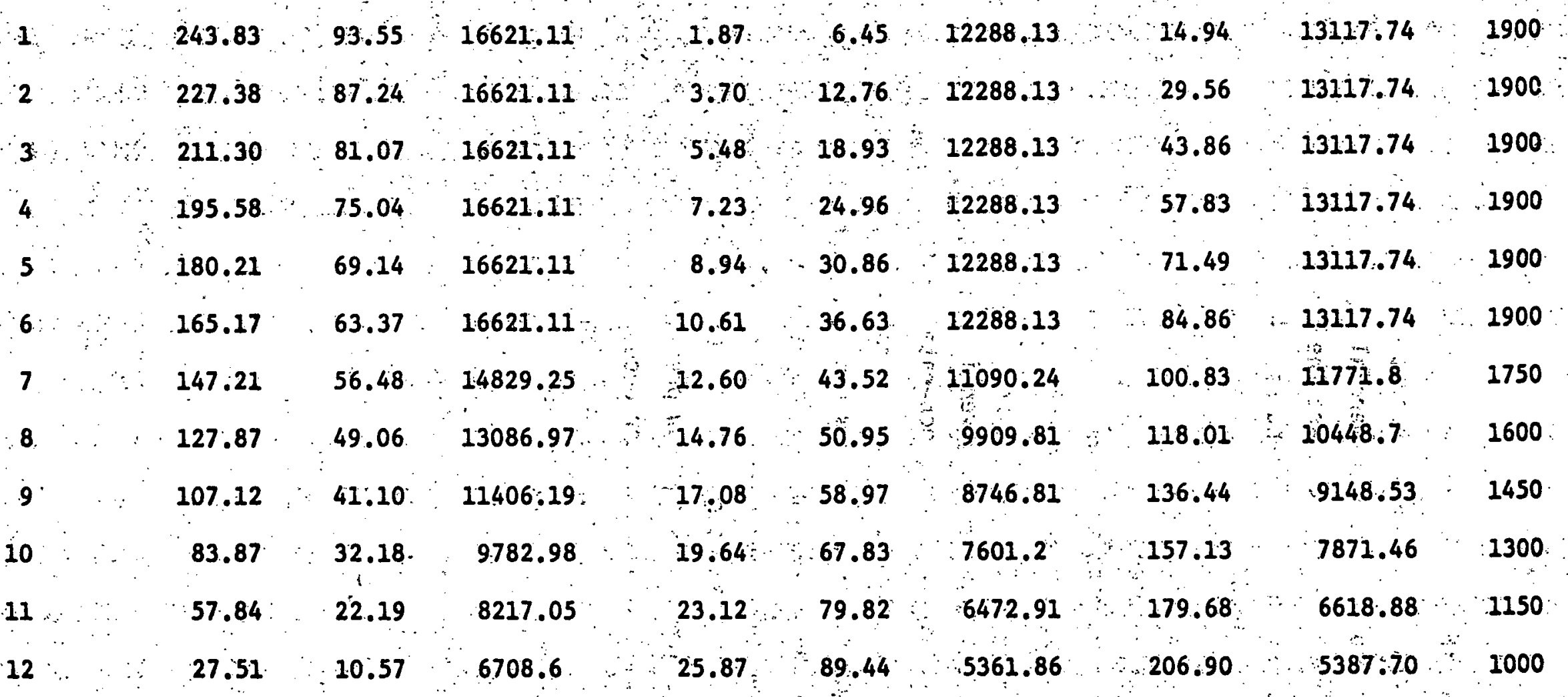

Total steam enterlng HTB -260.64 metrle tons/hx

Make up water flow rate -233.09 metrle tons/hr 
In general the outlet steam temperature from the last HTE must be less than the critical temperature of water $\left(374^{\circ} \mathrm{C}\right)$. The steam flow in each electrolyzer is controlled by the pressure difference between inlet and outlet of each unit. There are five equal size $\mathrm{H}_{2} / \mathrm{H}_{2} \mathrm{O}$ heat exchangers for hydrogen separation. Equipment for the power cycle is based on conventional commercial units so that the only major pieces of equipment to be sized are the hydrogen separation heat exchanger as well as oxygen heat exchangers. A summary of the heat exchanger parameters is given in Tables 6-4 through $6-\%$.

The overall mass and energy balance of the hydrogen production process using fusion energy is given in Fig. 6-2 and 6-3. It should be noted that all the high temperature electrolyzers are represented by one box which inciudes twelve electrolyzers as discussed previously. Detailed information of the electrolyzers are reported in Tables 6-2 and 6-3. The process flow sheets given in Figs. $6-2$ and $6-3$ show the balanced system. The electricity generated in the power conversion cycle is used for high temperature electrolysis: For $1827^{\circ} \mathrm{C}$ electric power generated from high and low pressure turbines is $138 \mathrm{MW}(\mathrm{e})$ and $436 \mathrm{MW}(\mathrm{e})$. Using $11 . M W(e)$ for auxiliaries, the net power generated in this cycle is $562 \cdot \mathrm{MW}(\mathrm{e})$ with a thermal to electrical conversion efficiency of 37.9 percent and heat rate of $2.3 \times 10^{6} \mathrm{cal} / \mathrm{kwh}$. For $1377^{\circ} \mathrm{C}$, electric power generated from high and low pressure turbines is $146 \mathrm{MW}(e)$ and $462 \mathrm{MW}(\mathrm{e})$, respectively. New power produced is then 596.60 MW(e) with 11.2 MW(e) for auxiliaries. Power conversion efficiency is 37.6 percent with a heat rate of $2.3 \times 10^{6} \mathrm{cal} / \mathrm{kwh}$. 


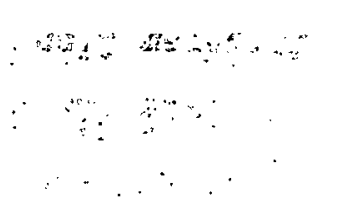

OXYGEN HEAT EXCHANGER - MAXIMUM HTE TEMPERATURE $=1377^{\circ} \mathrm{C}$

\section{Heat removed $=35.885 \mathrm{MW}(\mathrm{t})$}

Use four $655 \mathrm{~cm}$ long sections 2 pass heat exchanger in series

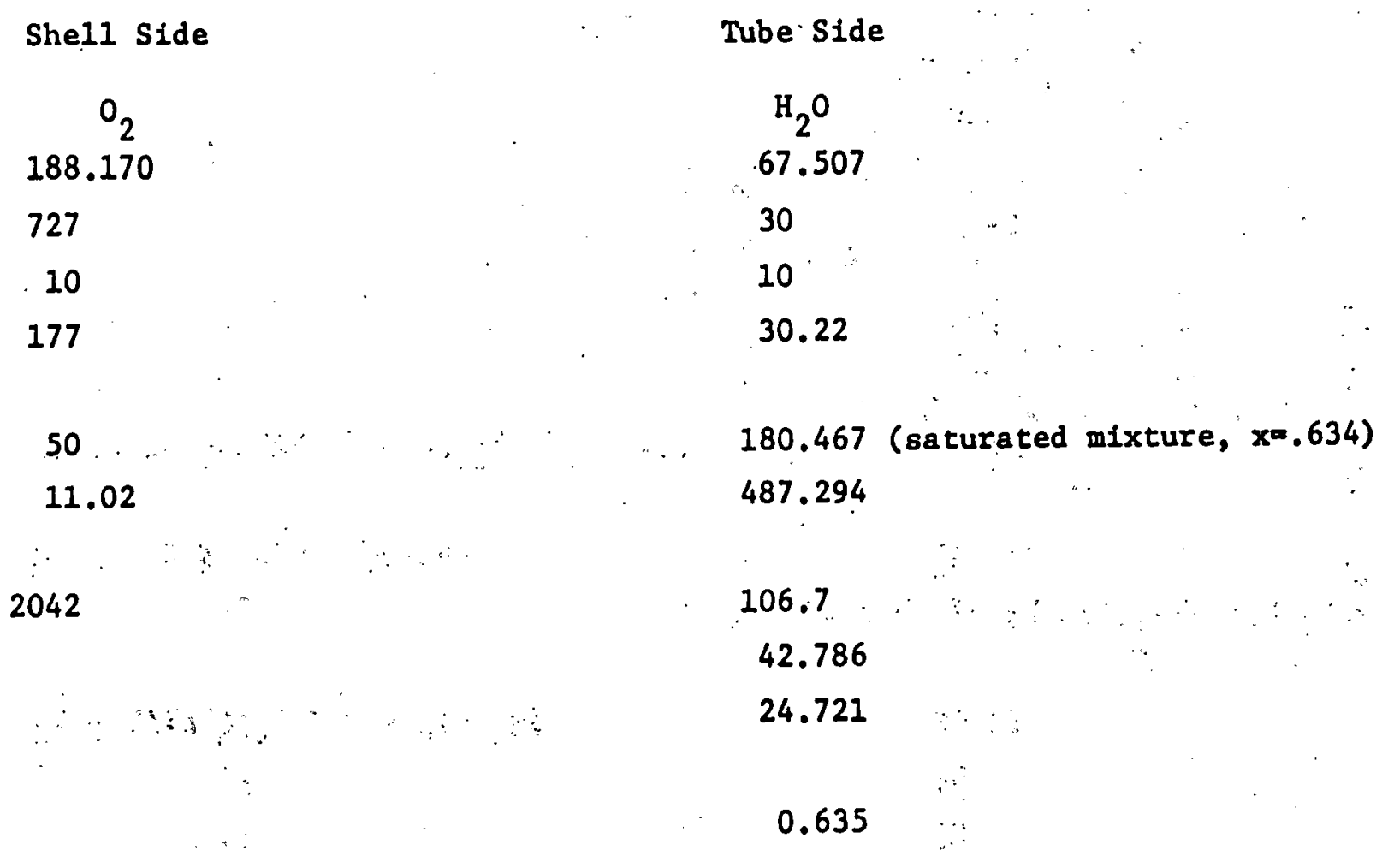

Tube size (cm) $0 . D$.

Tube material

No. of tubes

Heat transfer area $\mathrm{cm}^{2}$

Tube length $(\mathrm{cm})$

Tube spacting, cm

Shell s1ze, cm

Shell materlal
6.8. 316L for the first three and Hastelloy " $C$ " for the last one

\section{8}

$1.08 \times 10^{6}$

total 5242

triangular, $1.27 \mathrm{~cm}$
45.7 I.D.

stainless steel 
$\mathrm{H}_{2}-\mathrm{H}_{2} \mathrm{O}$ HEAT EXCHANGER - MAXIMUM HTE TEMPERATURE $=1377^{\circ} \mathrm{C}$

Heat removed from $\mathrm{H}_{2}=69.658 \mathrm{MW}$, from $\mathrm{H}_{2} \mathrm{O}=13.753 \mathrm{MW}$

Total heat removed $=83.411 \mathrm{MW}$

Shell Side

Substance

Flow rate $\mathrm{MT} / \mathrm{hr}$

Inlet temp. ${ }^{\circ} \mathrm{C}$

Inlet pressure atm

Inlet enthalpy cal/gm

as , ith

Outlet teimp. ${ }^{\circ} \mathrm{C}$

Outlet entbalpy cal/gm

$\stackrel{\infty}{i}$ Velocity calsec

Outlet steam flow MT/hr

Outlet water flow MT/hr

Tube size $(\mathrm{cm})$ O.D.

Tube material

No. of tubes

Heat transfer area $\mathrm{cm}^{2}$

Tube length $(\mathrm{cm})$

Tube spacing, $\mathrm{cm}$

Shell size, $\mathrm{cm}$

Shell materlal

50

$$
\begin{gathered}
\mathrm{H}_{2}-\mathrm{H}_{2} \mathrm{O} \\
\mathrm{H}_{2}=23.52, \mathrm{H}_{2} \mathrm{O}=12.73 \\
777 \\
10 \\
\mathrm{H}_{2}=2717.944, \mathrm{H}_{2} \mathrm{O}=979.167
\end{gathered}
$$

$$
\mathrm{H}_{2}=171.4, \mathrm{H}_{2} \mathrm{O}=50.194
$$

Inlet 3048; Outlet $\mathrm{H}_{2}=2042, \mathrm{H}_{2} \mathrm{O}-213$

180.467 (saturated mixture, $x=0.634$ )

487.294

106.7

99.452

57.462

0.635

6.8. 316 I

8700

$4.990 \times 10^{6}$

total 3459.48

triangular, 1.27 
?.3: 1 TABLE 6-6.

\section{OXYGEN HEAT EXCHANGER - MAXIMUM HTE TEMPERATURE $=1827^{\circ} \mathrm{C}$}

Heat removed $=39.513 \mathrm{MW}(E)$

Use five $731 \mathrm{~cm}$ long oection 2 pass heat exchanger in serles

Shell side

Substance

Flow rate $\mathrm{MT} / \mathrm{hr}$

Inlet temp. ${ }^{\circ} \mathrm{C}$ :

Inlet pressure atm

Inlet enthalpy. cal/gm

Outlet temp. ${ }^{\circ} \mathrm{C}$

Outlet enthalpy cal/gm

Velocity $\mathrm{cm} / \mathrm{sec}$

Outlet steam flow MT/hr

Outlet water flow MT/hr

Tube size (cm) O.D.

Tube màterial

No. of tubes

Heat transfer area $\mathrm{cm}^{2}$

Tube length (cm)

Tube opacing; $\mathrm{cm}$

Shell s1ze, cm

Shell material
$\mathrm{O}_{2}$

207:19

727

10

175.

50

.11 .02

2032

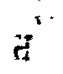
is on
Tube Side

$$
\begin{aligned}
& \mathrm{H}_{2} \mathrm{O} \\
& 70.55 \\
& 30 \\
& 10 \\
& 30.22
\end{aligned}
$$

180.46 (saturated mixture; $x=0.685$ )

$$
511.82
$$

106.68

48.33

22.22

$$
0.64
$$

8.8. $316 \mathrm{~L}$ for the first three and Hastelloy " $\mathrm{C}$ ". for the last one

$$
\begin{gathered}
3950 \\
2.8684 \times 10^{7} \\
\text { total } 3657 \\
\text { triangulax, } 1.27
\end{gathered}
$$

91.44

Stainless oteel 


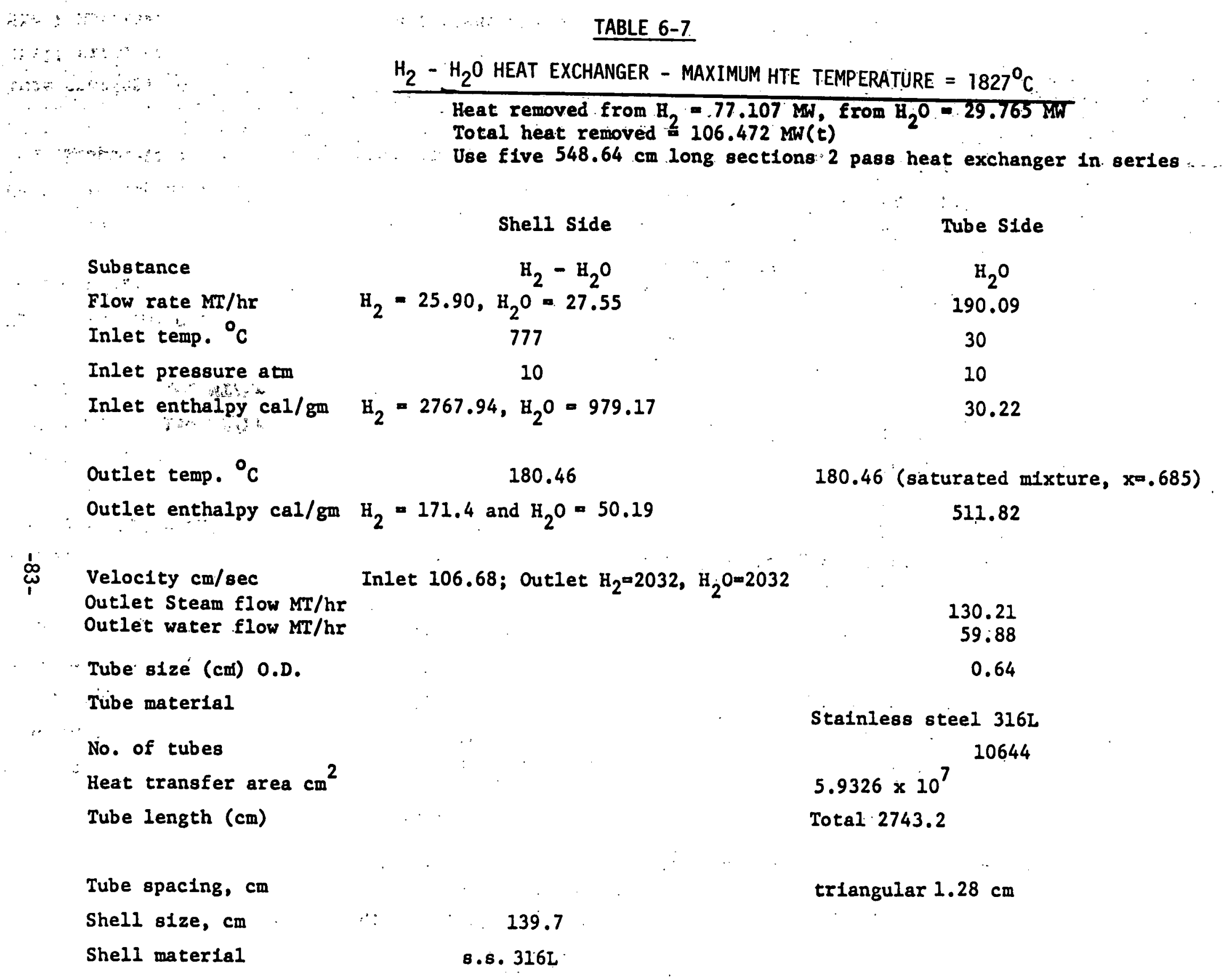




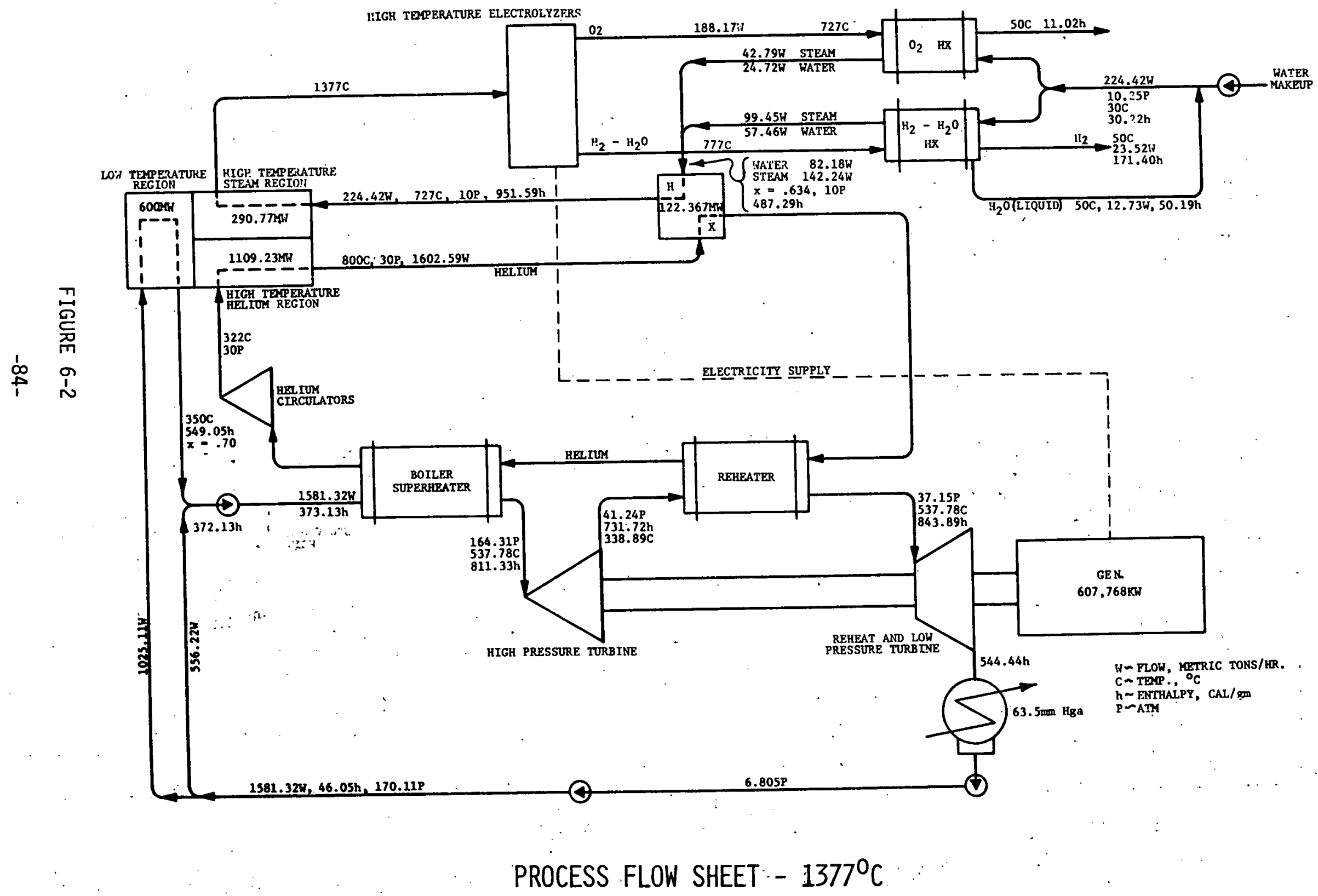




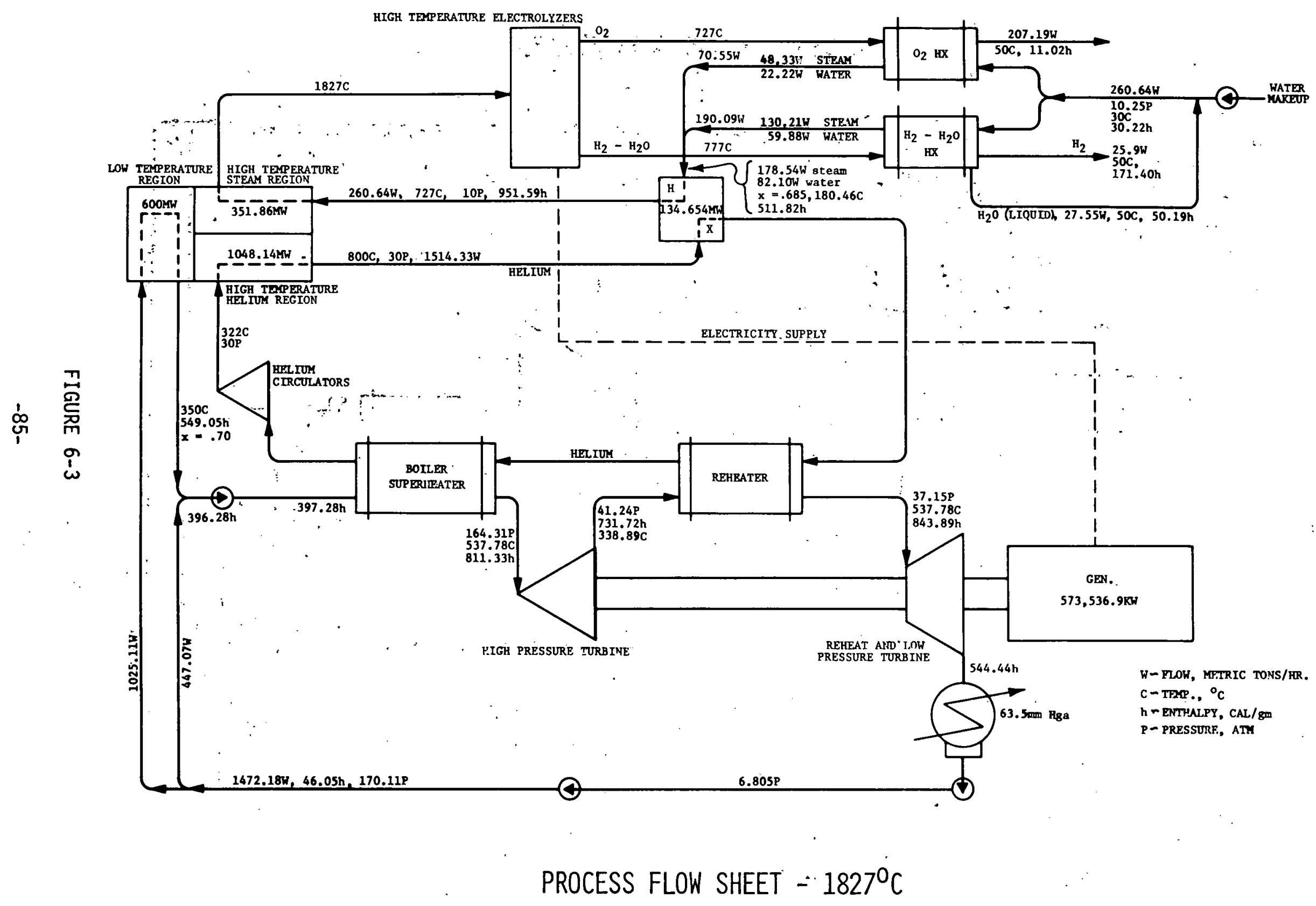




\subsection{ECONOMICS}

While it was not possible to do a complete economics study of the system, estimates of the capital investment costs as well as fuel production cost evaluations were made. This phase of the study relies on cost estimate assumptions for individual components, such as the fusion reactor, coalsynthetic fuel plant, etc. These results are summarized in Tables 7-1 through 7-3.

Before any costing can be done, some idea as to the fuel production capacity for a given fusion reactor size is necessary. Table 7-1 includes a summary of the hydrogen fuel production capacity of the reference design HTE system based on 'a $2000 \mathrm{MW}(\mathrm{th})$ fusion reactor with a conventional power cycle (CP) efficiency of $\sim 40$ percent. These results are compared with a system operating with an advanced high efficiency power cycle (AP), operating at $\sim 60$ percent efficiency. The maximum HTE temperature was fixed at $1600^{\circ} \mathrm{K}$ in both cases.

For a fixed reactor thermal rating, the hydrogen produced, 1.e., standard cubic feet/day (scf/d), increases in direct proportion with the system efficiency. In terms of equivalent gasoline production in barrels/day, a $2000 \mathrm{MW}(\mathrm{th})$ fusion reactor-HTE system is a relatively small fuels plant. Such a plant, operating at 70 percent efficiency for $\mathrm{H}_{2}$ production would produce the energy equivalent of $20,000 \mathrm{bbl} /$ day, which would fuel $\sim 500,000$ autos with average driving patterns. A factor of three reductions in coal feed (tons/day) is achieved in syngas (methane) production if fusion produced hydrogen is used, as compared to a conventional syrigas plant fed by coal. This large savings in coal usage realized with the fusion produced hydrogen would greatly extend coal resources and reduce environmental effects.

Table 7-2 summarizes some estimates on capital investment costs. Note that the syngas production rate is three times that reported in Table 7-1 and is based on a $6000 \mathrm{MW}(\mathrm{th})$ fusion reactor. The assumed costs of the fusion reactor plus electrolyzers are taken to be in the range of $\$ 400$ to $800 \mathrm{KN}(\mathrm{th})$ [ $\$ 1000-2000 / \mathrm{KW}(\mathrm{e})$ equivalent] based on reference designs for fusion reactors producing electricity at conventional efficiency 


\section{TABLE 7-1}

HIGH TEMPERATURE ELECTROLYSIS WITH CONVENTIONAL AND ADVANCED POWER CYCLE : "

FUEL PRODUCTION CAPACITY FOR 2000 MW(t) FUSION REACTOR

\begin{tabular}{|c|c|c|}
\hline$\because$ & $\underline{\mathrm{HTE}-\mathrm{CP}}$ & HTE-AP (FAST) \\
\hline High Temperature Region $-{ }^{0} \mathrm{~K}$ & $1600^{\circ} \mathrm{K}$ & $1600^{\circ} \mathrm{K}$ \\
\hline Cycle Efficiency - \% & $52.5 \%$ & $71.5 \%$ \\
\hline Hydrogen Production - SCF/D & $267 \times 10^{6}$ & $364 \times 10^{6}$ \\
\hline Hydrogen Production - MT/D & 638 & 868 \\
\hline Equiv. SNG: (Methane) - SCF/D & $86 \times 10^{6}$ & $117 \times 10^{6}$ \\
\hline Coal Hydrogenation with HTE $\mathrm{H}_{2}-\mathrm{T} / \mathrm{O}$ & 1,317 & 1,790 \\
\hline SNG. Production with HTE $\mathrm{H}_{2}-$ SCF/D & $134 \times 10^{6}$ & $182 \times 10^{6}$ \\
\hline $\begin{array}{l}\text { Conventional SNG Plant Equiv. - Coal } \\
\text { Feed T/D }\end{array}$ & 4,100 & 5,580 \\
\hline HHV Equiv. Gasoline - BBL/D & 14,800 & 20,130 \\
\hline
\end{tabular}


TABLE $7-2, \quad, \because \because$

CAPITAL INVESTMENT COST FOR A FUSION-SYNTHETIC FUEL PRODUCTION PLANT :

[Basis: Hydrogen Production Rate has Fuel Equivalent Value to a $250 \times$ $10^{6}$ SCF/D SNG Plant]

Efficiency: Output $\mathrm{H}_{2}$ Fuel Energy/Input Fusion Energy : Capital Cost of Plant $50 \%$

$\$ 2.4 \times 10^{9}$

$70 \%$

$\$ 1.7 \times 10^{9}$

Cost Assumption: Fusion Reactor + Electrolyzers $=\$ 400 / \mathrm{KW}(\mathrm{th})[\$ 1000 / \mathrm{KW}(\mathrm{e})$ Equivalent]

Efficiency: Output $\mathrm{H}_{2}$ Fuel Energy/Input Fusion Energy Capital Cost of Plant $50 \%$

$70 \%$

$\$ 4.8 \times 10^{9}$

$\$ 3.3 \times 10^{9}$

Cost Assumption: Fusion Reactor + Electrolyzers $=\$ 800 / \mathrm{KW}(\mathrm{th})[\$ 2000 / \mathrm{KW}(\mathrm{e})$. Equivalent]

Coal Synthetic Fuel - SNG PTant Conventional SNG

Capital Cost of Plant $\$ 1.0 \times 10^{9}$

* Coal Feed Cost Equivalent to Additional $\$ 1.0 \times 10^{9}$ Investment at $\$ 25 /$ Ton 
Fusion-Synthetic Fuel Production Plant

Assumption: 15\% Fixed Charge - Fusion Reactor

+ Electrolyzers $=\$ 400 / \mathrm{KW}(\mathrm{th})$

- [\$1000/KW(e) Equitvalent]

Efficiency: Output $\mathrm{H}_{2}$ Fuel Energy/Input Fusion Energy

$\begin{array}{lr}50 \% & 4.70 \\ 70 \% & 3.40\end{array}$

Assumption: 15\% Fixed Charge - Fusion Reactor

+ Electrolyzers $=\$ 800 / \mathrm{KW}(\mathrm{th})$

$\therefore \quad[\$ 2000 / \mathrm{KW}(\mathrm{e})$ Equivalent]

Efficiency: Output $\mathrm{H}_{2}$ Fuel Energy/Input Fusion Energy

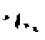

$$
50 \%
$$

9.40

6.80

Coäl Synthetic Fuel Plant (based on $\$ 25 /$ ton coal)

Syncrude ( $\$ 24 / B B L)$

4.00

SNG

$3.00-4.00$

Fission - Electrolytic Synfuel Plant

Assumption: Reactor + Electrolyzers - $\$ 1000 / \mathrm{KW}(\mathrm{e})$

$30 \%$ Efficient System

7.85 
(30 - 40 percent). A conventional syngas fuel plant costs $\sim$ one billion dollars and an additional one billion dollars is needed for coal feed operating costs which can be considered as a tradeoff for the additional capital investment for the fusion reactor process. .

Results show that the fusion-HTE system based on the lower fusion costs is slightly more than the total cost of a syngas system at the lower efficiency (50 percent) and slightly less at the higher efficiency (70 percent). Doubling the fusion plus electrolyzer costs increase the total costs accordingly.

Table 7-3 is an evaluation of fuel production costs. Assuming fixed charges to be 15 percent in a fusion-synfuels plant, the fuel costs based on the lower fusion costs are competitive with those based on a conventional coalsynfuels plant. Fuel costs resulting from the fusion-synfuels plant would be approximately one-half that of a comparative fission electrochemical system. Looked at from another perspective; the hydrogen produced from a fusion-synfuels plant is equivalent to an energy cost corresponding to $\sim 45 \$$ to $60 \$ / g a l l o n$ of gasoline. Since all of these comparisons are based on assumed costs, no definitive conclusions can be drawn except that if the cost per unit of thermal output of a fusion HTE plant is comparable to that projected for fusion electroc plants, fusion produced hydrogen should be economically competitive. 


\subsection{RESEARCH AND DEVELOPMENT REQUIREMENTS}

Throughout the study a number of key issues have been identified and discussed as they relate to blankets, high temperature electrolysis and the processes involved. The majority of potential study areas are materials related. The unique ability of fusion neutrons to directly heat the interior of a blanket to very high temperatures has been identified to offer great potential for high efficiency power cycles using fusion heat. The $R$ and $D$ requirements are yet to be fully defined.

In the blanket area, the key issues are:

1) the integrity of the oxide interior in a steam atmosphere with radiation exposure and possible thermal cycling;

2) the long-term stability of the thermal insulators; and

3) the integrity of stainless steel or some other cool metallic structure (an issue common to all fusion blankets).

With regard to the high temperature electrolyzers, the issues are centured about:

1) strength of materials as it relates to the porous support tube; temperature limits of the oxides and metals; pore size, sintering and mass transport effects;

2) electrochemical properties as they relate to high temperature electronic conduction in electrolytes; electrochemical kinetics.

3) High temperature electrodes 


\subsection{CONCLUSIONS}

Based on results obtained from the study as well as comparisons with other methods of hydrogen production, the following tentative conclusions reached are:

1) HTE has the highest potential efficiency for production of synfuels from fusion; a fusion to hydrogen energy efficiency of $\sim$ 70 percent appears possible with $1800^{\circ} \mathrm{C}$ HTE units and 60 percent power cycle efficiency; an efficiency of $\sim 50$ percent appears possible when $1400^{\circ} \mathrm{C}$ HTE units and 40 percent power cycle efficiency;

2) relative to thermochemical or direct decomposition methods HTE technology is in a more advanced state of development, eg, single cell units have been built and tested at $1000^{\circ} \mathrm{C}$;

3) based on efficiency results HTE methods would appear to have potentially lower unit process or capital costs compared with thermochemical or direct decomposition methods;

4) while design efforts are required HTE units offer the potential to be quickly run in reverse as fuel ceills to produce electricity for restart of tokamak and possible spinning reserve for a grid system. 


\section{APPENDIX A}

THERMODYNAMIC ANALYSIS OF A HIGH TEMPERATURE ELECTROLYSIS CYCLE APPLII.? TO FUSION REACTOR TECHNOLOGY FOR. SYNTHETIC FUEL. PRODUCTION

The basis for the energetics of a high temperature electrolysis process for hydrogen production is the thermodynamics of the decomposition of water.

$$
\begin{gathered}
\mathrm{H}_{2} \mathrm{O}(l)=\mathrm{H}_{2} \mathrm{O}(\mathrm{g}) \\
\mathrm{H}_{2} \mathrm{O}(\mathrm{g})=\mathrm{H}_{2(g)}+\frac{1}{2} \mathrm{O}_{2}(\mathrm{~g}) \\
\text { \& refers to liquid state } \\
\mathrm{g} \text { refers to gaseous state }
\end{gathered}
$$

The degree of decomposition of water as a function of temperature is expressed by the Gibbs free energy

$$
\Delta G=\Delta H-T \Delta S
$$

where $\Delta G=$ free energy change for reaction $(2), \mathrm{Kcal} / \mathrm{mol}$

$\Delta H=$ enthalpy change for reaction (2), $\mathrm{Kcal} / \mathrm{mol}$

$T=$ absolute temperature, ${ }^{0} \mathrm{~K}$

$\Delta S=$ entrophy change for reaction (2), $\mathrm{Kcal} / \mathrm{mol}{ }^{{ }^{0}} \mathrm{~K}$

The electrolytic decomposition of water is controlled by the relationship

$$
\Delta G=n f E
$$

$n=$ number of gram equivalents or electron changes per atom, for

$$
0, n=2
$$

$f=$ Faraday's constant 96,500 Coulomb/gm equiv.

$E=$ emf or voltage potential of cell, volts

A good conversion factor to remember associated with equation (4) is 23.06 $\mathrm{Kcal} / \mathrm{mol} / \mathrm{ev}$ per gm equivalent. The cell voltage can then be calculated for $\mathrm{H}_{2}$ as 


$$
E=\frac{\Delta G}{2 \times 23.06} \text { volts }
$$

Thus in an electrolyzer, the electrical energy supplied to the cell is related to $\Delta G$ in the energy equation, the non-work energy needed for the decomposition is expressed by the TAS term, and the total energy is related to the total enthalpy change for the system, $\Delta H$.

The thermodynamic values for the water decomposition reaction (A-2) as a function of temperature, in ${ }^{0} \mathrm{~K}$, is given in Figure $A-1$. This information is well known and readily available from many sources; the best thermodynamic compilation dates back to the NBS Circular 500 (1952). It is noted that for this system, $\Delta H$ remains almost constant with temperature, increasing only very slightly up to temperatures as high as $4200^{\circ} \mathrm{K}$. The $T \Delta S$ term steadily rises and as a result the $\Delta G$ term steadily decreases until it reaches zero at a temperature on the order of $4200^{\circ} \mathrm{K}$. The quantity $\Delta G$ relates to the amount of electricity fed to the cell and the $T \Delta S$ is the thermal energy required to maintain a constant temperature in the cell. The physical interpretation of the chart is as follows. At room temperature $\left(298.2^{\circ} \mathrm{K}=25^{\circ} \mathrm{C}\right) \Delta G$ is $54: 64 \mathrm{Kcal} / \mathrm{mol}$ and $T \Delta S$ is $3.16 \mathrm{Kcal} /$ mol. This means that 94.5 percent of the total energy, which is $\Delta H=$ $57.80 \mathrm{Kcal} / \mathrm{mol}$, must be supplied by $D C$ electrical energy and 5.5 percent as thermal energy. It should be noted that in operating an electrolytic cell at room temperature, the 5.5 percent thermal energy needed is absorbed by the cell from the surroundings. If the cell would be insulated from the surroundings, the temperature of the ideal cell would drop, acting : like a refrigerator. As the temperature of the cell is raised, the $T \Delta S$ term increases. The fraction of the thermal energy input required increases and the electrical energy needed decreases. Figure $A-l$ shows the fraction of thermal energy input and indicates that at $2160^{\circ} \mathrm{K}\left(1: 886.8^{\circ} \mathrm{C}\right)$ 50 percent of the energy input for water decomposition would be thermal energy and 50. percent electrical energy. Theoretically, at $4200^{\circ} \mathrm{K}$ ail the energy can be put in as thermal energy for water decomposition and no electrical energy would be required. This would be a true thermal splitting of water. However, this temperature cannot be reached 
FUSION - HTE - SYNTHETIC FUELS

THERMODYNAMICS OF WATER DECOMPOSITION (STEAM)

$$
\mathrm{H}_{2} \mathrm{O}_{(g)}=\mathrm{H}_{2}(g)+1 / 2 \mathrm{O}_{2}(g)
$$

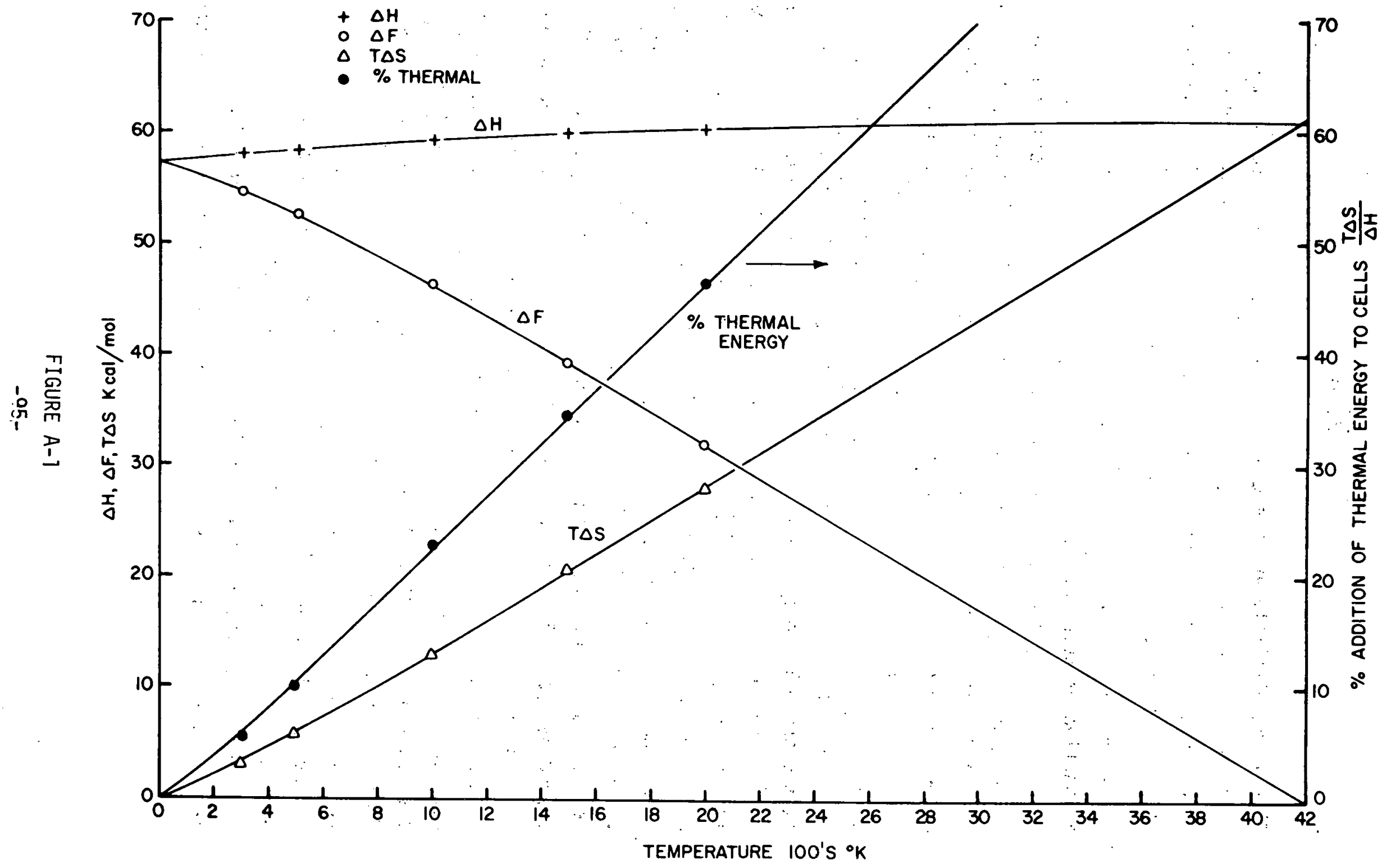


because other dissociative chemical reactions take place, forming the free radicals, $\mathrm{H}, \mathrm{O}$, and $\mathrm{OH}$ which are energy absorbing and limit the upper temperature. For example, the adiabatic equilibrium temperature for a $\mathrm{H}_{2}-\mathrm{O}_{2}$ flame is $3080^{\circ} \mathrm{K}\left(2807^{\circ} \mathrm{C}\right)$ and the equilibrium composition contains about 10 percent $\mathrm{OH}$ as well as additional amounts of $\mathrm{H}, 0, \mathrm{O}_{2}, \mathrm{H}_{2}$, and $\mathrm{H}_{2} \mathrm{O}$ species. Up to about $2500^{\circ} \mathrm{K}$ the effect of free radical formation is not very significant.

The increasing quantities of thermal energy input to an electrolytic cell brings the system closer to an all thermochemical system. However, in electrolysis, which is a one-step hydrogen producing process, there is always some amount of electrical energy used in the cell. In this respect it is a hybrid process.

The application of the thermodynamic data of Figure A-1 to a fusion reactor energy source is as follows. The system represented in Fig. A-2 combines high temperature electrolysis with a conventional power cycle.

In a D-T plasma approximately 80 percent of the energy is given off in the form of high energy $14 \mathrm{MeV}$ neutrons. The neutrons penetrate the first wall and are slowed down in the blanket. The neutron energy is deposited in refractory materials. A process gas passes over the refractory oxides and absorbes the heat at a high temperature. The blanket structure is insulated from the high temperature refractory material and is independently cooled. The remaining 20 percent of the energy, i.e., $x$-rays, etc., is deposited on the first wall which is cooled by the blanket structural coolant system. This is the low temperature region referred to in Fig. A-2. The heat (temperature on the order of $350^{\circ} \mathrm{C}$ and $2000 \mathrm{psi}$ ) is transported to the conventional power cycle. In the high temperature region (HTR) of the blanket, process steam (in this case water vapor) at about $10 \mathrm{~atm}$ is heated to as high a temperature as is compatible with the refractory materials and is then sent to the high temperature electrolysis (HTE) loop. The HTE then takes the heat transferred from the HTR region by the process water vapor and with the DC electrical energy generated in the conventional power cycle, decomposes the water 


\section{FUSION REACTOR - HTE-CONVENTIONAL POWER CYCLE}

FOR SYNTHETIC FUEL $\left(\mathrm{H}_{2}\right)$ PRODUCTION

SIMPLIFIED SYSTEM DIAGRAM

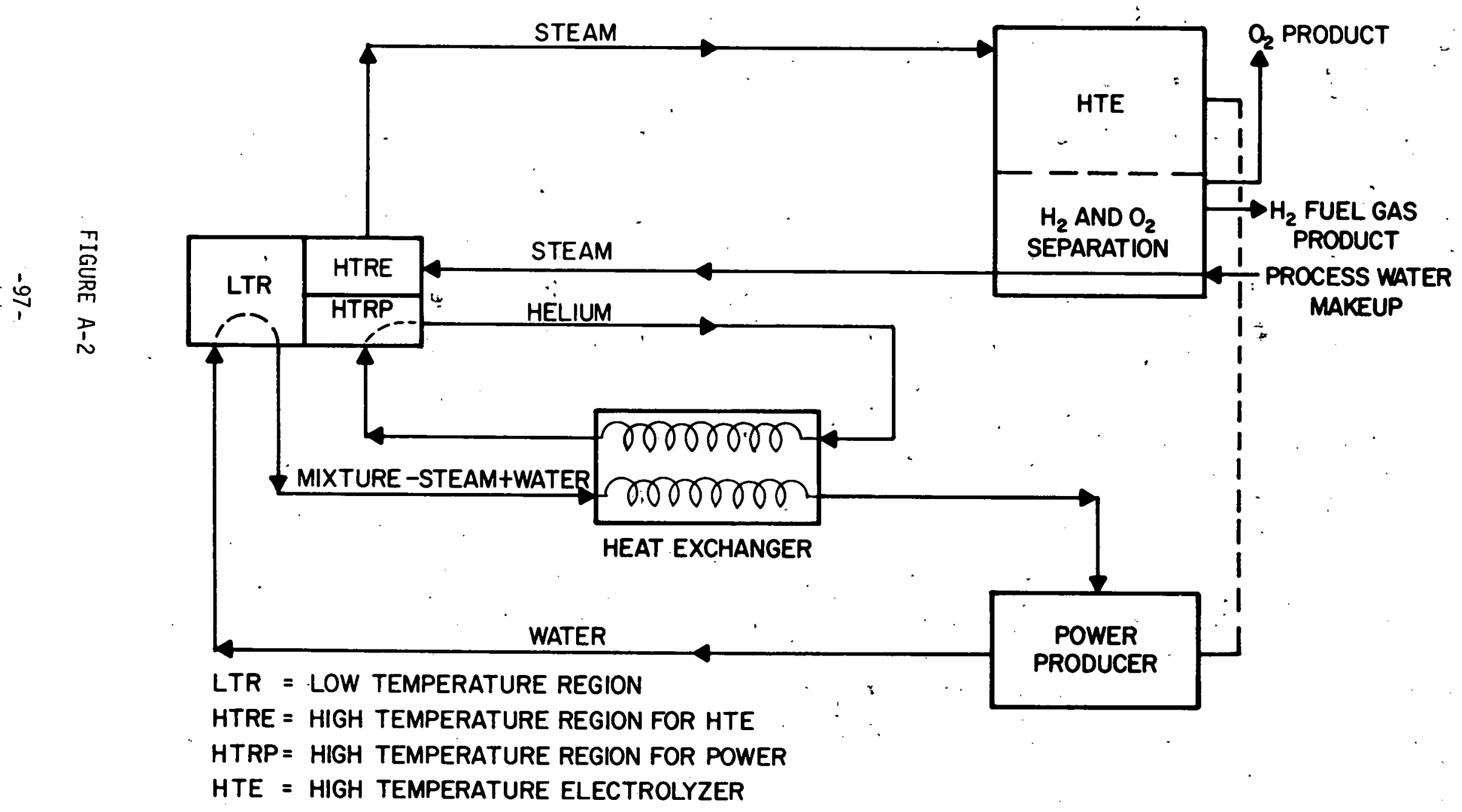


to hydrogen fuel gas product and gaseous oxygen product. At this point, we place the constraint that the system must be energetically balanced. This means that the energy generated by the fusion reactor is only used to produce hydrogen gas. Thus depending on the temperature that can be achieved in the high temperature region of the fusion reactor blanket, the ratio of thermal energy to electrical energy is fixed by the thermodynamic conditions established in Figure $A-1$. This means that not all the energy in the HTR can be used in the HTE so that the remainder must be used in the conventional power cycle to generate electrical power for the HTE. Thus, the HTR is divided into two regions; one marked HTRE for the electrolyzer circuit and the other HTRP for the power cycle, the latter incorporating a helium cooled tritium breeding blanket. The first wall is independently cooled at the same process conditions as the LTR. This assumption is realistic since in calculating overall energy conversion efficiency, if all the HTR energy is used for process heat then electrical energy would have to be obtained from another reactor source which may operate at a lower efficiency.

Thus, in Figure A-2 power is produced from both the LTR and the HTRP regions. Process water makeup is shown being put into the $\mathrm{H}_{2}$ and $\mathrm{O}_{2}$ separation units and sent to the HTRE blanket. Actually additional heating is required for this process stream before it's sent to the blanket. This is shown in the more detailed flow sheet described in Section 2 of this report. The energy analysis assumes that:

(1) 100 units of thermal energy total is generated by the fusion reactor,

70 units of thermal energy generated in the HTR, 30 units of thermal energy: generated in the LTR (x-rays, etc.) let $x=$ fraction of the 70 units in HTR which can be used in HTE; this is the fraction absorbed in HTE, then $1-x=$ fraction of the 70 units in HTR which is used in the HTRP part of the conventional power cycle. 
(2) the conventional power cycle operates at a maximum of 40 percent efficiency (conversion of thermal energy to DC electrical energy) and

(3) the high temperature electrolyzer operates at close to 100 percent current efficiency which is a fairly reasonable assumption at elevated temperatures.

For a balanced system:

$$
\frac{\text { Thermal energy }}{\text { Electrical energy }}=\frac{T \Delta S}{\Delta G}=\frac{70 x}{0.4[30+(1-x) 70]}
$$

Assuming an average temperature for the HTE, the ratio of $T \Delta S / \Delta G$ can be obtained from Figure A-1. From Eq. $(A-6) \times$ can be computed. The cycle efficiency of the entire system defined as conversion of total fusion energy to hydrogen fuel gas energy is then:

$$
\% \text { Cycle efficiency (LHV) }=\frac{0.4[30+(1-x) 70]+70 x}{100} \times 100
$$

Table A-1 1ists a number of values of the hydrogen fuel production cycle efficiency. Equation (A-7) cycle efficiency is based on the lower heating value (LHV) of hydrogen since the thermodynamics are based on Eq. (A-2) for water in the gaseous state. The convention for the sale of fuel is based on the higher heating value (HHV). The distinction between the higher and lower heating value concerns the phase of the water formed when the hydrogen in a fuel is oxidized. If all the water formed during combustion is in the liquid phase when the products are at a constant temperature $T_{0}$, the heating value measured (enthalpy) is the higher heating value. However, if this water is in the vapor phase, the heat transferred from the products will be less, and the heating value measured is the lower heating value. Since water is fed to the system in the liquid state, to base the calculations on the HHV, the latent heat of vaporization (latent heat $=10 \mathrm{k} \mathrm{cal} / \mathrm{mole}_{2} \mathrm{O}$ ) must be 
Fusion Energy-High Temperature Electrolysis with Conventional Power Cycle for Production of Hydrogen Fuel Gas

$100 \%$ HTE efficiency

$40 \%$ Conventional power cycle efficiency

$70 \%$ of fusion energy generated in high temperature region

$30 \%$ of fusion energy generated on low temperature region

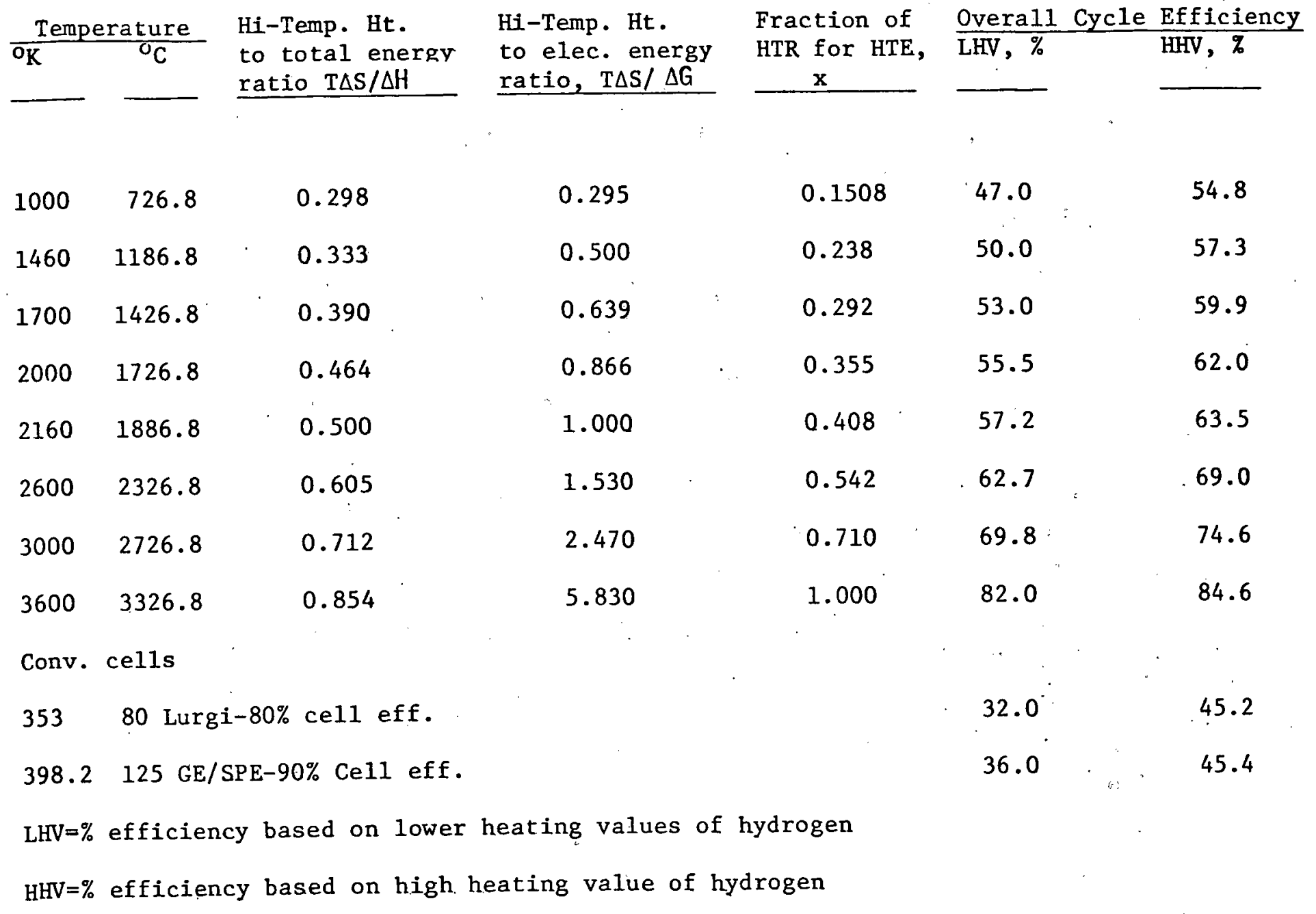


accounted for in the calculations. To correct the gaseous energy input requirement to the liquid input energy requirement, $10 / 58 \times 100=17.24$ units of energy. per unit of steam must be accounted for in addition to the fusion energy input. The HHV cycle efficiency converted from the LHV efficiency is then given by the following:

$$
\text { HHV Cycle Efficiency }=\frac{1.1724 \times \text { LHV }_{\text {eff }}}{100+0.1724 \text { LHV }_{\text {eff }}}
$$

The HHV efficiency is given in Table A-1 along with the LHV and a plot of both LHV and HHV efficiency for both conventional $(40 \%)$ and advanced $(60 \%)$ power cycles are shown in Figure A-3. There is approximately 7 to 8 percentage points improvement in HHV over LHV. It is also noted that based on the assumptions made, ideally the highest efficiency that can be obtained is at an HTE temperature of $3600^{\circ} \mathrm{K}$ when $\mathrm{x}=1$ and all the HTR heat $(70 \%)$ goes to the HTR and the LTR heat $(30 \%)$ goes to providing the electricity. The efficiencies as calculated are idealized in that pumping and heat losses from the various process units will reduce the efficiency. In addition at very high temperatures $\left(>2300^{\circ} \mathrm{K}\right)$ material temperature limitations may impose practical operating limits. Below a $1000^{\circ} \mathrm{K}$ the over-voltage problem may impose a lower operating limit. Furthermore 40 percent efficiency may be too high a value for the conventional power cycle. All these additional inefficiencies are taken into account in the actual process design of the reference system. The value of the HTE system can be compared to conventional fusion power with low temperature or conventional electrolyzers. The well-known Lurgi electrolytic cells operate at $30 \mathrm{~atm}$ and $80^{\circ} \mathrm{C}$ at an efficiency of 80 percent. The advanced GE-solid polymer electrolyzers (SPE) operate at $125^{\circ} \mathrm{C}$ and are reported to yield efficiencies of 90 percent. When combining these efficiencies with the 40 percent conventional power cycle, the range of LHV efficiency values of 32 to 36 percent are obtained and the HHV efficiencies are 42.2 to 45.4 percent. At $1700^{\circ} \mathrm{K}$ $\left(1426.8^{\circ} \mathrm{C}\right)$ which is a reasonably high temperature for HTE cells, a HHV 
efficiency of 56.9 percent can be obtained. Thus, the HTE cycle yields from 14.5 to 17.7 percentage points higher than a conventional electrolyzer cycle and thus yields an improvement of from 31.2 to 42.0 percent in efficiency over conventional systems on a comparable basis. This improved efficiency should be translated to lower operating and capital cost for a synthetic fuel process and would seem to justify a development: program for HTE.

In addition to the $\mathrm{H}_{2}$ efficiency gains as a consequence of high temperature, a substantially higher $\mathrm{H}_{2}$ efficiency can be achieved with the inclusion of an advanced power cycle (60\% efficiency) in the system. For example, at $1700^{\circ} \mathrm{K}$ a HHV efficiency of 72 percent can be realized (compared with $57 \%$ with a lower power cycle efficiency). This improved efficiency should likewise be translated into lower operating and capital cost for a synthetic fuel process and would seem to justify a development program for advanced power cycles based on high temperature blankets. 


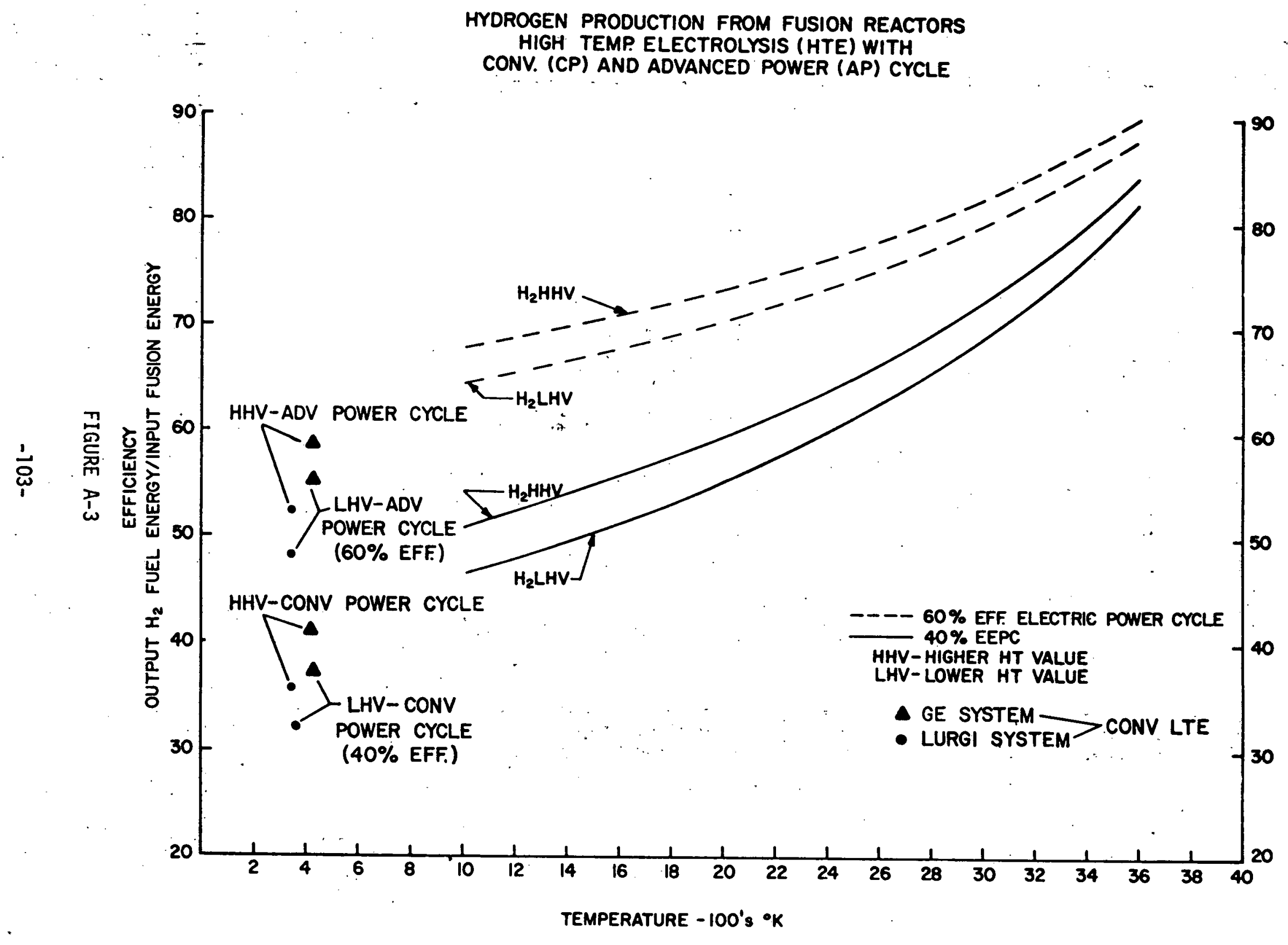


BLANKET NEUTRONICS

Figure B-1 compares the heating rate distributions for HTE modules with a stainless: steel or vanadium structure. The interior is $\mathrm{MgO}$ in both cases. The heating rates are very similar. Figure $B-2$ shows the heating rate distribution for an $\mathrm{Al}_{2} \mathrm{O}_{3}$ interior and stainless steel structure: "It appears similar to that for modules with MgO interiors.

Figures B-3 through. B-5 show the neutron flux distritubions for the same three HTE module designs. There appears to be somewhat more attenuation of the $14 \mathrm{MeV}$ neutron flux with an $\mathrm{Al}_{2} \mathrm{O}_{3}$ blanket interior, but this can be compensated for by using a slightly thiçker shield with the MgO blanker. The difference in attenuation between SS and $\dot{V}$ structures does not appear to be significant.

Figures $B-6$ and $B-7$ show the heating rate distributions for the electric' generation modules. Figure $B-6$ compares $S S$ and $V$ structures with the

c. same $\mathrm{PbO} / \mathrm{C} / \mathrm{LiAlO}_{2}$ interior. Blankets with stainless steel structures have a volumetric heating rate in the front part of the module shell that is approximately twice (Table 4-1) that of modules with vandium structure. This would appear to be a significant advantage for vanadium structures. Aluminum and titanium also have substantially lower heating rates, with aluminum having a considerably lower heating rate.

Figures B-8 through B-11 show the $14 \mathrm{MeV}$ and total neutron flux distributions for the four electric generation blankets investigated (SS and $\mathrm{PbO}, \mathrm{V}$ and $\mathrm{PbO} ; \mathrm{SS}$ and $\mathrm{Be}$, and $\mathrm{V}$ and $\mathrm{Be})$. The four cases have similar attenuation characteristics and no substantial difference is observed between them. The hot interior/cool structure energy split for the various blankets (Tabie 4-1) is on the order of 70/30 for the electric generation modules, and $60 / 40$ for the HTE process heat modules. The higher ratio for the electric generation modules probably results from the energy release from neutron absorption in $\mathrm{Li}^{6}$ (4.8 MeV/neutron absorption). In the electric generation modules, this release accurs in the hot interior, while there is no $\mathrm{Li}^{6}$ reaction in the HTE process heat modules of Table 4-1. The hot/cool energy splits in Table 4-1 are calculated using a $\mathrm{P}_{0} \mathrm{~S}_{4}$ approximation, and increase slightly for the more accurate $P_{3} S_{8}$ approximation. 
The peak value for hot/cool energy spl it is the $V$, Be blanket where 77 percent of the fusion energy is deposited in the hot interior. It should be noted that the alpha particle energy ( $3.5 \mathrm{MeV} /$ fusion reaction) is assumed to be completely deposited in the cool structure. With a divertor and high temperature ceramic heat exchange surfaces, some of the alpha particle energy could be recovered at very high temperatures. 


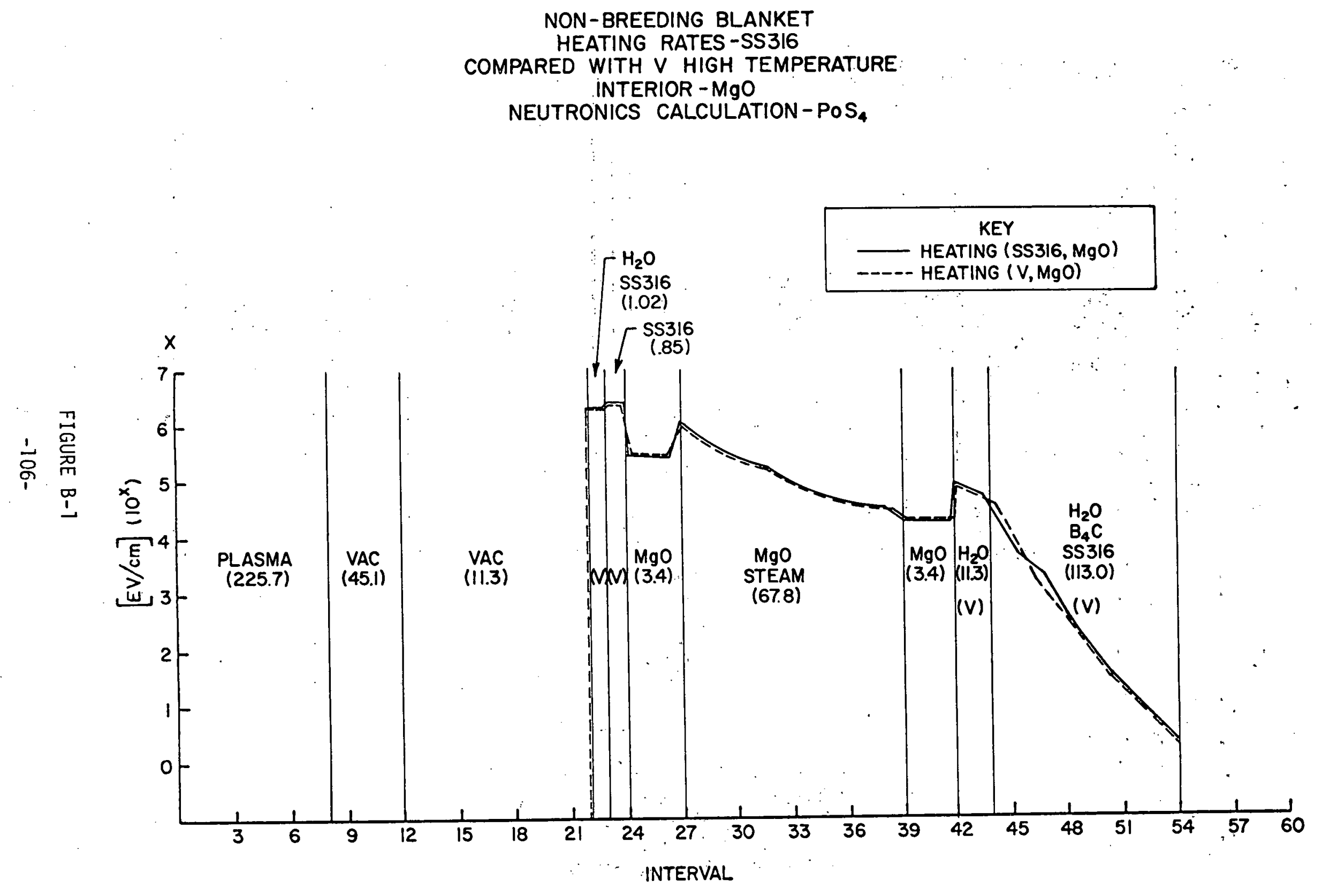




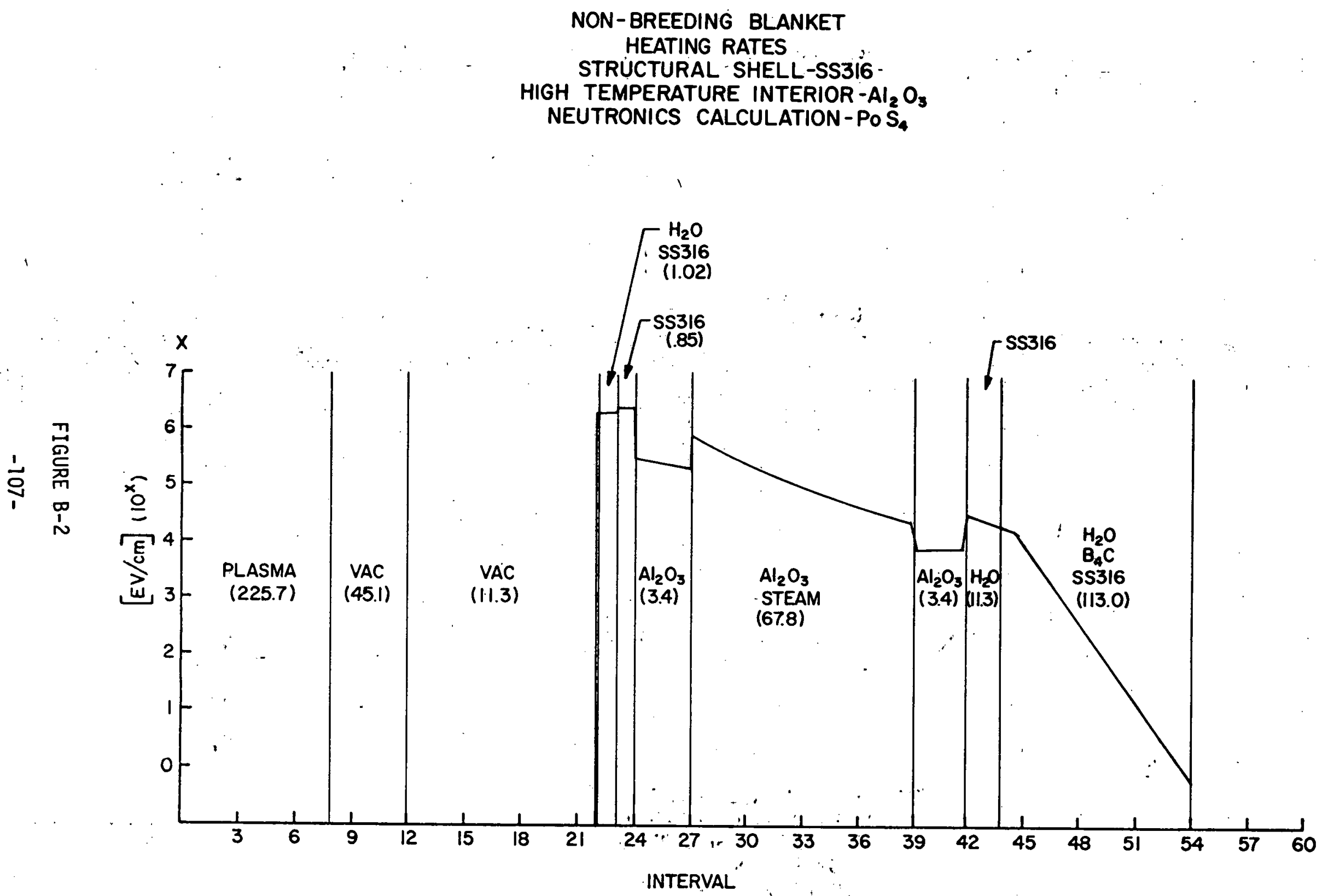




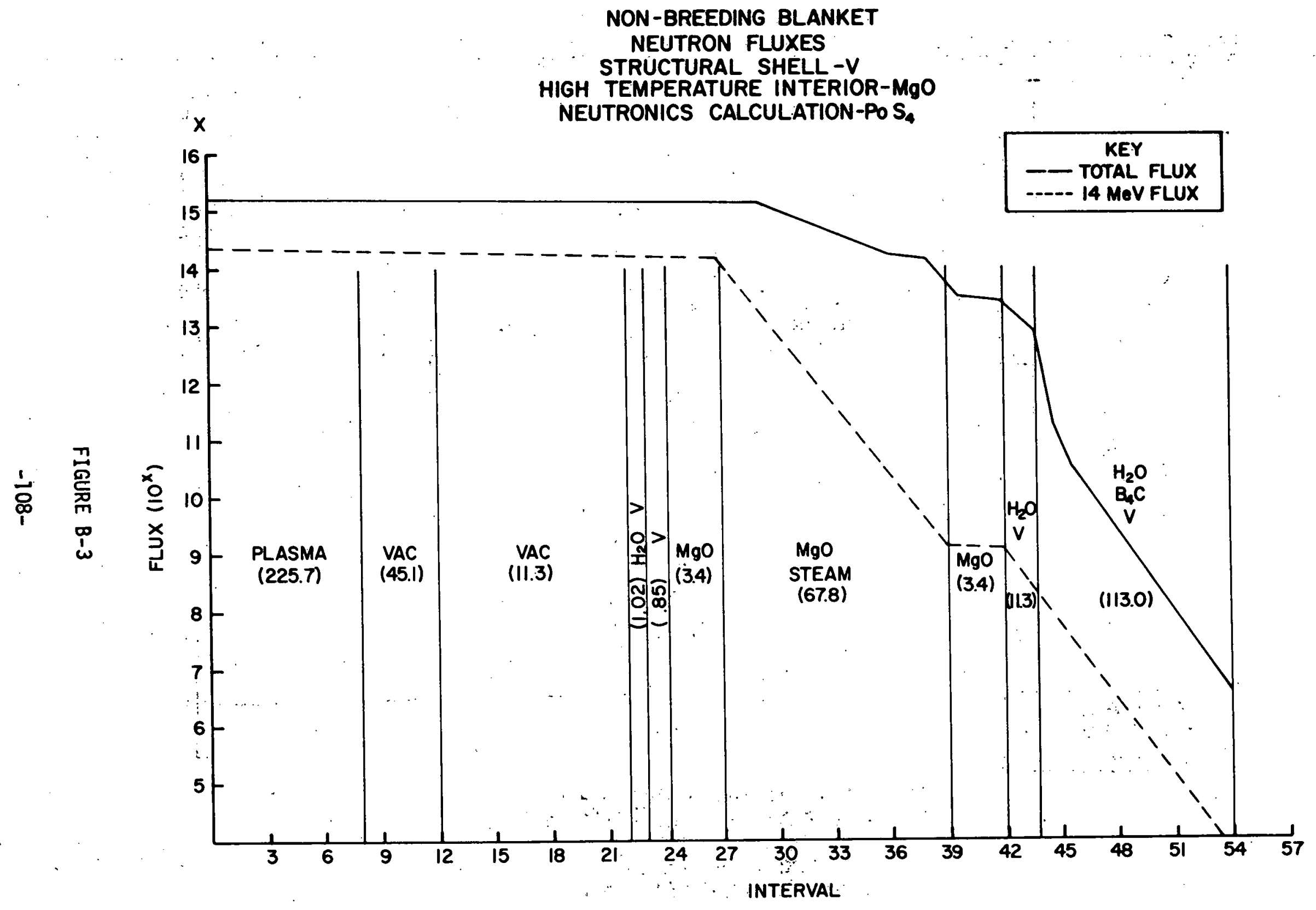




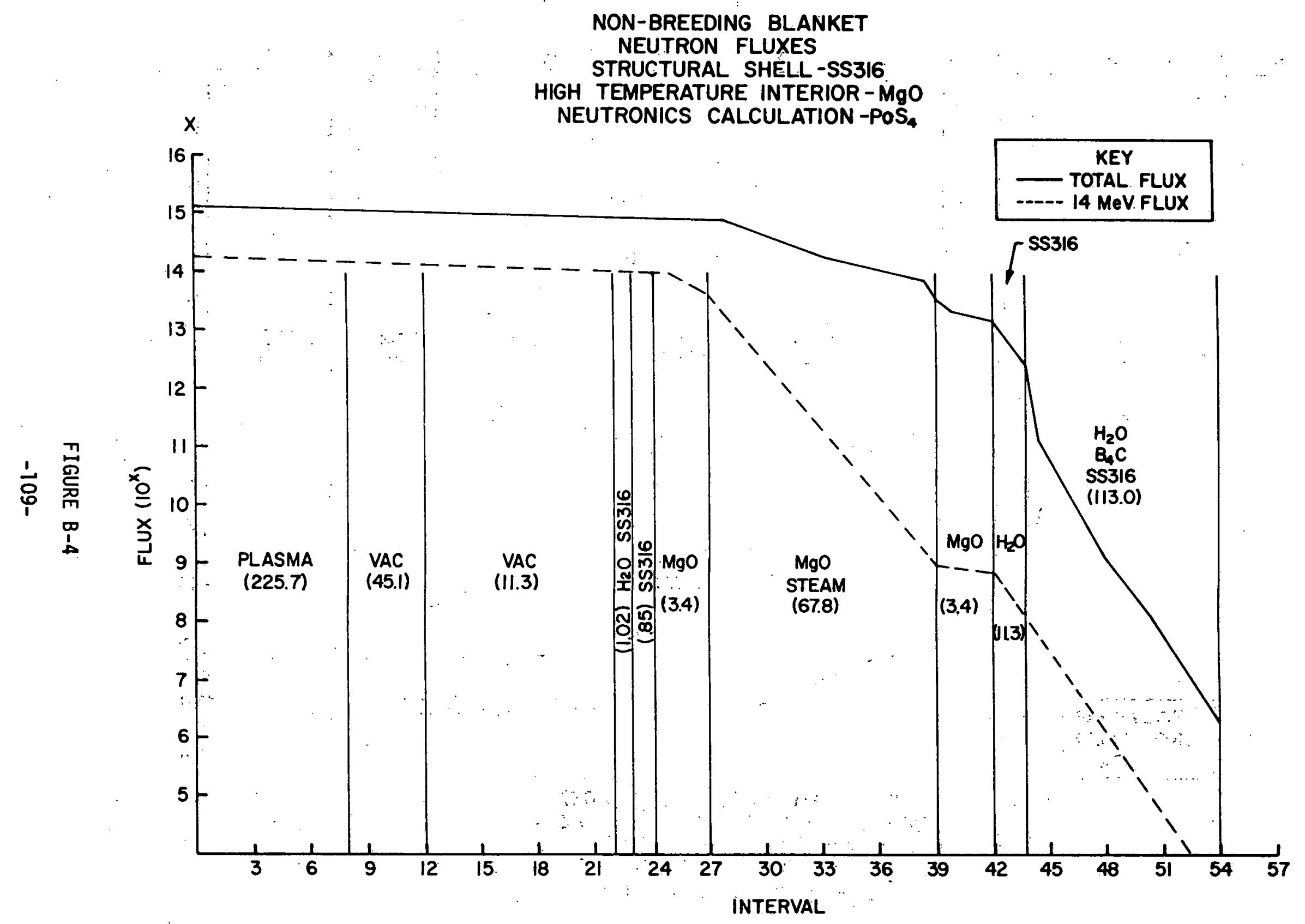




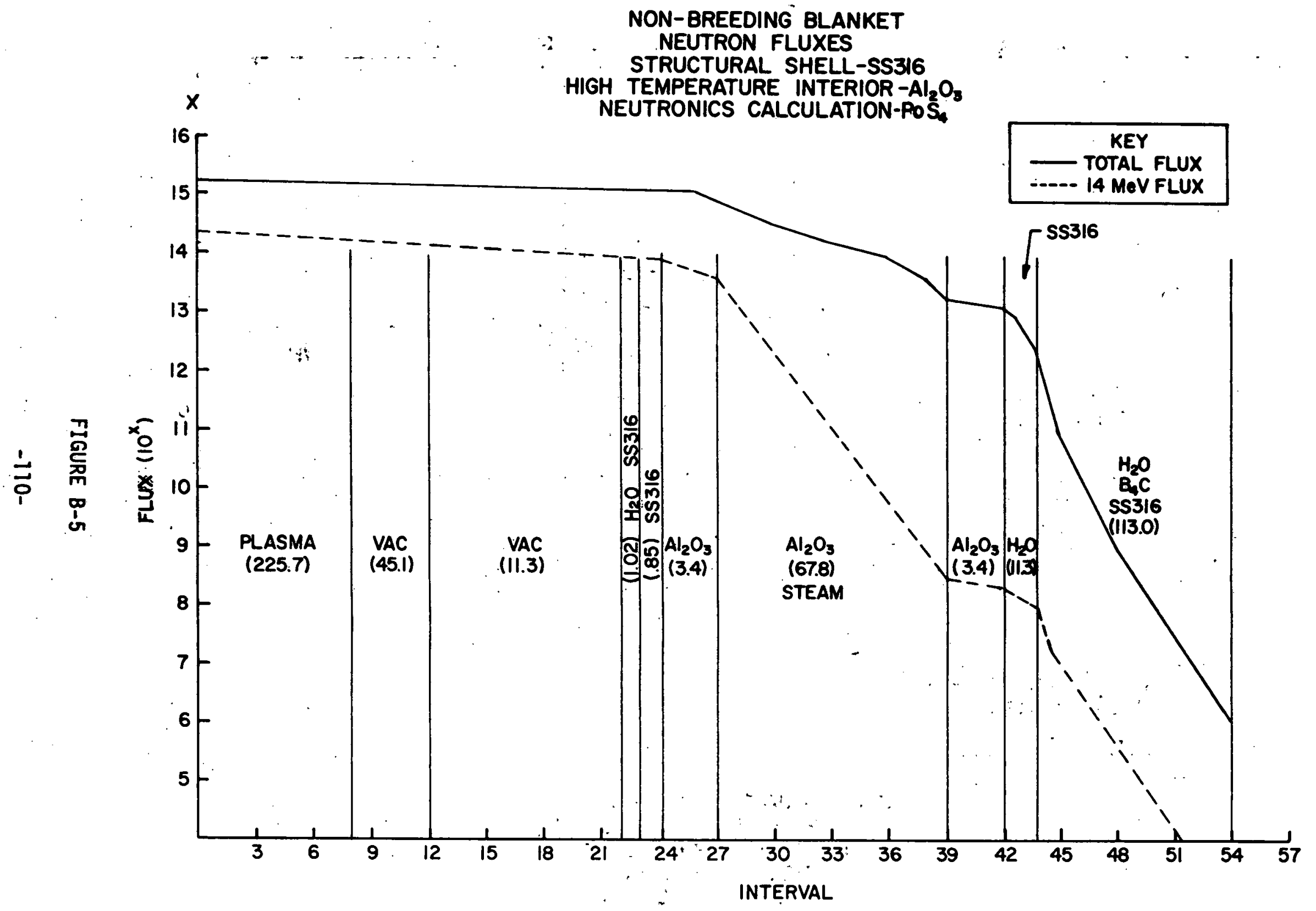




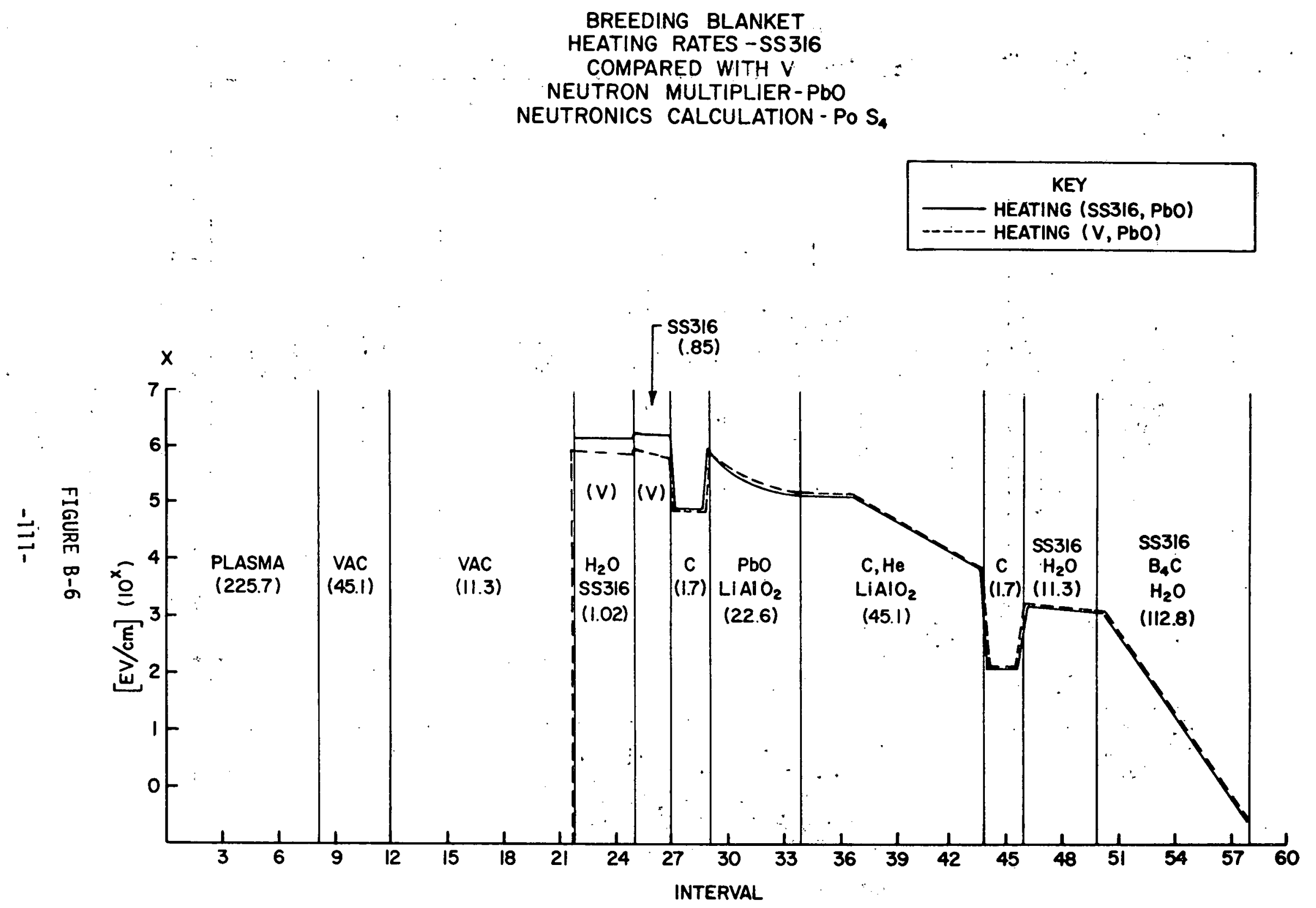




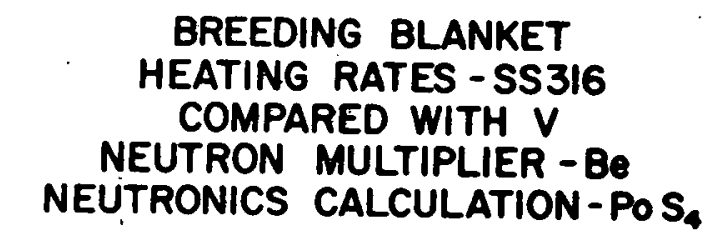

KEY

HEATING $\left(5 S 316, B_{0}\right)$

-.-- heATING $(\mathrm{V}, \mathrm{Be})$

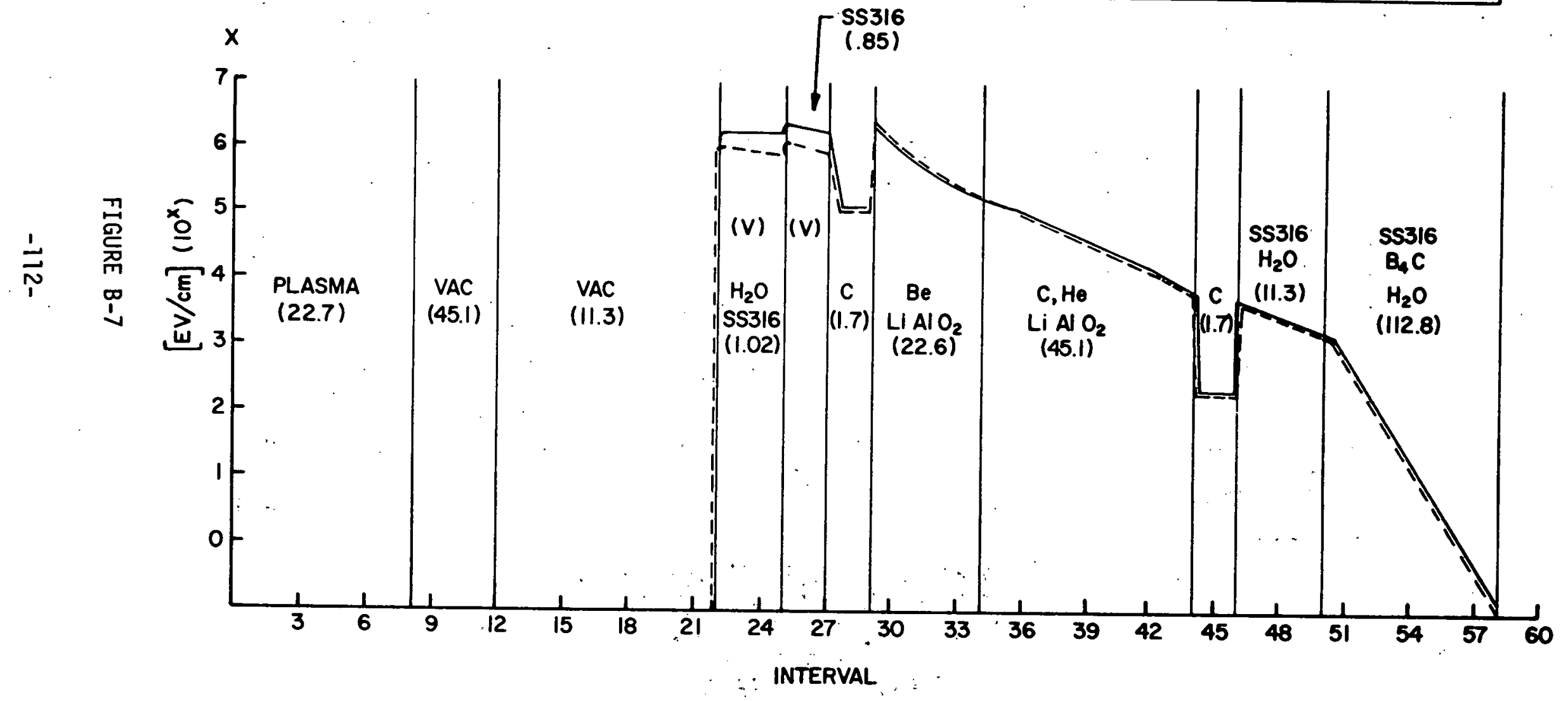




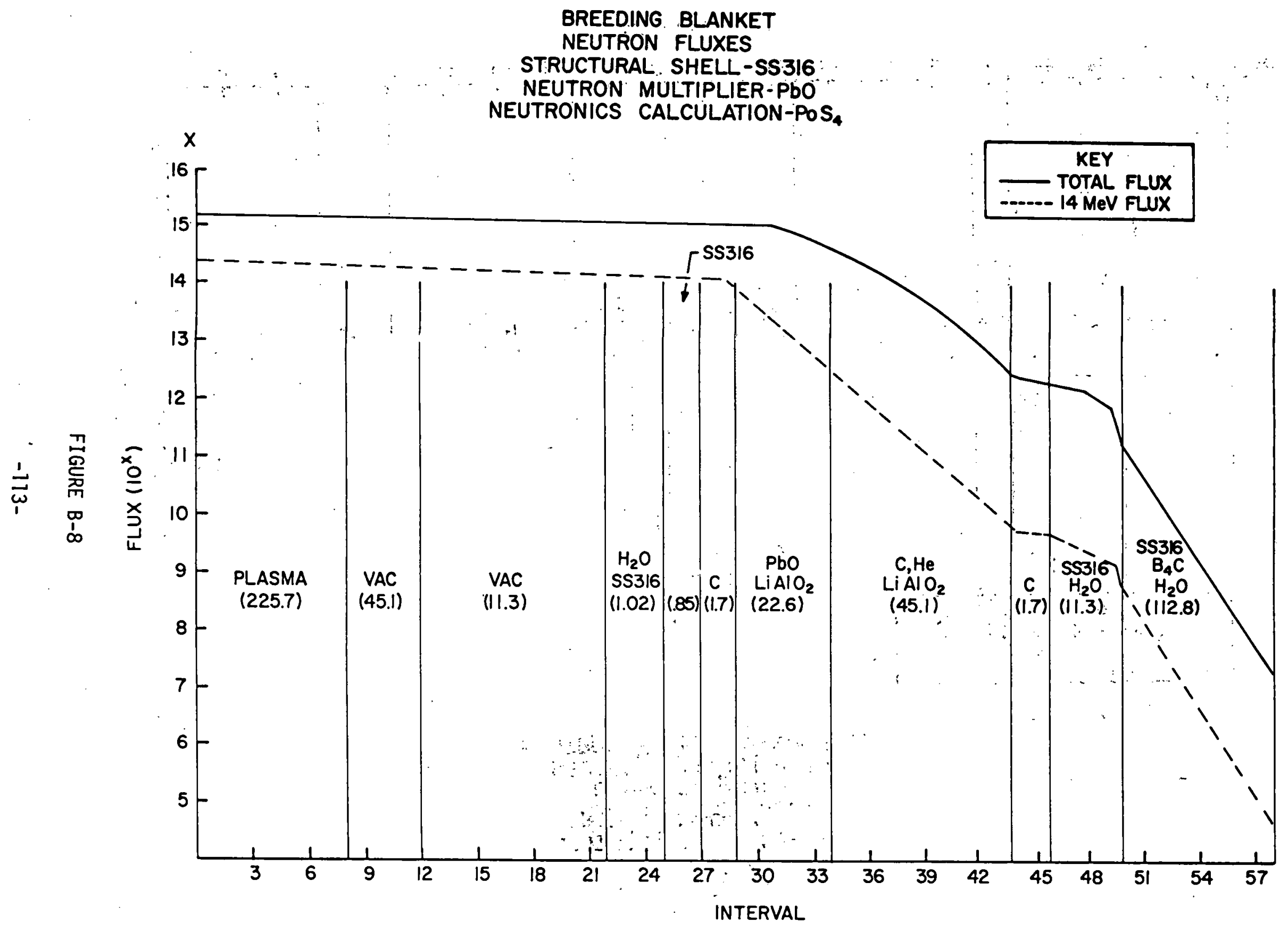




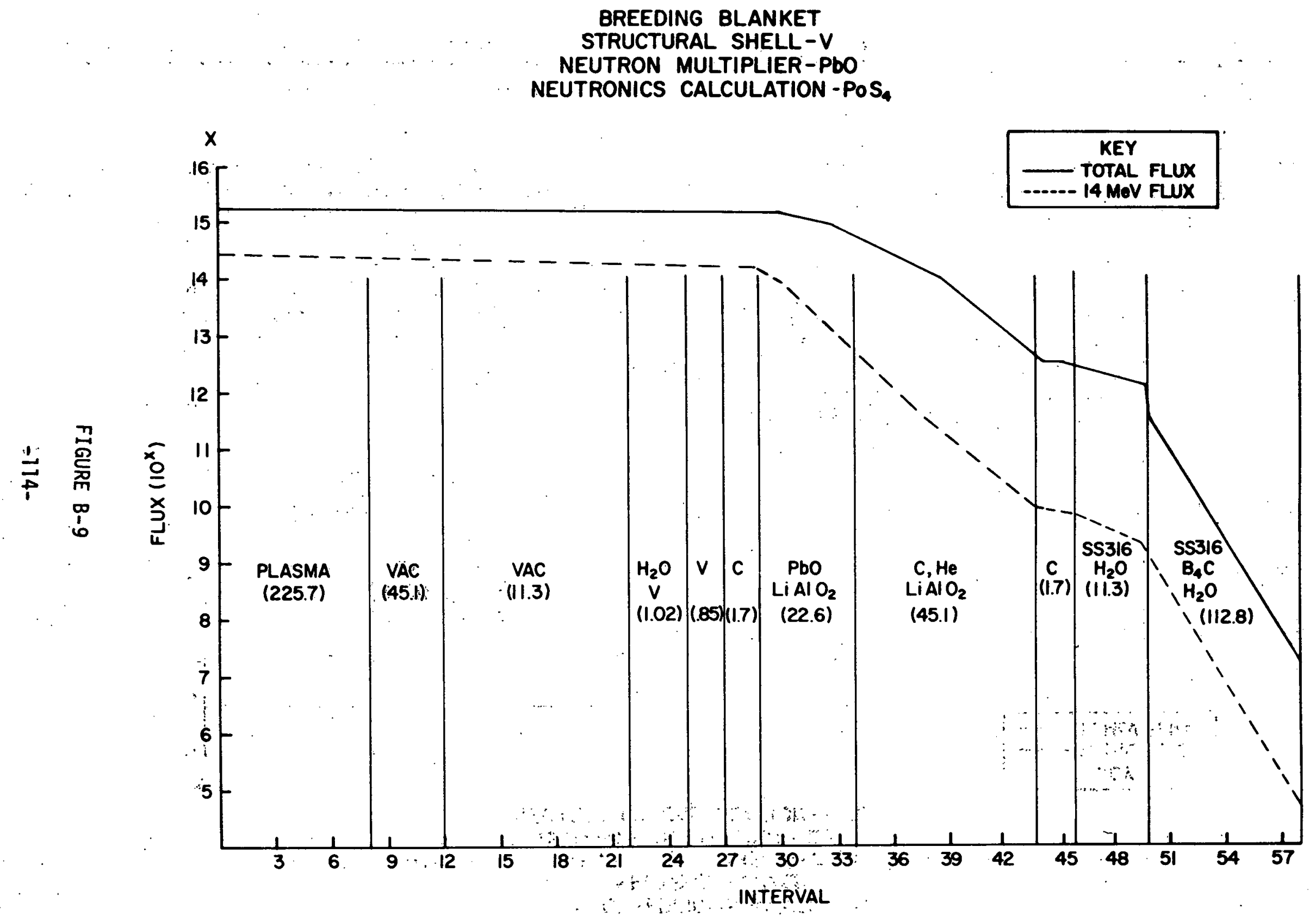




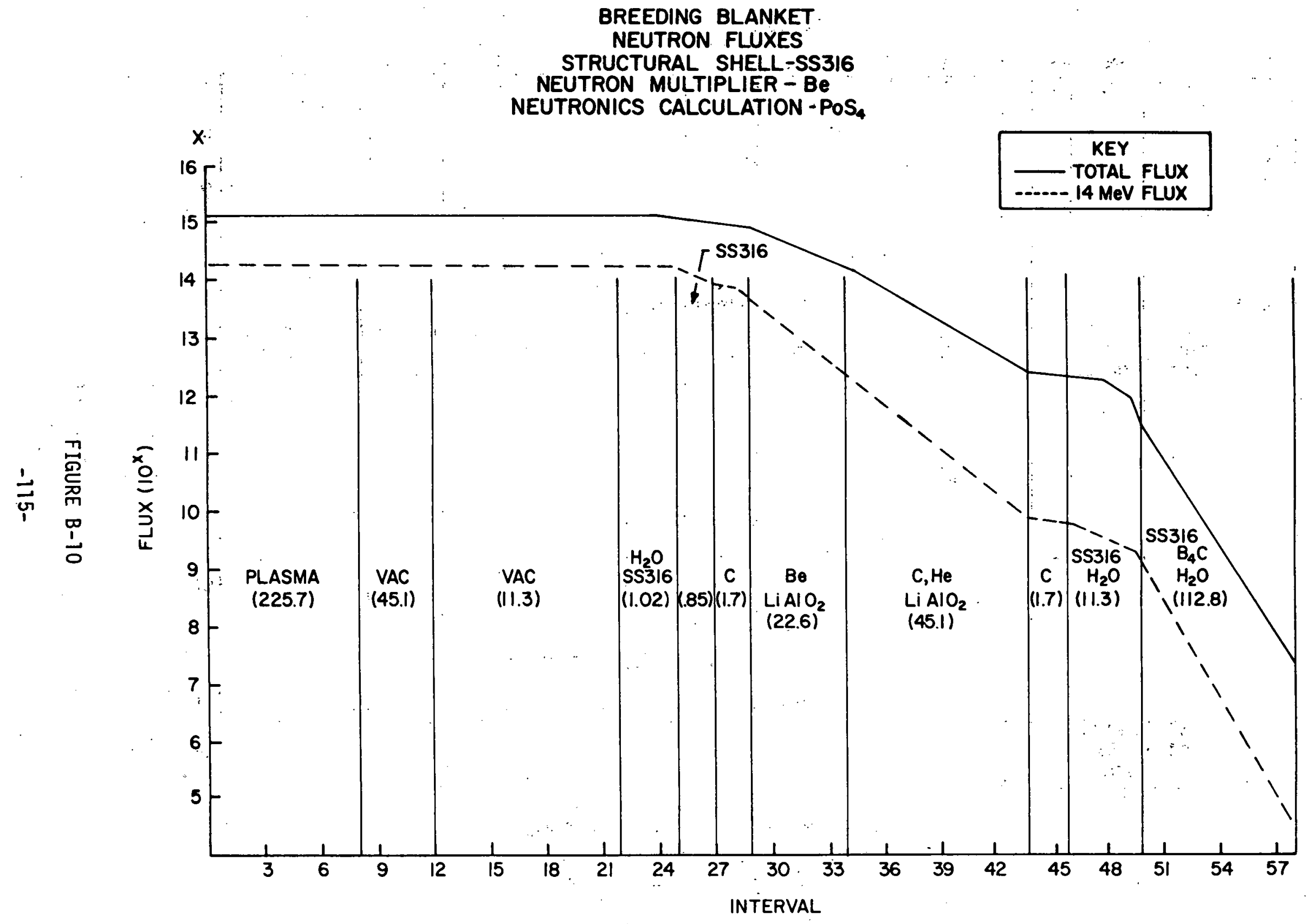




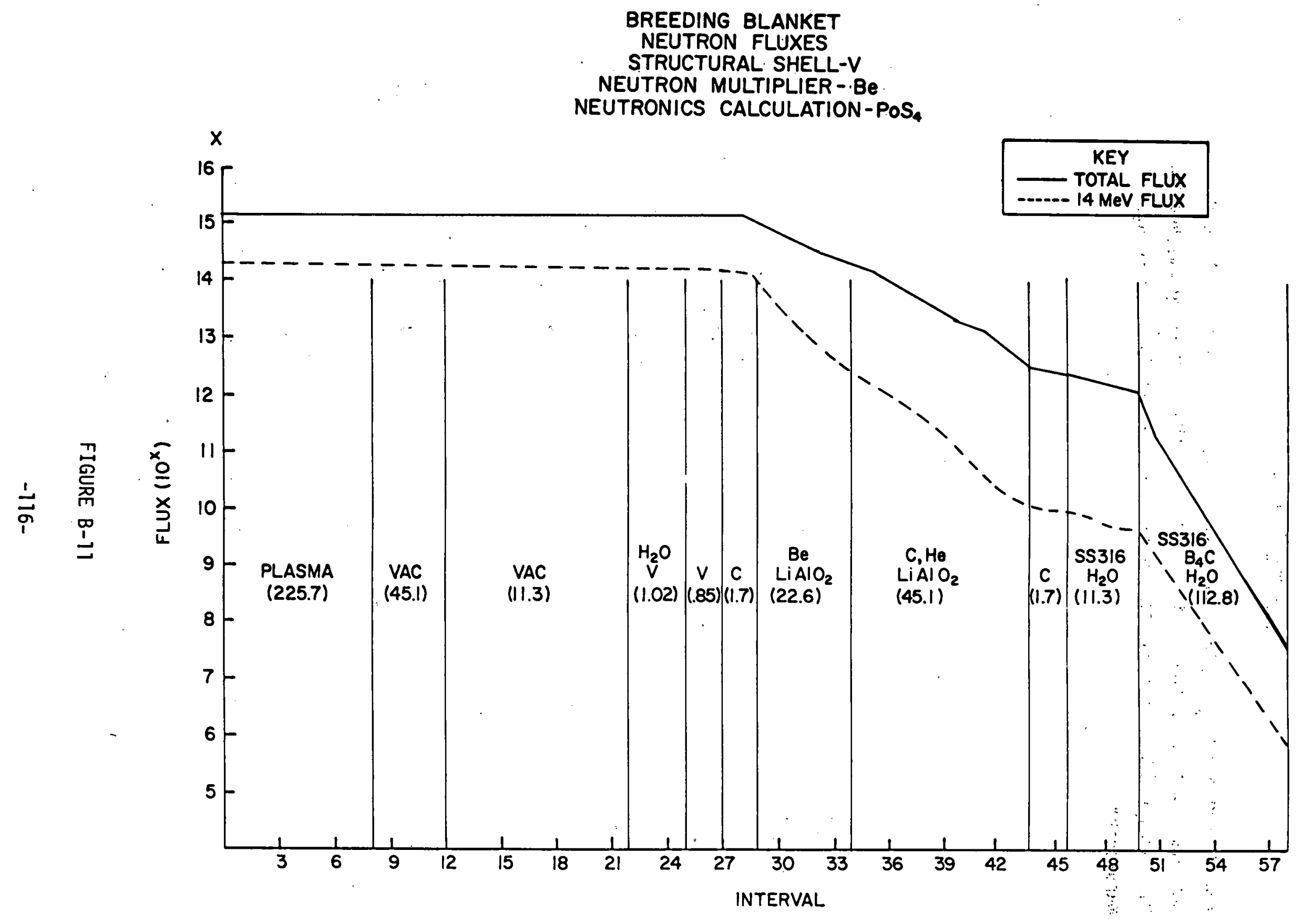




\section{ACKNOWLEDGMENTS}

The authors wish to express their deep appreciation to Mr. Stan Majeski and his staff for preparation of the drawings in this report, and to Ms. Carolyn Eterno and Ms. Pam Walton for preparation and typing of the manuscript. 


\section{REFERENCES}

\section{Chapter 1}

1. Booth, L. A., et. al., "Fusion Energy Applied to Synthetic Fuel Production". - A report.to the ERDA Division of Magnetic Fusion Energy A pref iminary study by an ad-hoc advisory group; (September, 1977)

\section{Chapter. 3}

1. Kelley, J., "Hydrogen Tomorrow - Demands and Technology Requirements," Jet Propulsion Laboratory, Pasadena, California (Dec, 1975).

2. Armstrong, C. H., "Effect of Recent Advancements in Gas Turbine Technology on Combined Cycle Efficiency," ASME Paper 74-PWR-8, Joint Power Generation Conference, Miami Beach, California (Sept 15 - 19, 1974).

3. Hausz, W., "Hydrogen Systems for Electric Energy," 72-TMP-15, General Electric Company - TEMPO Center for Advanced Studies, Santa Barbara (1972).

4. Keenan, J. H., et. al., "Steam Tables," Wiley (1969).

5. Coleman, H. W., et. al., "Interim Report - Diagnostics Assessment for Advanced Power Systems," SAND 77-8216 (March, 1977).

\section{Chapter 4}

1. Powe11, J. R., et. at., "Minimum Activity Blankets Using Aluminum Structure," Proc. First Topical Meeting on the Technology of Controlled Nuclear Fusion, Vol. I, Conf.-740402-P1-USAEC, p. 533 (1974).

2. Powel1, J. R., et. al., "Preliminary Reference Design of a Fusion Reactor Blanket Exhibiting Very Low Residual Radioactivity," BNL 19565 (Dec 1974).

3. Benenati, R. et. al., "BNL Minimum Activity Aluminum Blanket Designs," Proceedings of Magnetic Fusion Energy Blanket and Shield Workshop - A Technical Assessment," Powe11, J. R., et. al., Editor, ERDA-76/117/2 (March 29 - April 2, 1976).

4. Benenati, R. F., et. al., "Low Activity Aluminum Blanket," Nuclear Engineering and Design, 39, pp. 165-180 (1976).

5. Powell, J. R., and Wiswall, R. H, "Tritium Recovery from Fusion Blankets Using Solid Lithium Compounds," BNL 20563 (October 1975). 


\section{REFERENCES (Continuted)}

\section{Chapter 5}

1. Salzano, F. J., and Srinivasan, S., Editors, "Proceedings of the First International Energy Agency Water Electrolys is Workshop, BNL 21165 (September $23-25,1975$ ).

2. Isenberg, A. 0., and Brecher, L. E., "Water Vapor Electrolysis at High Temperatures," Ibid, p. 165.

3. Doenitz, W., "Perspectives and Research and Development Program for High-Temperature Vapor Phase Electorlys is of Water," Ibid, p. 158.

4. Spacil, H. S., and Tedmon, Jr., C. S., Electrochemical Dissociation of Water Vapor in Solid Oxide. Electrolyte Cells," J. Electrochem. Soc., 116, 1618, 1627 (1969).'

5. Chem. Eng. News, 46 (1968).

6. Hsu, M. S. S., and Reed, T.-B., "Electrochemical Power and Hydrogen Generation from High Temperature Electrolytic Cells," Eleventh Intersociety Energy. Conversion Eng. Conf., State Line, Nevada, p. 443 (1976).

7. Steel, B. C. H., "High Temperature Fuel Cells and Electrolyzia in Electrode Processes in Solid State Ionics, Klutz, M., and Dupuy, J., Editors, Pub. D. Reidel Pub. Co. (1976).

8. Isaacs, H. S., Srinivasan, S., and Harry, I. L., "Proceedings of the Workshop on High Temperature of Solid Oxide Fuel Cells.," (May 5 - 6, 1977).

9. Suerdrup, E. F., Warde, C. J., Glasser, A. D., "From Electrocatalys is to Fuel Cells," Edt. G. Sandstede, University of Washington Press (1972).

10. Hsu, M. S. S., Morrow, W. E., and Goodenough, J. B., "High Efficiency Electrochemical Plant," Tenth Intersociety Energy Conversion Eng. Conf., University of Delaware, Neward, Delaware (August 1975).

Chapter 6

1. Kubaschewski, O., Evans, E. L. L., and. Alcock, C. B., "Metallurgical Thermochemestry," Four,th Edition, Pergamon Press, p. 398 - 403.

2. Spencer, R. C., "Method of Predicting the Perfromance of Steam Turbine Generators $16500 \mathrm{KW}$ and Larger," ASME Paper 62-WA-209. 
Chapter 3.

Chapter 4.

Chapter 6

$6-1$

DIFFERENCES IN ELECTRICAL" ENERGY REQUIREMENTS BETWEEN STANDARD STATES AND THE NERNST EQUATION

MASS AND ENERGY BALANCE OF ELECTROLYZER UNITS - MAXIMUM HTE TEMPERATURE $=.1827^{\circ} \mathrm{C} \ldots$

OXYGEN HEAT EXCHANGER - MAXIMUM HTE TEMP-

$\mathrm{H}_{2}=\mathrm{H}_{2} \mathrm{O}$ HEAT EXCHANGER - MAXIMUM HTE TEMPERATURE $=1377^{\circ} \mathrm{C} \ldots \ldots \ldots \ldots \ldots \ldots \ldots \ldots$ VENTIONAL AND ADVANCE'D POWER 'CYCLE-FUEL PRODUCTION CAPACITY FOR $2000 \mathrm{MW}(T)$ FUSION REACTOR

CAPITAL INVESTMENT COST FOR A FUSION-SYN- 


\section{LIST OF FIGURES}

FIGURE NUMBER

TITLE

PAGE

Chapter 2

2-1

GENERAL HTE PROCESS WITH CONVENTIONAL

POWER CYCLE

$2-2$

FUSION REACTOR-HIGH TEMPERATURE

ELECTROLYSIS SYSTEM (FR-HTES)

Chapter 3

3-1

FR-HTE PROCESS FLOW SHEET

TURBINE INLET TEMPERATURE/PRESSURE TRENDS

TEMPERATURE-ENTROPY DIAGRAM FOR FAST

CYCLE

$3-4$

FAST POWER CYCLE (FUSION, HEAT SOURCE) ....... . 19

3-5

EFFICIENCY DIAGRAM FOR FAST CYCLE :

21

Chapter 4

4-1

BLANKET CROSS-SECTION - HTE PROCESS

HEAT MODULE ....................... 28

4-2

ELECTRIC PRODUCTION MODULE-T BREEDING

SCHEMATIC SHOWING MODULE REMOVAL

4-4

$\because \quad$ BREEDING BLANKET HEATING RATES-POS

COMPARED WITH $P_{3} S_{8}$ NEUTRONICS

CALCULATIONS

STRUCTURAL SHELL-V

NEUTRON MULTIPLIER-Be

4-5

BREEDING BLANKET NEUTRON FLUXES-

$\mathrm{POS}_{4}$ COMPARED WITH $\mathrm{P}_{3} \mathrm{~S}_{8}$ NEUTRONICS

CALCULATIONS

STRUCTURAL SHELL-V

NEUTRON MULTIPLIER-Be 
Chapter 5

$5-1$

'HTE CELL' DESIGN (WESTINGHOUSE FUEL CELL) ...... 48

$5-2$ BASIC ELECTROLYTIC CELL (HTE) ........... 5 I

$5-3$. . POTENTIAL VARIATION WITH TEMPERATURE ........ 52

$5-4$ OXYGEN PARTIAL PRESSURE AS A FUNCTION OF TEMPERATURE

HTE VESSEL $\ldots \ldots \ldots \ldots \ldots \ldots \ldots \ldots \ldots \ldots \ldots \ldots \ldots \ldots \ldots \ldots \ldots \ldots$

$5-6$

DETAILED CROSS SECTION OF HTE CELL ......... 59

$5-7$

TUBE SHEET SECTION $\ldots \ldots \ldots \ldots \ldots \ldots \ldots \ldots \ldots \ldots$

$5-8$

ELECTROLYTE THICKNESS AS A FUNCTION

OF. TEMPERATURE

Chapter 6

Appendix A

$A-1$

A-2 :

A-3

Appendix B. . .

B-1

$B-2$
FUSION-HTE-SYNTHETIC. FUELS THERMODYNAMICS

OF WATER -DECOMPOSITION (STEAM)

FUSION REACTOR-HTE-CONVENTIONAL POWER

- CYCLE- FOR SYNTHETIC FUEL - $\left(\mathrm{H}_{2}\right)^{\prime}$ PRODUCTION

HYDROGEN PRODUCTION FROM FUSION REACTORS-

1

HIGH 'TEMP. ELECTROLYSIS' (HTE) WITH CONV.

(CP) AND ADVANCED POWER (AP) CYCLE

103

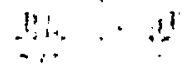

-NON-BREEDING BLANKET HEATING RATES-SS316 COMPARED WITH $V$ HIGH TEMPERATURE

INTERIOR-MgO

NEUTRONICS CALCULATION-POS

NON-BREEDING BLANKET. HEATING RATES

STRUCTURAL SHELL-SS316

HIGH TEMPERATURE INTERIOR-Al ${ }_{2} \mathrm{O}_{3}$

NEUTRONICS CALCULATION-POS 
NON-BREEDING BLANKET NEUTRON FLUXES

STRUCTURAL SHELL-V

HIGH TEMPERATURE INTERIOR-MgO

NEUTRONICS CALCULATION-POS $4 \ldots \ldots \ldots \ldots \ldots \ldots .108$

B-4 NON-BREEDING BLANKET NEUTRON FLUXES

STRUCTURAL SHELL-SS376

HIGH TEMPERATURE INTERIOR-MgO

NEUTRONICS CALCULATION-POS 4

109

B-5 NON-BREEDING BLANKET NEUTRON FLUXES

STRUCTURAL SHELL-SS316

HIGH TEMPERATURE INTERIOR-A1 ${ }_{2} \mathrm{O}_{3}$

NEUTRONICS CALCULATION-POS

B-6

BREEDING BLANKET HEATING RATES-SS316

COMPARED WITH V

NEUTRON MULTIPLIER-PbO

NEUTRONICS CALCULATION-POS

B-7

BREEDING BLANKET HEATING RATES-SS316

COMPARED WITH $V$

NEUTRON MULTIPLIER-Be

NEUTRONICS CALCULATION-POS $4 \ldots \ldots \ldots \ldots \ldots \ldots . \ldots \ldots$

B-8 BREEDING BLANKET NEUTRON FLUXES

STRUCTURAL SHELL-SS316

NEUTRON MULTIPLIER-PbO

NEUTRONICS CALCULATION-POS

B-9

BREEDING BLANKET STRUCTURAL SHELL-V

NEUTRON MULTIPLIER-PbO

NEUTRONICS CALCULATION-POS

BREEDING BLANKET NEUTRON FLUXES

STRUCTURAL SHELL-SS316

NEUTRON MULTIPLIER-Be

NEUTRONICS CALCULATION-POS

BREEDING BLANKET NEUTRON FLUXES

STRUCTURAL SHELL $-V$

NEUTRON MULTIPLIER-Be

NEUTRONICS CALCULATION-POS 